May 2003 - NREL/TP-500-33445

\title{
Integration of Xantrex HY-100 Hybrid Inverter with an AC Induction Wind Turbine
}

D. Corbus, C. Newcomb, S. Friedly

\section{National Renewable Energy Laboratory}

1617 Cole Boulevard

Golden, Colorado 80401-3393

NREL is a U.S. Department of Energy Laboratory

Operated by Midwest Research Institute $\bullet$ Battelle $\bullet$ Bechtel

Contract No. DE-AC36-99-G010337 
May 2003 ・ NREL/TP-500-33445

\section{Integration of Xantrex HY-100 Hybrid Inverter with an AC Induction Wind Turbine}

D. Corbus, C. Newcomb, S. Friedly

Prepared under Task No. IG135000

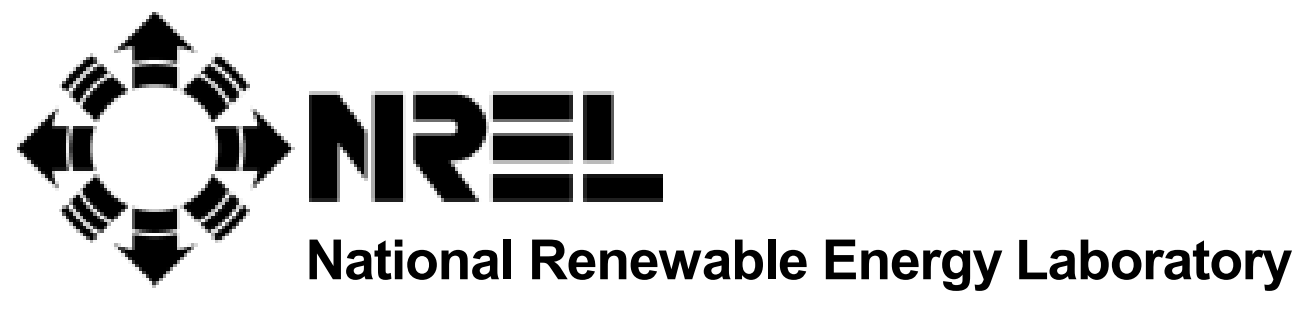

1617 Cole Boulevard

Golden, Colorado 80401-3393

NREL is a U.S. Department of Energy Laboratory

Operated by Midwest Research Institute • Battelle • Bechtel

Contract No. DE-AC36-99-G010337 


\section{NOTICE}

This report was prepared as an account of work sponsored by an agency of the United States government. Neither the United States government nor any agency thereof, nor any of their employees, makes any warranty, express or implied, or assumes any legal liability or responsibility for the accuracy, completeness, or usefulness of any information, apparatus, product, or process disclosed, or represents that its use would not infringe privately owned rights. Reference herein to any specific commercial product, process, or service by trade name, trademark, manufacturer, or otherwise does not necessarily constitute or imply its endorsement, recommendation, or favoring by the United States government or any agency thereof. The views and opinions of authors expressed herein do not necessarily state or reflect those of the United States government or any agency thereof.

Available electronically at http://www.osti.gov/bridge

Available for a processing fee to U.S. Department of Energy and its contractors, in paper, from:

U.S. Department of Energy

Office of Scientific and Technical Information

P.O. Box 62

Oak Ridge, TN 37831-0062

phone: 865.576 .8401

fax: 865.576.5728

email: reports@adonis.osti.gov

Available for sale to the public, in paper, from:

U.S. Department of Commerce

National Technical Information Service

5285 Port Royal Road

Springfield, VA 22161

phone: 800.553.6847

fax: 703.605.6900

email: orders@ntis.fedworld.gov

online ordering: http://www.ntis.gov/ordering.htm 


\subsection{Table of Contents}

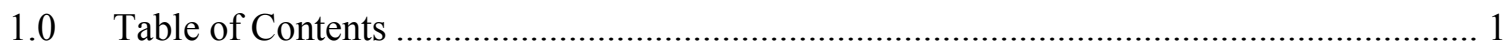

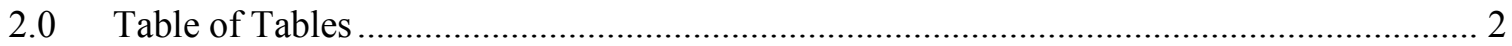

$3.0 \quad$ Table of Figures..................................................................................................... 2

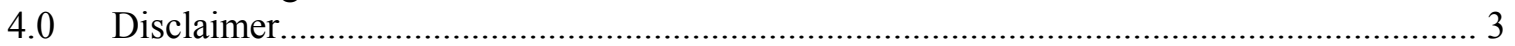

$5.0 \quad$ Background of Wind-Diesel Inverters..................................................................... 3

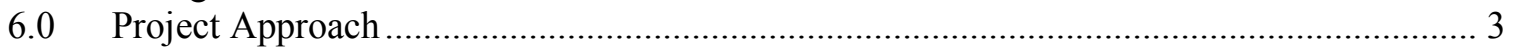

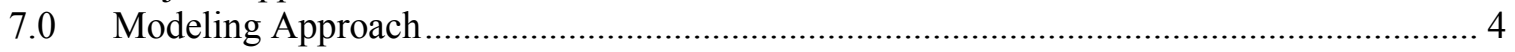

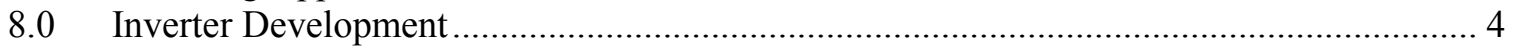

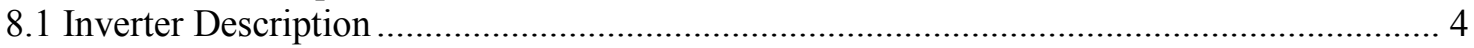

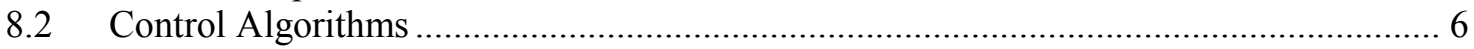

9.0 Testing of the Modified Inverter ............................................................................. 8

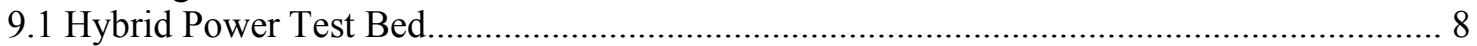

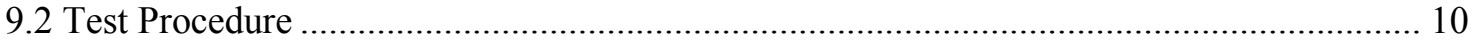

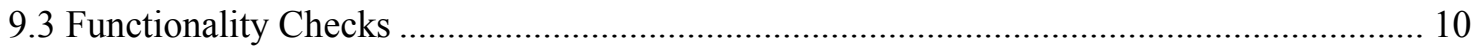

9.4 Test Results with AC Source Simulator ...................................................................... 10

9.5 Testing with the AOC 15/50 Wind Turbine ................................................................... 10

10.0 Summary of Inverter Testing................................................................................... 11

Appendix A: Xantrex HY-100 Inverter Description ............................................................ 12

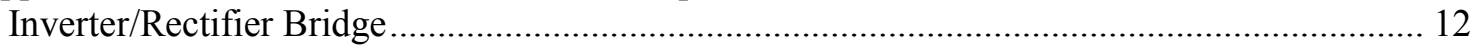

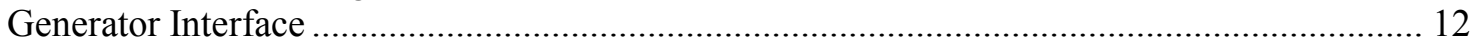

Battery Charge Controller........................................................................................ 12

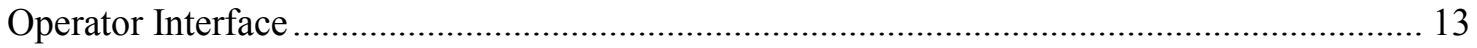

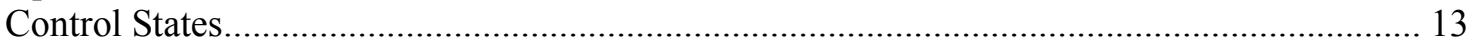

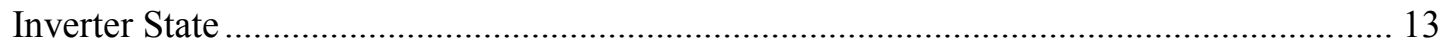

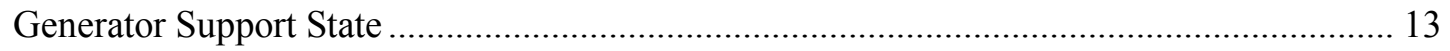

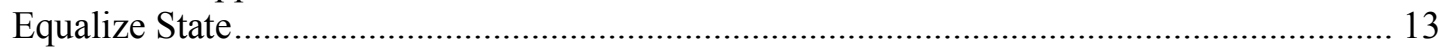

Generator Only State

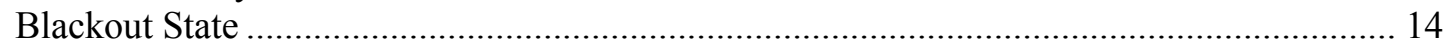

Inverter/Rectifier Bridge Control.................................................................................. 14

Battery Charge Controller Control................................................................................ 14

Generator Interface Control ..................................................................................... 14

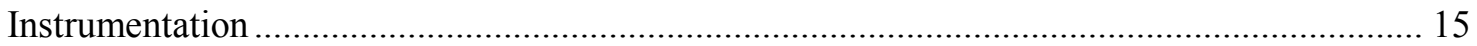

Self-Protection, Fault Detection, and Alarms …………………........................................ 15

Performance Specifications ....................................................................................... 16

Appendix B: MATLAB Dynamic and Transient Wind-Diesel Models ........................................ 17

Appendix C: Inverter Test Results ............................................................................. 78

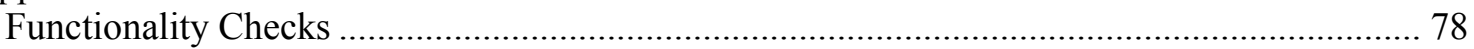

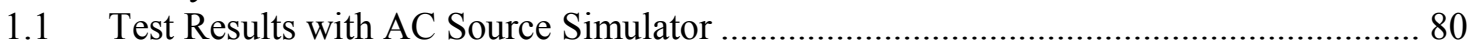

1.1.1. Test: Village Load Step Changes: Adding Load...................................................... 80

1.1.2 Test: Village Load Step Changes: Decreasing Load................................................... 81

1.1.3 Test: Wind Turbine Trip Offline: Diesel Generator On ............................................... 82

1.1.4 Test: Wind Turbine Trip Offline: Diesel Generator Off ............................................. 83

1.1.5 Test: Battery Charging ...................................................................................... 83

1.1.6 Test: State Transition from Inverter to Charge and from Charge to Inverter................ 85

1.1.7 Test: Transition to Shutdown on Inverter Fault ...................................................... 88

1.2 Testing with the AOC $15 / 50$ Wind Turbine............................................................. 88

1.2.1 Test: Wind Turbine Startup at High Power with Diesel ............................................ 88

1.2.2 AOC 15/50 Soft Start Mode Start Up ……………………………………………... 89 
Appendix D: A Preliminary Description of Parallel Operation of the Inverter with a Diesel Genset

\subsection{Table of Tables}

Table 1. Inverter Settings 78

Table 2. Functionality Checks Performed

\subsection{Table of Figures}

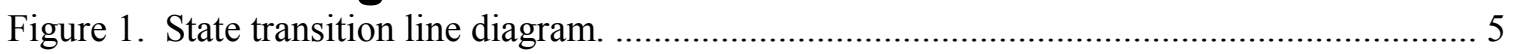

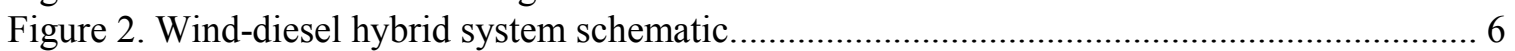

Figure 3. Dispatch matrix zones........................................................................ 7

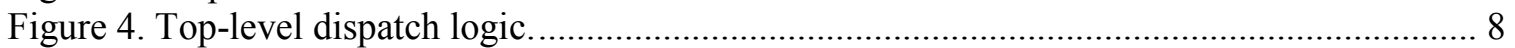

Figure 5. Hybrid Power Test Bed (HPTB) configuration. ................................................ 9

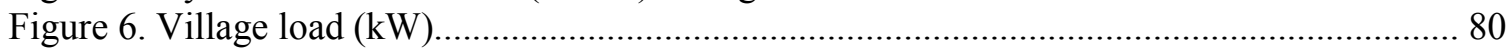

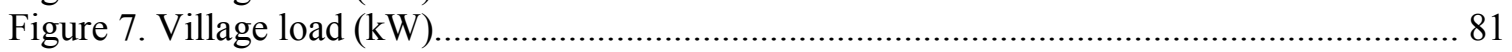

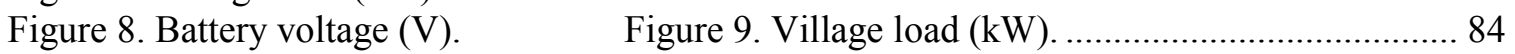

Figure 10. AC SIM power $(\mathrm{kW}) . \quad$ Figure 11. Genset power $(\mathrm{kW}) \ldots \ldots \ldots \ldots \ldots \ldots \ldots \ldots \ldots . . . . . . \ldots 4$

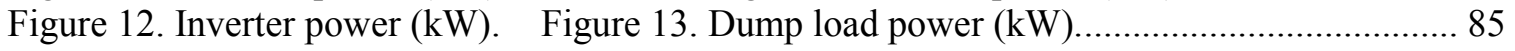

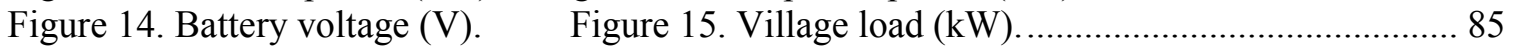

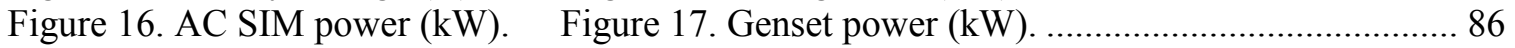

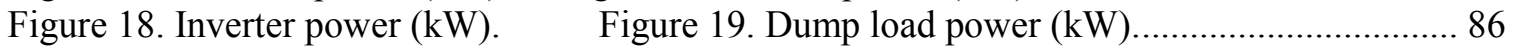

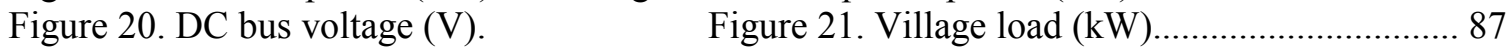

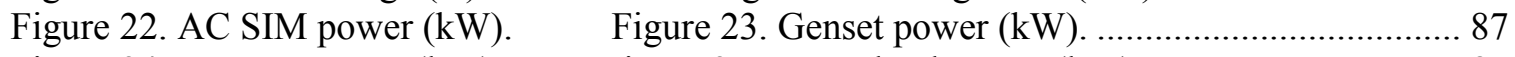

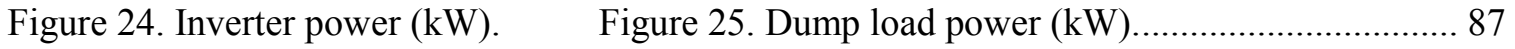




\subsection{Disclaimer}

This report was prepared as an account of work sponsored by an agency of the United States Government. The test results documented in this report define the characteristics of the test article as configured and under the conditions tested. The U. S. Government, its agencies, and its employees do not make any warranty, express or implied, or assume any legal liability or responsibility for the usefulness of any information, apparatus, product, or process disclosed, or represent that its use would not infringe privately owned rights. They also do not assume legal liability or responsibility for the performance of the test article or any similarly named article when tested under other conditions or using different test procedures.

Neither Midwest Research Institute nor the U. S. Government shall be liable for special, consequential, or incidental damages. Reference herein to any specific commercial product, process, or service by trade name, trademark, manufacturer, or otherwise does not necessarily constitute or imply its endorsement, recommendation, or favor by the U.S. Government or any agency thereof. The views and opinions of the authors expressed herein do not necessarily state or reflect those of the U.S. Government or any agency thereof.

The National Renewable Energy Laboratory (NREL) is a national laboratory of the U. S. Department of Energy; as an adjunct of the U. S. Government, it cannot certify wind turbines. The information in this report is limited to NREL's knowledge and understanding as of this date.

\subsection{Background of Wind-Diesel Inverters}

Wind-diesel systems have been used for remote power for many years in various configurations. Most of the wind-diesel systems to date have been based on a system design that uses small wind turbines (1-10 kilowatts, or $\mathrm{kWs}$ ) connected to a DC bus. These systems can use inverter controllers that are designed for photovoltaic (PV) systems because the inverter design is similar for the two technologies. However, larger AC wind turbines (50-150 kWs) are significantly cheaper than small DC wind turbines (and much cheaper than PV systems) on an installedkilowatt basis and are better matched to many remote off-grid energy requirements, such as village electrification. Because of these advantages, the use of larger wind turbines in wind-diesel systems is advantageous.

Converters are a key component in hybrid power systems. To date, wind-diesel hybrid power systems in the 50-150 kW size range have relied on rotary converters (i.e., a DC machine coupled directly to an AC synchronous generator) for power conversion. These systems are cheaper and have been more easily maintained in remote areas. However, these systems operate at lower efficiencies than solid-state inverters. The recent advances in power electronics in the past decade and the subsequent reduction in cost and increase in reliability make solid-state inverters a logical converter option for future wind-diesel systems.

\subsection{Project Approach}

Several issues must be addressed before solid-state inverters can be used in wind-diesel systems with larger wind turbines. This project addresses those issues by using a commercial hybrid inverter designed for PV-diesel systems and modifying the inverter for use with an AC induction wind turbine. Another approach would have entailed building an inverter specifically for use with an $\mathrm{AC}$ induction wind turbine, but that was beyond the scope of this project. 
The inverter chosen for this project was a Xantrex HY-100, an inverter designed for PV systems. The unit consists of an inverter/rectifier bridge, a generator interface contactor, a battery charge controller, a hybrid controller, and the associated control electronics.

Details of the inverter may be found in Appendix A.

A twofold approach was taken to integrating the existing inverter for use with an AC induction wind turbine: 1) development of a detailed model to model both steady-state and transient behavior of the system, and 2) modification and testing of the inverter with an induction wind turbine based on the modeling results. This report describes these two tasks.

\subsection{Modeling Approach}

Two models were written for the wind-diesel inverter system, the MATLAB NREL Modified Inverter Dynamic Model and the Modified Inverter Transient Model. The models were developed by Xantrex (formerly Trace Technologies) and NREL to model the system with an induction wind turbine and a dump load and to determine any needed modifications to the system controller.

The dynamic model is based on an energy balance among a wind turbine, inverter/battery, diesel generator, grid load, and dump load. Logic for transitioning between states is computed by the MATRIX logic function (see Appendix B for a complete model description). The MATRIX uses filtered/averaged values for battery state of charge (SOC) and net load demand to determine which operating state should be requested. The battery's SOC is related to the battery's voltage and the grid's net load demand and is defined as grid load minus wind turbine output in kilowatts.

The transient model uses a MATLAB Simulink program to model the various system components and characterize the transient response of the system to variables such as voltage and frequency response to large shifts in dump load or grid power. A detailed description of the model may be found in Appendix B.

\subsection{Inverter Development}

\subsection{Inverter Description}

The inverter may operate with a diesel generator (as a current source) or in stand-alone mode (as a voltage source), and it can charge batteries with the diesel generator or excess energy from the wind turbine generator, which in this case is an Atlantic Orient Corporation (AOC) 15/50 wind turbine or a $65-\mathrm{kW}$ wind turbine simulator. The inverter is able to instantaneously control power flows between the AC and DC bus. A state diagram of the inverter developed by Xantrex technologies is shown in Figure 1. 


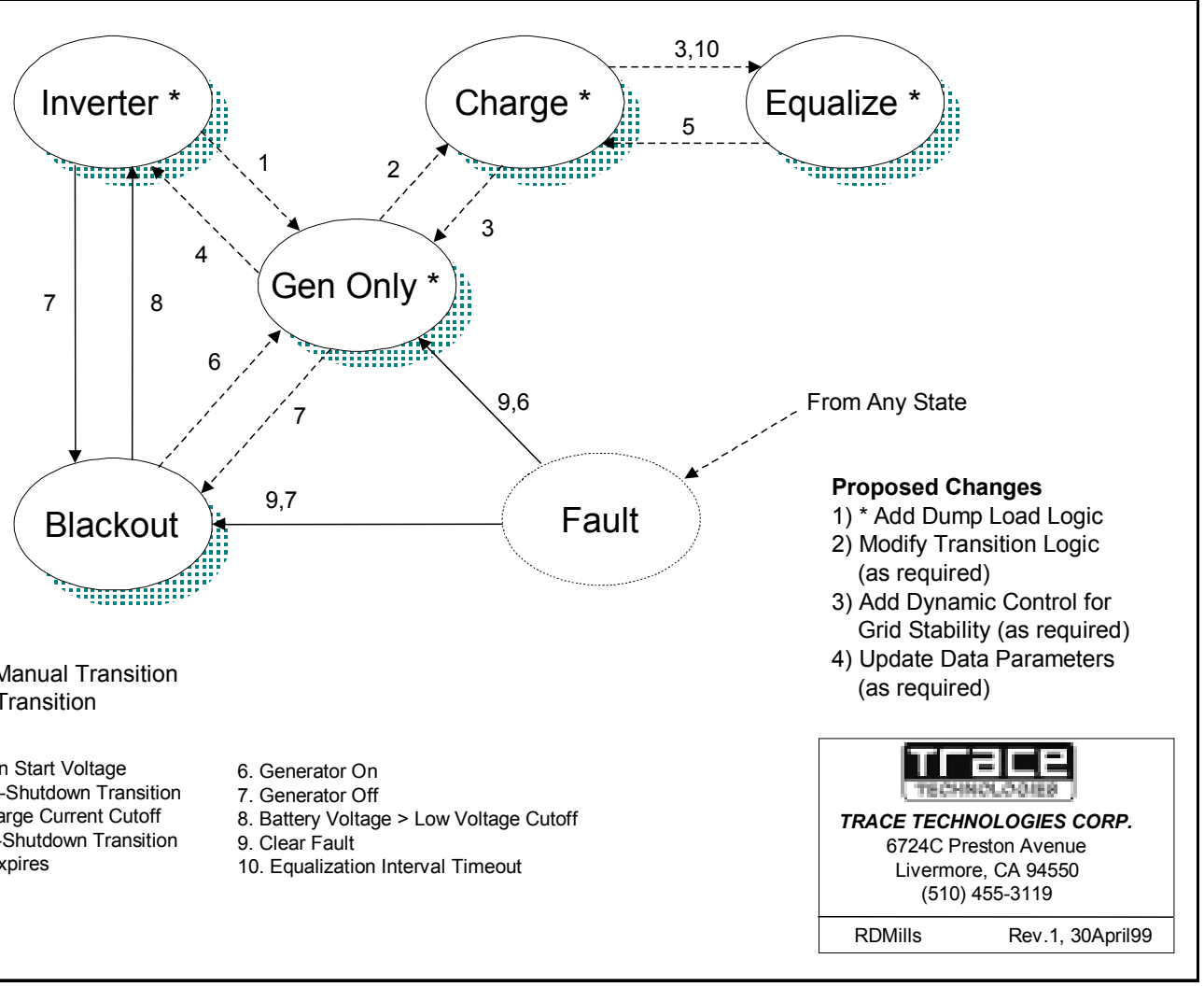

Figure 1. State transition line diagram. 


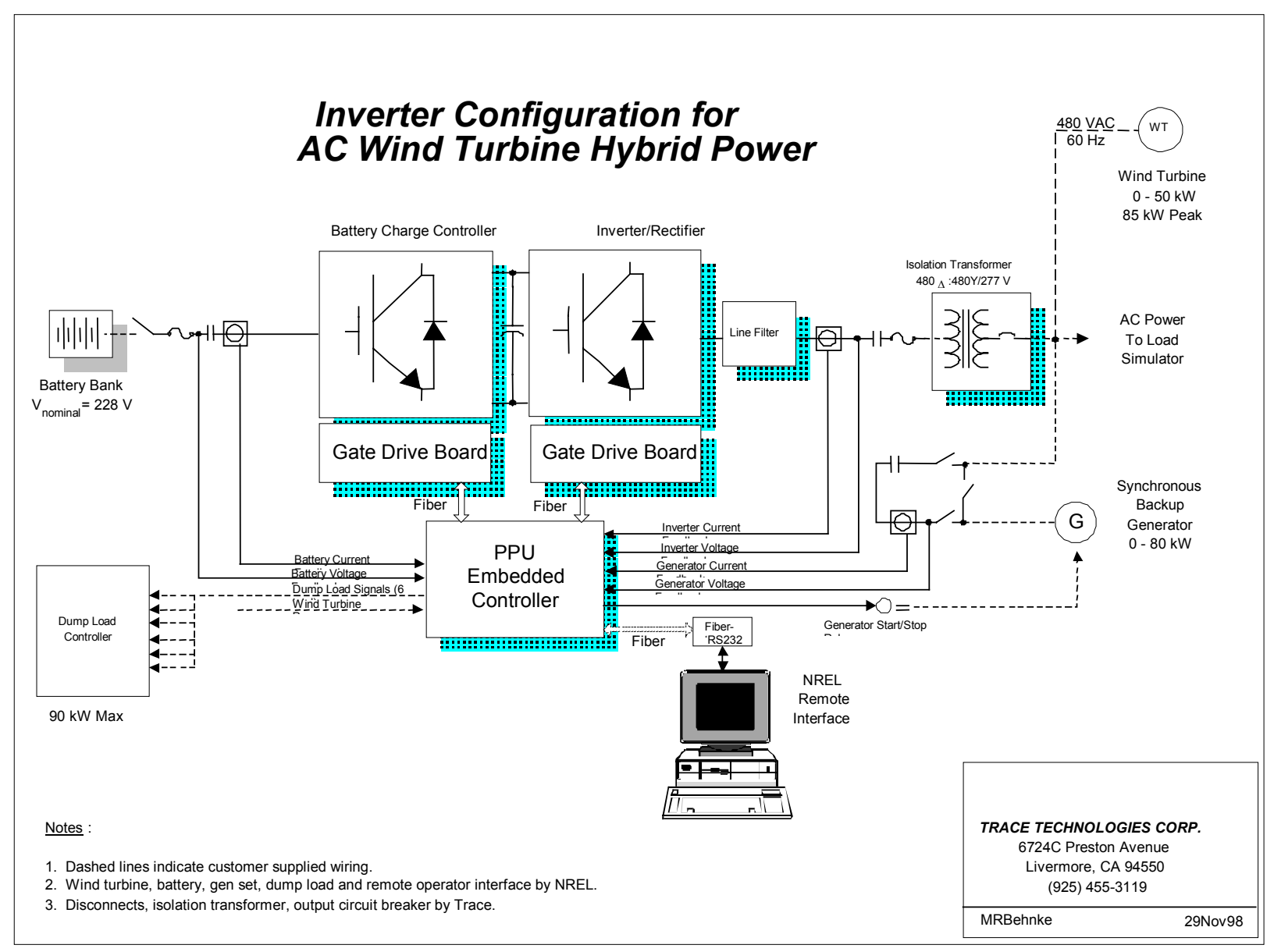

Figure 2. Wind-diesel hybrid system schematic.

\subsection{Control Algorithms}

Control algorithms that provided for robust operation under all possible conditions were written for the inverter controller. The basic inverter control algorithm is for operation of the inverter in a battery-charging configuration with an AC-connected wind turbine with 1) diesel connected or 2) diesel not connected. Additional control algorithms also include high-speed switching of a binary step dump load to control excess power flows from the wind turbine. The system was designed for a wind turbine with instantaneous power output (1-second average) from 0-85 kWs, typical of an AOC $15 / 50$. The inverter, which was connected to a $90-\mathrm{kW}$ binary step dump load, supplied control signals (3-32 VDC) to control the zero crossing solid-state switches for the dump load elements.

The inverter control algorithms were designed for operation under the following conditions:

- No diesel gensets online - Wind turbine generator (WTG) power output from 0-85 kWs with the WTG or batteries supplying load (depending on the "village" load and the WTG power output; i.e., net load) and the WTG charging the batteries when the 
WTG power is greater than load. AC dump load is used for dissipation of excess power and to limit battery-charging current when the batteries are full.

- Diesel gensets online - The inverter operates in parallel with diesel gensets and the WTG; the diesel follows the load and the WTG power is used to charge the batteries or is dissipated by the dump load when the batteries are fully charged. During periods of no wind, the diesel may also charge the batteries.

- Control algorithms were designed to instantaneously shift power bi-directionally from the DC to AC bus.

The transition from diesel-on mode to diesel-off mode and vice versa is an important state transition that is controlled by the hybrid system controller and based on battery state of charge and net load (i.e., village load minus wind turbine output), as shown in Figure 3. A minimum load of about $10 \mathrm{~kW}$ is always kept on the diesel generator to prevent running the generator under a no-load condition. The maximum operating efficiency of the generator is at $80 \%$ or higher load. When the net load is low, the system transitions to a diesel-off state at a user-selected battery voltage so as to maximize wind turbine energy capture to the system. When the net load is high and the battery voltage is low, the system transitions to the diesel-on state so that the load can be met and the batteries charged. The specific parameters for the "matrix" shown in Figure 3 (see Appendix B) would vary depending on the type of battery bank.

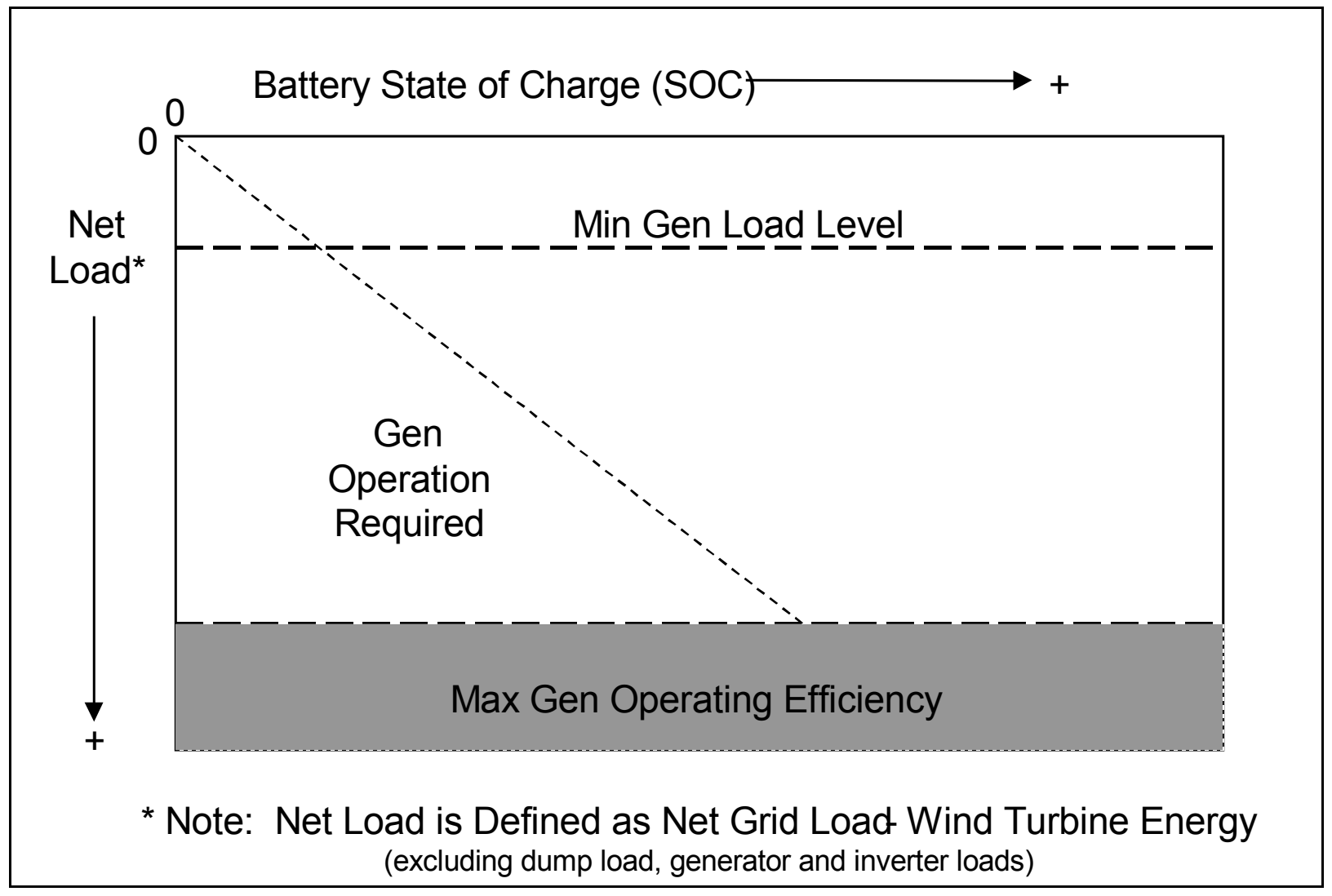

Figure 3. Dispatch matrix zones. 
The top-level dispatch logic of the system can be found in Appendix B in the Matlab Simulink model. A key component of the dispatch logic is shown in Figure 4. The dispatch logic shows the control of the state transition from diesel-on mode to diesel-off mode or vice versa, depending on the battery SOC and the net load. The dispatch logic calls on the matrix tables (found in Appendix B and exemplified by the dispatch zones in Figure 3). Provisions were made for expanding the dispatch logic to include the rate of change of wind turbine power and net load.

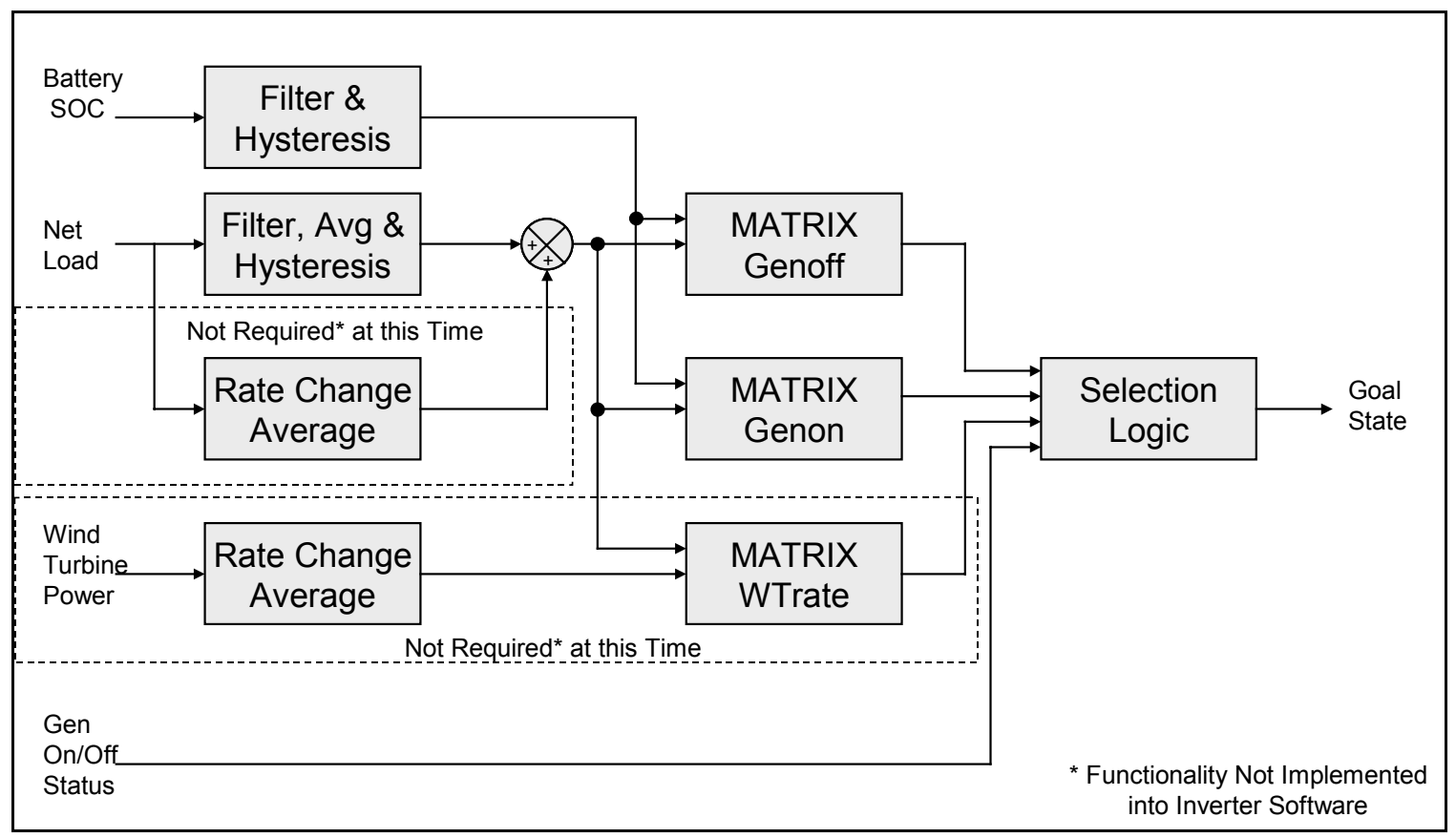

Figure 4. Top-level dispatch logic.

The charging algorithm is designed such that any energy produced in excess of the load is directed to the battery bank until the battery bank voltage reaches the dump-load-enable set point (Max_Bat_Hi). Once this set point is reached, the dump load is used to limit the charge current. The actual charge current during the finish charge stage is determined by the finish charge start and end voltage set points and the start and end charge current set points.

The converter control algorithms were developed based on the MATLAB Simulink model and the description above. This control logic was incorporated into a new revision of the HY-100 controller code by Xantrex engineers for testing at the National Wind Technology Center (NWTC). This code operated at the topmost level of the control code and did not run at the faster inner-loop control code that controlled parameters such as inverter frequency and voltage. The latest code revision for the hybrid controller code was NREL Tag revision 13.

\subsection{Testing of the Modified Inverter}

\subsection{Hybrid Power Test Bed}

Testing of the modified inverter was conducted at the NWTC's Hybrid Power Test Bed (HPTB). The HPTB is a multi-purpose test facility that combines a state-of-the-art Labview data 
acquisition system with a switch panel that can easily switch in different "devices," such as wind turbines, inverters, batteries, and load banks. A schematic of the HPTB test configuration for the Xantrex inverter testing is shown in Figure 5. All data sampling was conducted at $600 \mathrm{~Hz}$, and the data averaging time is two seconds unless noted differently.

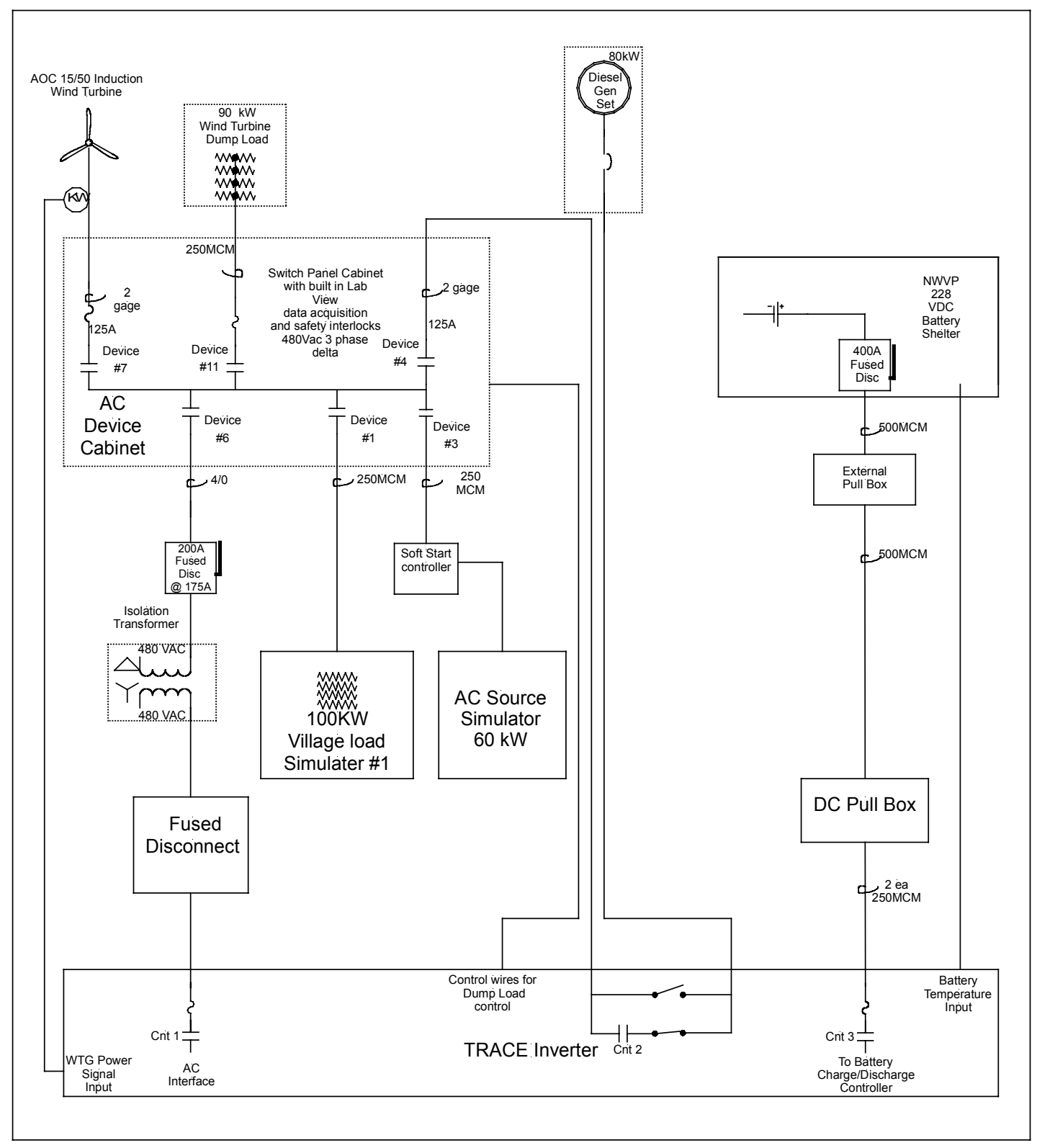

Figure 5. Hybrid Power Test Bed (HPTB) configuration. 


\subsection{Test Procedure}

The testing goal for the Xantrex inverter was to conduct both dynamic and transient testing with the wind turbine or wind turbine simulator to verify that the inverter can handle expected conditions during operation. Due to unavailability of the AOC wind turbine, testing was conducted primarily with the AC source simulator. Testing with the AOC 15/50 was limited to wind turbine start-up tests and some steady-state tests.

The results of the test, along with the test procedures, may be found in Appendix C. A summary of the tests is contained in the rest of this section.

\subsection{Functionality Checks}

Before running the tests, functionality checks were conducted to verify proper inverter operation and state transition for steady- and quasi-steady-state operation. These checks verified that the system operated the way the hybrid controller intended it to operate, and any shortcomings were noted. Although many of these checks had been performed on previous software revisions for the hybrid controller, these checks were necessary to benchmark the latest revision of the software code. Before starting the test, all inverter settings were confirmed on the inverter and recorded. Details of the functionality tests may be found in Appendix C.

\subsection{Test Results with AC Source Simulator}

The AC source simulator is a variable-speed drive that is connected to a nominal $60-\mathrm{kW}$ induction generator that has a soft start connected in series. It is controlled via the HPTB's Labview system. Control features include power setting and rate of power change.

The purpose of the testing with the AC source simulator was to verify that the inverter operated according to the control algorithms described in Section 8.2. This included verifying state transitions, with emphasis on transition from inverter state to charge and vice versa, as well as the battery charging algorithms. In addition, the system was tripped for special transient events such as the wind turbine "tripping" off-line at rated power. Because there is a limitation on the ramp rate for the power during contact closure, the AC source simulator could not "simulate" a hard start representative of an actual $\mathrm{AC}$ induction wind turbine.

The test setup for the AC Source Simulator can be seen in Figure 5. The test results are summarized in Appendix $\mathrm{C}$, including time series plots from screen dumps for some of the tests.

\subsection{Testing with the AOC 15/50 Wind Turbine}

The purpose of this testing was to verify that the AOC $15 / 50$ soft start was operational with the Xantrex inverter and that the inverter could bring the AOC $15 / 50$ on to the grid without faulting the inverter or over-speeding the turbine. In addition, longer-term steady-state testing was conducted to verify that the system operated as designed.

Start-up testing was conducted to verify that the inverter could start the AOC 15/50 wind turbine. The inverter did start the AOC 15/50 several times; however, the test was not repeatable, and many times the AOC did not start successfully with the inverter but instead faulted on an overspeed condition. Changes were made to the AOC soft start to change the rate at which the soft 
start would ramp the current and voltage, but an acceptable solution was not obtained. A solution that would allow the inverter to start the AOC reliably with the existing soft start is possible, but it would require further changes to the soft start and further testing, which is not possible under the scope of this project.

Once the AOC 15/50 turbine was online, the system ran without fault. Total run time with the AOC online was in excess of 80 hours, with much of the time in high winds (winds greater than $12 \mathrm{~m} / \mathrm{s}$ ), with good transitions between diesel-on mode and diesel-off mode.

\subsection{Summary of Inverter Testing}

Modifications were made to the TRACE HY-100 inverter to allow it to operate in a wind-diesel configuration with an induction wind turbine generator on the AC bus. The modifications included addition of a dump load to the system and modifications to the controller software to allow for battery charging and regulation of the system with the system operating with the wind turbine in both diesel-on and diesel-off modes (i.e., charge mode and inverter mode).

Testing was conducted to validate the modeling of the system and to verify operation with an actual wind turbine, including start-up with the AOC 15/50 wind turbine. The results of the testing were positive in that the inverter operated as designed with the wind turbine.

One shortcoming from the testing was that the inverter was not always able to start the AOC $15 / 50$ wind turbine. Adjustments to the soft start of the AOC 15/50 wind turbine and further testing with the inverter would likely enable the inverter to start the AOC 15/50 wind turbine, but this work was not possible under the scope of this project.

A problem to be addressed in the future is the leading power factor for the inverter. When the inverter is used to power a mini-grid that has more than 15kVARs leading, it enters a state characterized by extreme harmonic distortion before faulting (approximately 10 seconds). This is a problem when certain loads have power factor correction capacitors that are always in the circuit, such as wind turbines with soft starts. This problem would need to be addressed through future work but does not appear to be a major impediment to the use of solid-state inverters with $\mathrm{AC}$ induction wind turbines in wind-diesel applications.

One drawback to the inverter is the standing losses. The standing losses, or "parasitic losses," can be as high as $3 \mathrm{kWs}$ and should be included in any design for a wind-diesel system. Any attempts to use inverters of this topology in the future for wind-diesel systems should seek to reduce the standing losses of the inverter. One of the benefits that should be realized by a solid-state inverter as compared to a rotary converter for a wind-diesel system is higher efficiency, but the standing losses of the inverter prevent this.

Parallel operation of the inverter with a diesel generator was examined at the end of the project. This would allow the system to meet a load equal to the maximum power of the inverter plus the maximum power of the diesel, thereby increasing the capacity of the wind-diesel system. A description of this analysis is contained in Appendix D. 


\section{Appendix A: Xantrex HY-100 Inverter Description}

The modified PPU will be a self-contained unit consisting of an inverter/rectifier bridge, a generator interface contactor, a diversion load controller, a battery charge controller, and their associated control electronics.

\section{Inverter/Rectifier Bridge}

Type: Three-phase, bi-directional, voltage-fed bridge converter

Switching Device: 1GBT, 1200V/600A rating

Switching Frequency: $10 \mathrm{kHz}$

DC Link Voltage: 420 VDC (regulated)

Nominal AC Output/Input Voltage: 208 VAC, three-phase, three-wire

Nominal AC Output Frequency: $60 \mathrm{~Hz}$

ContinuouskVa@208 VAC

Surge Capability: $150 \%$ of continuous rating for 10 seconds

Load Power Factor: 0 lagging to 0 leading

Hardware-Based Protection

Voltage Transient: MOV-type surge arrestor, 650V MCOV, $20 \mathrm{kA}$ surge current (8x20us) capability, ANSI/IEEE C62.41 Category C

Short Circuit: Current-limiting semiconductor fuses, 300 A continuous, 200kA interrupting capacity

\section{Generator Interface}

Contactor Rating:100 kVA @208 VAC (300 A continuous)

Start/Stop Relay: Normally open contact rated 12 amps@ @ 480 volts

Disconnects: $600 \mathrm{VAC}, 400 \mathrm{~A}$, three-pole load-break disconnect switches for generator input and output located in enclosure mounted on side of PPU enclosure

Bypass: 600 VAC, 400 A, three-pole load-break disconnect switch for bypass of PPU in common enclosure with generator disconnects

\section{Battery Charge Controller}

Type: Bi-directional, current regulated, DC-DC buck and boost converter 
Switching Device: IGBT, 1200V/600A rating

Switching Frequency: $10 \mathrm{kHz}$

Nominal Battery Voltage: 228 VDC

Maximum Equalizing Voltage: Field settable to 300 VDC

Low Voltage Cutoff: 200 VDC (1.75 VPC)

Battery Manual Disconnect Switch: 440 VDC, 600 A, three pole, load break disconnect switch

\section{Operator Interface}

LCD/Keypad: Piezoelectric keypad and two-line LCD display located on door of enclosure

Enable/Disable Switch: Keypad enable/disable switch located on door of enclosure

E-Stop: Maintained-position, mushroom head emergency stop button located on door of enclosure

\section{Control States}

The PPU shall be a state-controlled machine with clearly defined valid states and state transitions for each of the PPU components. Except during state transitions, the PPU shall always reside in one of five states, as described below.

\section{Inverter State}

- Inverter/rectifier bridge regulates AC line voltage

- Generator off-line

- Inverter controls diversion load to limit battery charge current

- Battery charge controller regulates DC bus

\section{Generator Support State}

- Generator online, regulating AC voltage

- Inverter/rectifier bridge regulates DC bus

- Battery charge controller regulates generator load current (including support of generator in AC-current regulation mode if load exceeds generator rating. Generator support refers to current flow from the PPU to the grid should the load power exceed the generator power rating.)

- Inverter controls diversion load to limit battery charge current

\section{Equalize State}

- Generator online

- Inverter/rectifier bridge regulates DC bus

- Equalize can be set for Manual or Automatic Mode

- Automatic Equalize will occur at a field-settable interval of 1 to 100 days 


\section{Generator Only State}

- Generator online

- Inverter/rectifier bridge, battery charge controller and diversion load control disabled

\section{Blackout State}

- Generator and wind turbine offline

- Inverter/rectifier bridge, battery charge controller and diversion load control disabled

\section{Inverter/Rectifier Bridge Control}

Inverter State Control Method: Current-regulated pulse-width-modulation (PWM), with AC line voltage outer control loop; voltage references generated by embedded controller

Generator Support and Equalize State Control Method: Current-regulated, sinusoidal PWM, with DC bus voltage outer control loop; current references derived from generator voltages

\section{Battery Charge Controller Control}

Inverter State Control Method: Current-regulated PWM, with DC bus voltage outer control loop

Generator Support Control Method: Current-regulated PWM, with battery voltage and generator current outer control loops; all charge algorithm set points field settable

Equalize State Control Method: Current-regulated PWM, with battery voltage outer control loop; all equalize algorithm set points field settable

Generator Start Voltage: Field settable from 0 to 350 volts, with field-settable current and temperature compensation factors

Charge Voltage: Field settable from 0 to 350 volts, with field-settable current and temperature compensation factors

Low Voltage Discharge Cutoff: Field-settable from 0 to 350 with field-settable current compensation factor

Equalization Voltage: Field-settable from 0 to 350 volts with field-settable current compensation factor

Equalization Timer: Field-settable from 0 to 168 hours

Equalization Interval: Field-settable from 1 to 100 days

\section{Generator Interface Control}

Warm-Up Time Delay: Field-settable from 0 to 20 minutes

Cool-Down Time Delay: Field-settable from 0 to 20 minutes 


\section{Instrumentation}

Instrumented Parameters: The following parameters shall be available through the operator interface LCD and transmitted to the optional DAS. Instrument error shall not exceed $2.5 \%$ of full-scale values, unless otherwise noted.

\begin{tabular}{|l|l|}
\hline Inverter Voltage & Generator Voltage \\
\hline Inverter Current & Generator Current \\
\hline Inverter Real Power & Generator Frequency \\
\hline Inverter Reactive Power & Generator Real Power \\
\hline Inverter Frequency & Generator Reactive Power \\
\hline Battery Voltage & Alarm Codes \\
\hline Battery Current & Heat Sink Temperature \\
\hline Battery Power & Operating State \\
\hline
\end{tabular}

Communication Medium: Fiber-optic pair; fiber ports provided on PPU embedded controller

Communication Medium: Fiber-optic pair; fiber ports provided on PPU embedded controller

Communication Protocol: Supplied by subcontractor

\section{Self-Protection, Fault Detection, and Alarms}

Embedded controller algorithms will include the following fault detectors. All faults are latching and result in an automatic transition to a fault state. If the generator is operating at the time of the fault, the generator start-stop contact and generator contactor will remain closed. If the generator is not operating, the start/stop contact and generator contactor will close. Upon clearance of the fault from either the operator interface or the optional DAS, the PPU will transition to either the Generator Only or Blackout state, depending on the operating state of the generator.

\begin{tabular}{|l|c|c|}
\hline \multicolumn{1}{|c|}{ Fault } & User Settable? & Setpoint Range \\
\hline \hline Serial communication timeout & No & N/A \\
\hline Interrupt timeout & No & N/A \\
\hline Matrix control failure & No & N/A \\
\hline State machine failure & No & N/A \\
\hline Bus precharge fault & No & N/A \\
\hline Bus regulation fault & No & N/A \\
\hline DC bus overvoltage & No & N/A \\
\hline DC bus undervoltage & No & N/A \\
\hline Gate drive fault & No & N/A \\
\hline Matrix overtemperature & No & to 100 A \\
\hline Magnetics overtemperature & No & N/A \\
\hline DC ground fault & Yes & N/A \\
\hline Emergency stop & No & N/A \\
\hline Key switch & No & N/A \\
\hline Door interlock & No & N/A \\
\hline Battery overvoltage & No & 0 to 350 V \\
\hline Battery overcurrent & No & Yes \\
\hline Battery low voltage disconnect & & \\
\hline
\end{tabular}




\begin{tabular}{|l|c|c|}
\hline Inverter overvoltage & Yes & 208 to 250 V; 0 to 10 sec \\
\hline Inverter undervoltage & Yes & 166 to 208 V; 0 to 10 sec \\
\hline Inverter overfrequency & Yes & 60 to 65 Hz; 0 to 10 sec \\
\hline Inverter underfrequency & Yes & 55 to $60 \mathrm{~Hz}$; 0 to $10 \mathrm{sec}$ \\
\hline Inverter overcurrent & No & N/A \\
\hline Generator overvoltage & Yes & Same as inverter \\
\hline Generator undervoltage & Yes & Same as inverter \\
\hline Generator overfrequency & Yes & Same as inverter \\
\hline Generator underfrequency & Yes & Same as inverter \\
\hline
\end{tabular}

\section{Performance Specifications}

EMI/RFI Emissions: Not to exceed FCC Part 15 Rules for Class A device

Efficiency (exclusive of transformer losses): > 94\%

Voltage Regulations: $\pm 5 \%$ of nominal, phase-to-phase

Frequency Regulation: $\pm 0.5 \mathrm{~Hz}$ of nominal

Voltage Distortion: Less than 5\% THD under linear load

Battery Voltage Ripple: 5 V maximum (2\% of nominal battery voltage) 
Appendix B: MATLAB Dynamic and Transient Wind-Diesel Models 


\section{NREL Dispatch Dynamic Model Document}

1.0 Scope

This document provides toplevel instructions for running the MATLAB NREL Modified Inverter Dynamic model. Also included are descriptions of the various functions within the model along with their flow diagrams.

This model is based on an energy balance between a wind turbine, inverter/battery, generator, grid load and dump load elements. Logic for transitioning between states is computed by the MATRIX logic function. The MATRIX logic uses filtered/averaged values for battery state-of-charge (SOC) and net load demand to determine which operating state should be requested. The battery's SOC is assumes to be related to the battery's voltage and the grid's net load demand is defined as grid load minus wind turbine output in $\mathrm{kW}$.

The time step for this model is based on 1.0 SIMULINK model step $=1.0$ second simulation time. The minimal inputs include a time vector ( $\mathrm{sec}$ ), grid load vector ( $\mathrm{kW}$ ) and a wind speed (mps) vector. The outputs are located within in the toplevel diagram of the model and duplicated within the "Control Panel" for ease of use. The output values include; generator on cycles, generator fuel usage, lost energy (dump load) and generator run time.

\subsection{Requirements}

The NREL Dispatch model was developed using Math Works MATLAB SIMULINK program. Therefore to run the model you will need to have MATLAB software, with the SIMULINK option installed on your computer. Please note this model was developed on an IBM compatible PC.

The initial model development used MATLAB Version 9. Several compatibility issues, with Windows ' 98 , were encountered early on and therefore the MATLAB program was upgraded to Version 11.0 for all further developmental efforts. It is recommended that Version 11.0, or later, be used to run this model.

NOTE: This document was written assuming the operator has a familiarity with the program MATLAB/SIMULINK, although I have tried to cover each step in enough detail so you do not need to be an expert.

\subsection{Operating Procedures}

The procedure for running the model involves five steps A) opening the model in MATLAB/SIMULINK, B) set-up the input vectors, C) modify model settings (as required), D) run the model and finally E) review the data. Each step is discussed in more detail below. [Note: any input, to be typed in from the keyboard, is identified by enclosing the text within $\diamond$ brackets. The greater than/less than brackets are not part of the input.] 
Step A) Open the NREL dyn model in MATLAB

1) Open the MATLAB program as any Windows based program. This will open a MATLAB workspace titled 'MATLAB Command Window'.

2) At this point you may want to load any previously saved workspace variables using the $<$ load 'filename' $>$ command. See 'Step B' below for more details.

3) Now type < simulink $>$ and hit enter. This will open the SIMULINK portion of the program.

4) Under File on the Library:SIMULINK window menubar select 'Open'. Locate the appropriate directory and find the file named nrel5dy0.mdl. Double click on the file.

5) You should now have the MATLAB workspace, the Library:SIMULINK toolbar, the model nrel5dy0 and an Untitled SIMULINK Window open. Note, you can close the Untitled SIMULINK Window since it will not be used.

Step B) Set-up the Input Vectors

You will need to provide a time, grid load and wind profile "vector" to the SIMULINK model. To make the vector data available to the model, it must exist in the MATLAB workspace environment. The model's input variables include the following:

\begin{tabular}{cll} 
Variable Name & \multicolumn{1}{c}{ Description } & Units \\
$T$ & A column vector for time & seconds \\
U & A column vector for grid load & $\mathrm{kW}$ \\
W & A column vector for wind speed & $\mathrm{mps}$
\end{tabular}

Four additional variables must exist in the MATLAB workspace environment, they are;

\section{MXEVON1}

MXEVOFF 1

MXBLON1

MXBLOFF 1
A $10 \times 10$ matrix for the gen on

State conditions, function of

Net load and battery SOC

(evaluation settings)

A $10 \times 10$ matrix for the gen off

State conditions, function of

Net load and battery SOC

(evaluation settings)

A $10 \times 10$ matrix for the gen on

State conditions, function of

Net load and battery SOC

(baseline settings)

A $10 \times 10$ matrix for the gen off

State conditions, function of

Net load and battery SOC

(baseline settings) 
The four matrix variables, with default settings, are included in the dynenv mat file. This file should be copied into the same directory where the SIMULINK model is located. Prior to opening the SIMULINK model, type the following; <load 'dynenv.mat'> to load the default environmental variables. Note: this file also contains several developmental cases which can be used for diagnostic purposes.

The time step is based on $1.0=1.0$ second which matches the dynamic model's imbedded time constants. Also note that it takes the first ten minutes of simulation time to completely "initialize" the various simulation filters. This should be taken into account when defining your input vectors. To load the time, grid load and wind speed vectors perform the following steps.

1) Click on the MATLAB workspace, to make it the active window.

2) Now you can enter the data manually or load it from a previous secession, using the save and load commands. To retrieve data saved from a previous secession, type $<$ load 'filename' $>$. To verify the vectors are available you can type < who $>$ in the MATLAB workspace and the available variables will be listed.

3) To load the data manually, type the following for the T, time, vector; $<\mathrm{T}=[0 \text { :step:endtime }]^{\prime} ;>$. Where step is the value of the time step desired and endtime is the end time value. Note: the 'character will transpose the vector from horizontal to a vertical vector. Also the ; will suppress the values of the vector from being echoed to the workspace.

4) To manually load the U, grid load, vector type the following; $\left.<\mathrm{U}=\left[\begin{array}{ll}\mathrm{u} 1 \mathrm{u} 2 \mathrm{u} 3 \ldots \\ \mathrm{u}\end{array}\right]^{\prime} ;\right\rangle$. Where u1,u2, u3 ... are grid load values for the time steps defined in 'Step C'. Remember the first time value is 0.0 .

5) To manually load the $W$, wind speed, vector type the following; $<\mathrm{W}=[\mathrm{w} 1 \mathrm{w} 2 \mathrm{w} 3 \ldots]$ '; $>$. Where $w 1, \mathrm{w} 2, \mathrm{w} 3 \ldots$ are wind speed values for the time steps defined in 'Step C'. Remember the first time value is 0.0 .

Step C) Modify Model Settings

1) To modify any of the model parameters first click on the NREL_dyn model window to make it the active window.

2) Now click on the particular item you wish to change. A window will open with instructions on which changes are allowed.

3) Below are a few of the parameters one might want to modify;

Item to be Modified

Number of wind turbines

MATRIX config. (baseline or eval)

Wind Speed pre-processing

\section{Location \\ Control Panel}

Control Panel

Wind Plant Simulation 
State Matrix variables (for Gen On)

State Matrix variables (for Gen Off)

Gen fuel Usage

Inverter Charge Rate (high)

Inverter Charge Rate (low)

Dump Load Rate Limit

Min Gen Load Level

Min Inv. Load Level (when battery fully charged)

Min Dump Load Level

Dump Load Rise Rate

Dump Load Fall Rate

Initial Battery Capacity
MATRLX Logic/

Gennon MATRIX

MATRIX Logic/

Genoff MATRIX

Gen Fuel Usage/

Load to Fuel Table

Control Panel

Control Panel

Inverter Model/

Rate Limiterl

Control Panel

Control Panel

Control Panel

Inverter Model

Dump Load Logic/

Dump Load Controller/

Inc Rate

Inverter Model/

Dump Load Logic/

Dump Load Controller/

Dec Rate

Battery Model/

Integrator initial value

(Set Inverter Model/1 to 10 Hyst Bat/Hyster $5 \mathrm{~min} /$ Unit Delay Initial values to prevent start-up conflicts)

Step D) Run the Model

1) Once the input vectors are defined and any modification made to the model, you are now ready to run the model. This is accomplished by clicking the 'Simulation' button on the Menu bar of the NREL_dyn model window and clicking 'start'. Note: you should verify the simulation start and end times are consistent with the time input vector. These values can be found by selecting Parameter under the Simulation menubar item.

2) Depending on the size of the input vectors and the speed of your computer the run time can take several minutes to hours. Typical runs have taken up to 2 hours to run a 24 hour simulation (based on a 350 $\mathrm{mHz}$ PII processor). 
Step E) Review the Data

1) After running the model you can review the data collected by opening the various 'scopes' within the model.

2) Several key values are displayed on the toplevel model window. These include; Lost Energy, Generator Run Time, Generator Fuel Usage and Generator On Cycles.

3) The four key output values, identified above, are also located in the Control Panel sub-function, for the users convenience. Also included are seven control variables that can be manually set from the Control Panel (identified in 'Step C').

4) If you want data transferred to the MATLAB workspace for further analysis, add an output port to the appropriate location and then connect it to the desired variable data line. The output port (To Workspace block) can be obtained from the SIMULINK Library Browser under the Simulink/Sinks window. Click and hold on the icon and drag it to the appropriate model window. Once on the model window release. You can now move the output port to a location close to the signal line of the variable you are looking for. With the cursor over the signal line depress the 'Ctrl' key and the left mouse button and hold. Now move the cursor to the connector on the output port. Once at the proper location release. You should now have a data line connected to the output port. Now set the properties of the block by double elicking on the icon.

\subsection{Function Descriptions}

There are nine main sub-functions that make-up the model, each containing additional sub-function for ease of documenting. Below is a listing of each one along with a short description. Under most conditions there will be no need to access these functions but an understanding of them will assist in the proper usage of the model and its limitations.

\section{1) Wind Plant Simulation}

This sub-function includes four wind turbine models for calculating the wind turbine energy delivered to the grid. The number of wind turbines used by the simulation can be controlled by the "Number of Turbines" variable in the " Control Panel. An off-set value and transfer function are included to modify the wind speed input, to the turbines, to more accurately represent the power produced by a "windplant". These values can be modified as required. This function also includes the four sub-functions titled "Wind Turbine " Model".

2) Wind Turbine \# Model

This sub-function models a simple constant speed induction generator type wind turbine. Stall/Pitch control is used to limit max power output. The wind turbine aero dynamics are modeled by a simple first order lag with a $0.5 \mathrm{sec}$ time constant. The stall/pitch system is modeled using an integrator and first order lag of a $0.1 \mathrm{sec}$ time constant. This in turn modifies a "Kp" value which emulates the changing energy capture of the turbine. The loop is closed on a reference max power setting which is set at $62 \mathrm{~kW}$. 
Wind Turbine Model Assumptions:

1) Output power is the product of the modified input wind speed and $\mathrm{Kp}$ value. Kp is obtained from the "NREL Kp Look-Up Tablel" which uses a "pitch angle" to set the wind turbine's energy capture capability.

2) The output power below rated is assumed to be linear with wind speed, therefore a fixed Kp value at full power "pitch" is used. If the output power needs to be modified the "WS Look-Up Table2" can be used to modify the input wind speed to achieve the appropriate output power.

3) Pitch control is assumed to regulate max power. The dynamic response of the pitch system is defined by the Pitch Dyn (transfer function) block. The pitch integrator is limited to the min and max pitch values. The dynamics were based on the following:

Step 0 to 20 mps results in a peak power of $-85 \mathrm{~kW}$ and a settling time of $\sim 4 \mathrm{sec}$. Rated power set at $62 \mathrm{~kW}$.

\section{3) Matrix Logic}

This sub-function includes the logic to determine the desired control "State" the inverter should operate in. The MATRIX tables contain the desired operating states as a function of Net Load and Battery State of Charge (SOC). Note: these signals are filtered/averaged values, not the "raw" input signals. There are two MATRIX tables, for each configuration, one for when the generator is presently off (gennoff) and the other for when the generator is presently on-line (gennon). The logic selects from the appropriate table depending on the existing state of the generator. The operator can also select from two different MATRIX configurations. One is labeled "Baseline" and can be used for comparisons to other MATRIX configurations. It presently contains values to emulate the original inverter operation. The other table, labeled "Eval" should be used for new logic development. The values of these look-up tables can be modified as required. The values are included in a $10 \times 10$ matrix located in the MATLAB work environment. The matrixes are named;

$\begin{array}{ll}\text { MXBLON } & \text { Baseline Gen On } \\ \text { MXBLOFF } & \text { Baseline Gen Off } \\ \text { MXEVON } & \text { Evaluation Gen ON } \\ \text { MXEVOFF } & \text { Evaluation Gen Off }\end{array}$

This function also includes the sub-functions Gen-on Trans, Gen-off Trans and HCU States which control the states transitions. The Gen-on and Gen-off blocks include logic for transitioning between inverter and generator operation. They both include a hold state and a ramp state (or transition state). The hold state emulates the condition where the inverter is preparing to transition and the ramp state emulates the condition where the inverter is ramping the load to or from the generator. For generator on transitions the hold state is 2 and the ramp state is 1 . The actual transfer occurs when the inverter load reaches a set value defined by the Inv Low signal. This signal is calculated in the Ramp Inv Off sub-function.

For the generator off transition the hold state is 5 and the ramp state is 0 The actual transfer occurs when the generator load reaches a set value defined 
by the Gen_Low signal. This signal is calculated in the Ramp Inv On subfunction.

The hold and ramp times are settable. Refer to the appropriate block diagram for directions for setting these variables.

The HCU sub-function generates a Mux State signal containing the various state conditions. These include the transient_state, gen state, and current HCU state.

\section{4) Battery Model}

This sub-function models the battery storage hardware. The gainl variable sets the battery charge efficiency. The discharge efficiency is assumed to be $100 \%$. The battery voltage is output as a measure of the battery capacity. The table "V Look-Up Table" converts battery capacity, in Amp-Hrs to Volts per cell. "\# of Batteries" is the number of battery cells to obtain the total battery output voltage.

5) Generator Model

This sub-function models the generator hardware. The Integrator, Gain and "Gen Dynamics" functions model's the generator power production dynamics. The Gainl variable is used to quickly return the integrator to zero output to prevent integrator wind-up when the generator is turned off.

6) Dump Load Model

This sub-function models the dump load hardware. The "D to A" term is used to convert the six bit digital signal to an actual dump load level. The "Dump Load Dyn" function models the dump load dynamics.

7) Inverter Model

This sub-funetion models the Inverter hardware and logic. First, the operating state, as defined by the MATRIX logic, is decoded and the proper inverter action is taken.

State

Deseription

State 0 Transition from Generator on to Inverter on

State 1

State 2 Transition from Inverter on to Generator on Generator off and inverter supplying net load (Voltage source)

State 3 Generator on and inverter charging battery, at a high constant rate

State 4 Generator on and inverter charging battery, at a low constant rate

State $5 \quad$ Generator on and inverter off This function also includes the inverter control dynamics (Inv Ramp On/Off, Inverter Dyn., and Inv, Gain sub-functions), averaging and "digitizing" of the net load (1 to 10 Hyst Load function) and battery filtering and SOC (bat filter and 1 to 10 Hyst Bat functions) output values, and the dump load binary output signal (Dump Load Logic, A to D and Change to Integer functions).

\section{8) Dump Load Logic}

This sub-function models the dump load logic. It generates the dump load control signals (dump load hold signal, generator on signal, transition to generator on signal, and battery SOC at max when the inverter is providing the net load) for determining if the dump load should be turned on, off or hold last value. This function also includes the "Dump Load Controller" subfunction. 


\section{9) Dump Load Controller}

This sub-function models the dump load controller logic. If the conditions are right, 1) generator output level is below its min level or 2) the battery max charge is exceeded and the grid has excess energy, with the inverter controlling the grid, then the dump load is activated. At this time the dump load level is set by a simple proportional plus integral controller which increases the dump load quickly to resolve the above conditions and then reduces the load demand, at a slightly slower rate, as the condition returns to "normal". The proportional error term is single sided to increase the dump load during extremely fast transients. The integrator rates are set by the variables "DUMP_INC_GAIN" and "DUMP_DECR_GAIN". The "Min gen Level" and "Min Inv level" values set the lower operating power level for the generator and inverter respectively. This function also includes the "Integ/Limt" sub-function which actually calculates the dump load commanded value.

\section{0) 1 to 10 Hyst Load}

This sub-function models the logic to filter and then convert, to an integer value, the input signal "calculated net load" (negative value of the sum of inverter load, generator load, and dump load demand). The input signal first passes through a filter and averaging function contained in the "Digital $\mathrm{Lag} / \mathrm{Avg}$ " sub-function. The filter is a first order lag filter (time constant of $125 \mathrm{sec})$. The signal is then passed through a running average filter using five values updated, in series, every 60 seconds. This results in an overall effect similar to a first order lag filter with a $\sim 300 \mathrm{sec}$ time constant but the settling time is much faster, $\sim 800 \mathrm{sec}$.

Next the signal is scaled and converted to an integer value by the subfunction "Hyster". The conversion assumes no rounding-up and using a +0.5 hysteresis on the decrease side. The output value is updated every 200 seconds. The output signal is also limited to a range between 0 and 9 . This range is the present limits of the input values to the MATRIX tables. The output signal is labeled "Net load Int".

NOTE: The input signal defined above "calculated net load" was assumed to most accurately reflect the value for "Net Load" as defined as grid load minus wind turbine output.

\section{1) Bat Filter}

This sub-function performs a first order filter of the battery voltage signal, provided by the inverter controller. The time constant is presently set for $\sim 124 \mathrm{sec}$.

\section{2) 1 to 10 Hyst Bat}

This sub-function models the logic to convert, to an integer, the input signal "Bat Volt Filt". The input signal is first converted from a voltage to a value representing the battery "State of Charge" (SOC). This is performed by the "V to Units Look-up Table" sub-function. The "Hyster" sub-function is the same as the hysteresis function previously discussed, except it uses a $600 \mathrm{sec}$ 
update rate. Also included is logic to detect a low battery condition and set the output signal to a low value, in real time. This additional logic is required

to override the imbedded time delay of the "Hyster" sub-function. The output signal is labeled "Bat Volt Int".

NOTE: Filtering on this signal was moved outside this function because of the need for additional filtering on the battery voltage signal going to the dump load logic.

\section{3) Inv Ramp On/Off}

This sub-function models the inverter logic for transitioning the load to/from the inverter during generator on/off transients. The load demands during transfer conditions are calculated in the "Ramp Inv Off" and "Ramp Inv On" sub-functions. They use the various current state values and ramp times (Ramp_Off and Ramp_On variables) to determine the timing and rates to transfer the loads. They also calculate the signals (Inv_Low and Gen_Low) used for switching between generator and inverter operation during the transition. 
Part 5 SIMULINK Diagrams of Dispatch dynamic Model

Model Name: "nrel5dy0.mdl" Version 5.0 Rev 0 


\section{NREL Modified Inverter Model Revision Notes}

Version 1.0 Baseline

Rev 1: Changed 0 to 6 Hyst Logic, in Inverter Model, to simulate C code implementaton

Rev 2: Integlimit mod for C code impiementation

Rev 2: Changed Inc rate from 2.0 to 0.02 \& Dec ra:e from 0.3 to 0.003

Rev 2: Added step function bo force start-up in imerter mode, Required due to unit step delays in hyst function

Rev 2: Changed MATRIX Genon(1,3) from 3 to 2

Rev 3: Changed First order lag (4 Step Lag) function to discrefe implementation (Digital Lag)

Rev 3 . Updated wind turbine model for TSR input to Kp Table

Rev 3: Added offset to windspeed inputs to turbines $a 2,3$ and 4

Rev 3: Modified turbine logic to divide power delta by speed to get torque into integrator Rev 3; Added Ref Speed to properly calculate output power

Rev 3: Add real time low battery condition logic

Version 20 Update to NREL HW Configuration, Time Step set to 1.0 = 1.0 sec

Ver 2.0 Mod grid Dynamics for NREL HW

Ver 2.0 Change values for NREL H/W (Battery Model)

Ver 2.0 Modity for NREL. HW Config (battery off-set vo tage)

Ver 2.01 to 6 Hyst Bat: Modify for NREL HW (Battery Voltage to Storage)

Ver 2.0 Hyster. Update Unit Delay and Saturation Limits

Rev1: Added Rate Limiter to Reiay to stabilize dump load while gen operating

Rev1: Remowed Rate Limiter from Gen Model to Investigate stabity issue

Rev 1: Added HW delays to Dump Load Variables

Rev1: Changed Gain trom 0.02 to 0.008 so minimize potential aliasing in Averager

Version 4.0 Conversion to MATLAB Release 11 and Mods for S/W compatabity

Ver 4.0 Charged Imv err signal' to Net Load and Dump Load Logic to Inverter "load vakue

Ver 4.0 Changed Inv err signar to Inverter 'load' value 8 required Dump Lead conaroller changes

Ver 40 Added min Inv Load for dump load Controller

Rev 10 Change Charge to Discharge (high)

Rev 1.0 Changed max dump load to $90 \mathrm{~kW}$

Rev 1.0 Change Saturation Limits to 0 to 9

Rerv 1.0 Change a Batteries to $114 \mathrm{\& V}$ to Unts Tabie values

Rev 1.0 Changed Max Bat Level to 250 on $8243 \mathrm{Oft}$

Rev 1.0 Changed MATRIX row range to 0 to 9 and use new MATRIX tables

Rev 10 Added fiter to battery signal

Rev 1.0 Removed dump load rate filter (redurdant)

Rev 2.0 Added gen transition on logic to dump load

Rev 2.0 Changed start-up state to 2 (State 1 now represents gen transitioning on)

Rev3 D; Remowed initial lag of Sum2 digital fiter, not required

Rev3 0: Modifed Dump Load Integlimit function (added proportional gain term and mod rate limits)

Rev 3.0 Added minimum dump load value

Rev 4,0 Changed Battery Hyster input delay to 600 sec ZOH 8 output delay to 1 sec

Rev 4.0 Changed Load Hyster input delay to 200 sec $Z O H \&$ output delay to 1 sec

Rev 5.0 Added HCU_SYNC_TO_INV lock-out on gen_dump_on signa!

Rev 50 Updated Inverter transition onvolf logic

Rev 6.0 Modified State transition logic for gen orroff

Rev 6.0 Modified start-up state to 0 to minimize ransients 
Version 40 Conversion to MATLAB Reiease 11 and Mods for SWW compatability

Rev 7.0 Increase Grid Dynamics to $0.01 \mathrm{sec}$ time constant

Rev 70 Increase Gen Dynamics (Based on NREL best guess on 9/30/99)

Rev 7.0 Modify inverter Dynamics (faster response best guess 10/1/99)

Rev 7.0 Changed start-up state to 2

Rev 70 Changed DUMP_RATE_MIN to -20

Rev 7.0 Changed DUMP_DECR_GAIN to 0.3

Rev 7.0 Added hold function to Integhimit1 function

Rev 7.0 Added Dump Hold logic

Rev 7.0 Removed HCU_SYNC_TO_INV state lock-out on gen_dump_on

Rev 7.0 Calculated GEN_TRAN signal for dump logic

Rev 7.0 Added GEN_TRAN signal for gen_tran signal

Rev 7.0 Change sign of input (gen load) signal

Rev 7.0 Changed DUMP_PERR_GAN to 3.0 due to faster gen dynamics

Rev 80 Modified inverter On/Off switch to account for load transfer to/from Gen

Rev 8.0 Changed gen_dump_on signal to account for transition states

Rev 8.0 Added Ramp_Off caic to automate trans. load

Rev 80 Added Ramp_On calc to automate trans load

Rev 80 Added Ramp Off signal to set load transfer rate

Rev 8.0 Added Ramp_On signal to set load transfer rate

Rev 8.0 Caic Gen_Low signal to determine min gen load during tranter of load

Rev 8.0 Added low gen load transfer for load transition

Rev 8.0 Added delay to Gen_Low signal to address algebratic loop

Rev 9.0 Added transient_state calcioutput INV_TO_SHUTDOWN

Rev 9.0 Added Transibion state calcioutput SHUTDOWN_TO INVERTER

Rev 9.0 Add state mux signal

Rev 9.0 Added Demux for State Signal Scope

Rev 9.0 Added Demux to input state signal

Rev 9.0 Changed to Gen On Line state for gen OnNOtt signal

Rev 90 Revised gen tran signal to use transition state

Rev 90 Revised gen_dump_on signal to use gen state on

Rev 9.0 Changed bat_level_high to use only HCU_INV condition

Rev 9.0 Added Demux signal to State input 
Version 5.0 NREL Deliverable Version
Ver 5.0 Updated Dump_Hold logic (revoved HCU_SYNC_TO_SHUTDOWN)
Ver 5.0 Mod gen_dump_on to include GEN_RAMP state (no real change required)
Ver 5.0 Updated ramp time and added Inv_Low transition
Ver 5.0 Moved location of Gen_Low transition logic
Ver 5.0 Added Inv_Low Caic and mod ramp ott logic
Ver 5.0 Modified caic of Off ramp timers constant = [Rate] and constant3 = [pt]
Ver 5.0 Modified On Rate time variable inputs [Rate] 8 [pt] for simplify
Ver 5.0 Added ZOH to accuraty represent SM Implementation
Ver 5.0 Changed Net load Unit Delay to 200 sec
Ver 5.0 Changed battery Hyst Unit Delay to 600 sec
Ver 5.0 Incorporated wind turbine sim into model
Ver 5.0 Modified Integrator Rate limits and added ZOH (better simulate actual code) 


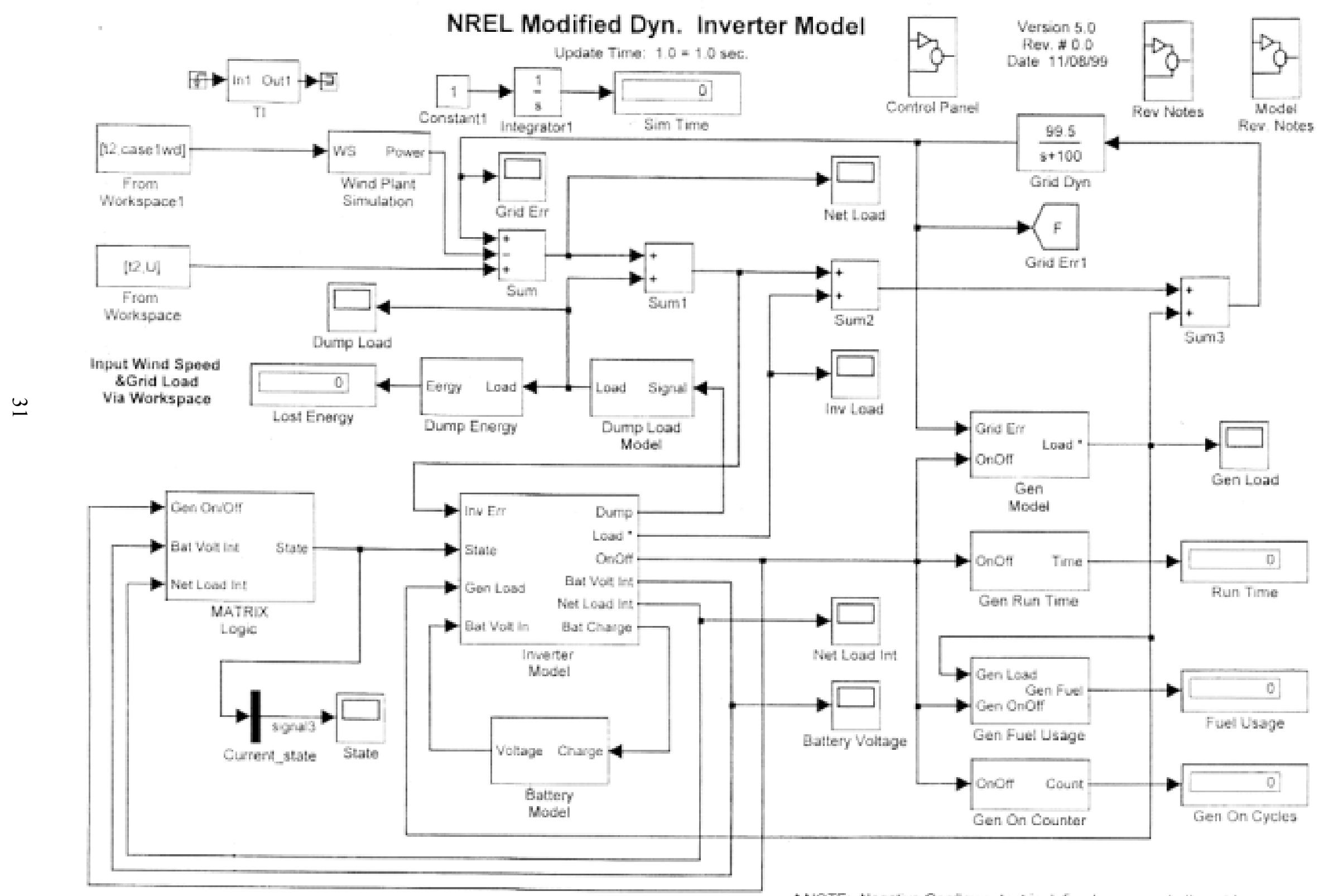

"NOTE: Negative Gen/inv output is defined as power to the gnd 
NREL Modifie iverter Model

Input/Output Control Panel
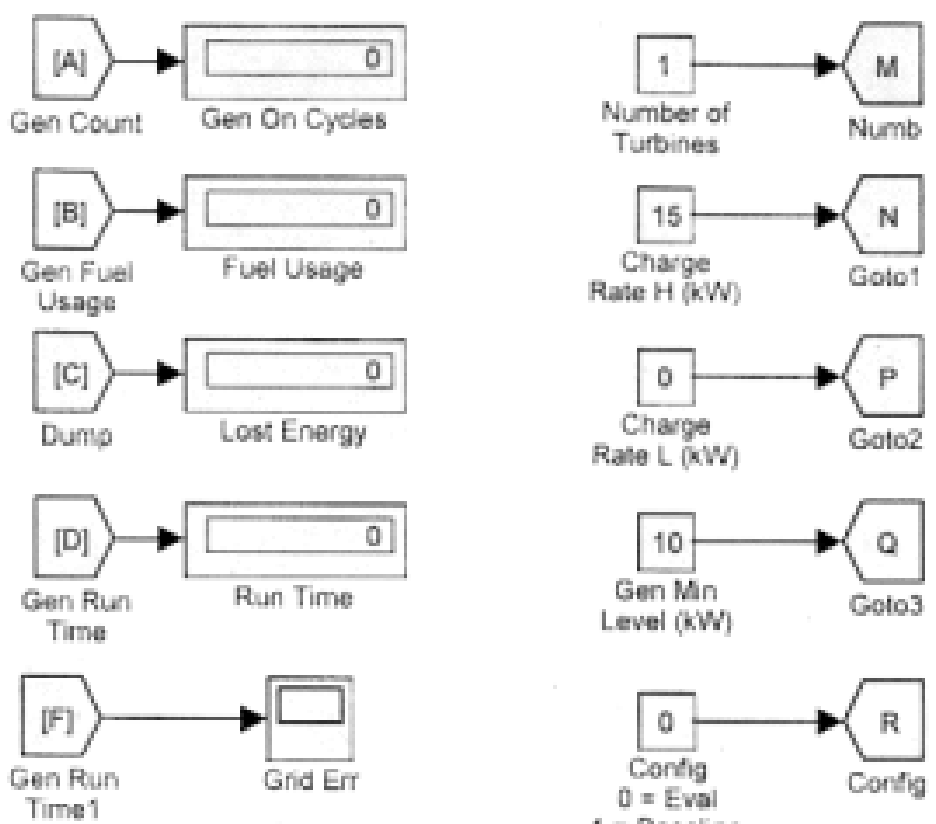

1 - Baseline
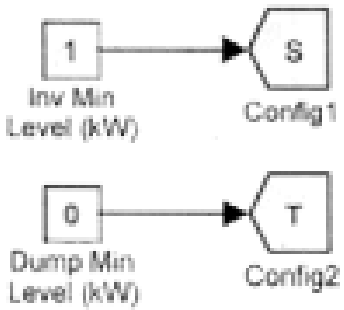

Ver 4.0 Added min Ifw Load fer dump load Controller

Rev 1.0 Change Discharge to Charge (high)

Rev 30 Added minumum dump laad value 
Dump Load Model

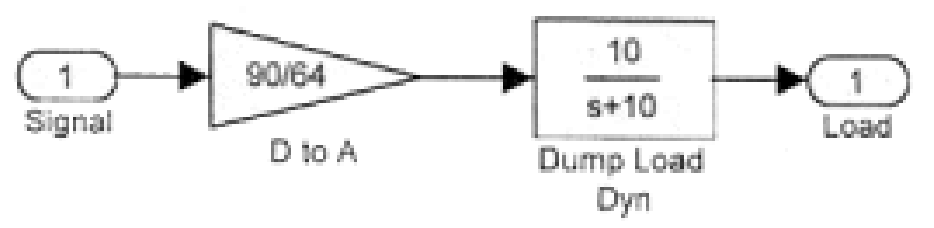

Rev 1.0 Changed max dump load to $90 \mathrm{~kW}$ 


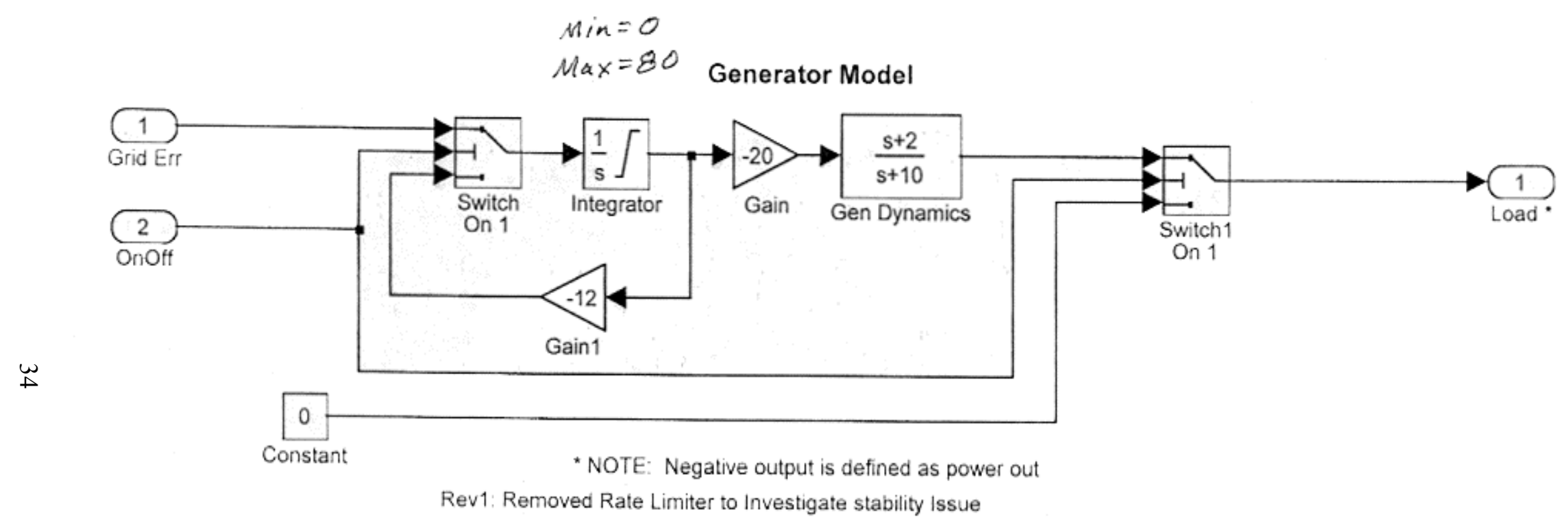

Rev1: Removed Rate Limiter to Investigate stability Issue 


\section{Battery Model}

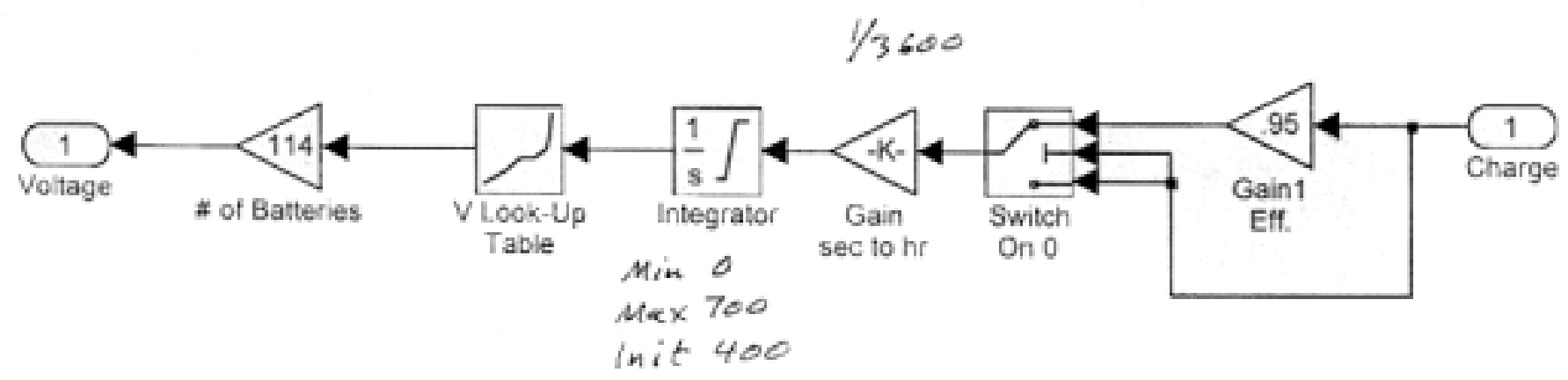

Ver 20 Change values for NREL HWW (Battery Model) Rev 1.0 Change \# Batteries to 114

\begin{tabular}{|c|c|c|}
\hline \multicolumn{3}{|c|}{$\checkmark$ look-Up Talle } \\
\hline Amp-hors & Volts/cell & $V_{0} / t^{\prime}\left(k_{0}-5\right)$ \\
\hline 0 & 1.6 & 182.4 \\
\hline 195 & 1.8 & 205.2 \\
\hline 390 & 2.03 & 231.4 \\
\hline 520 & 2.07 & 236.0 \\
\hline 650 & 2.20 & 250.8 \\
\hline 675 & 2.40 & 273.6 \\
\hline 700 & 2.80 & 319.2 \\
\hline
\end{tabular}


Wind Plant Simulation

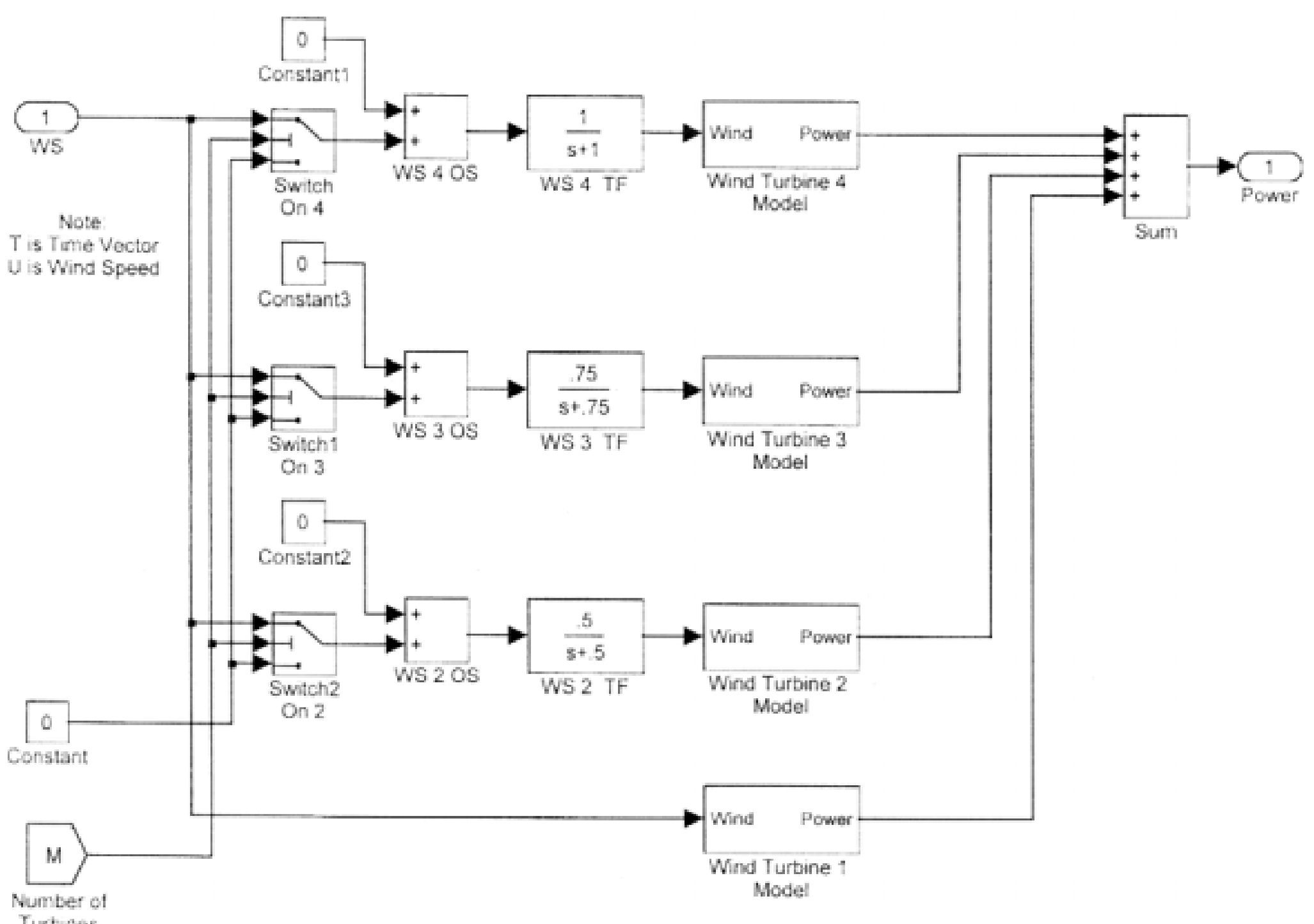

Rev 3 Added offset to windspeed inpuls u turbenes $\approx 2,3$, and 4 


\section{Wind Turbine1 Model}

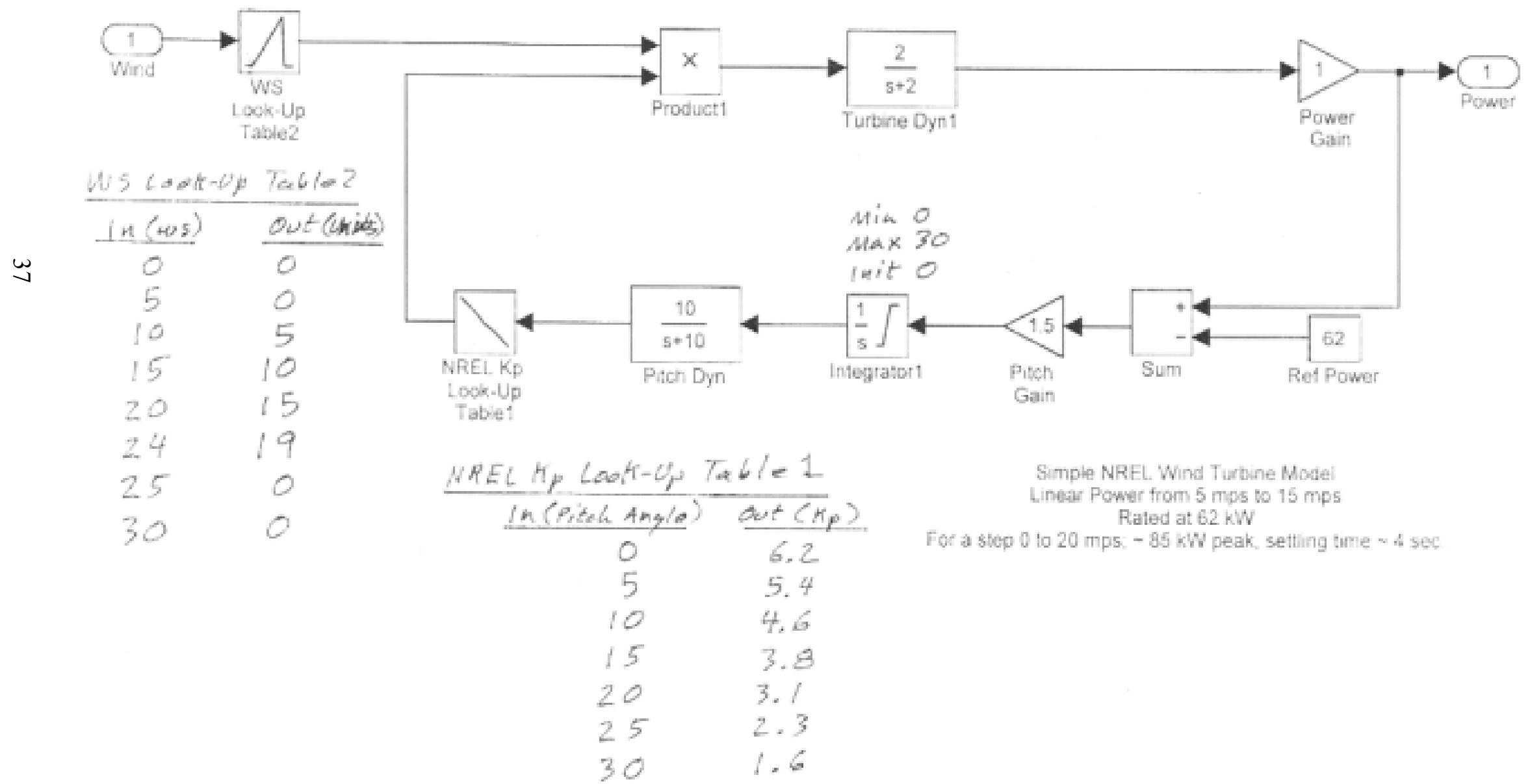


Matrix Logic

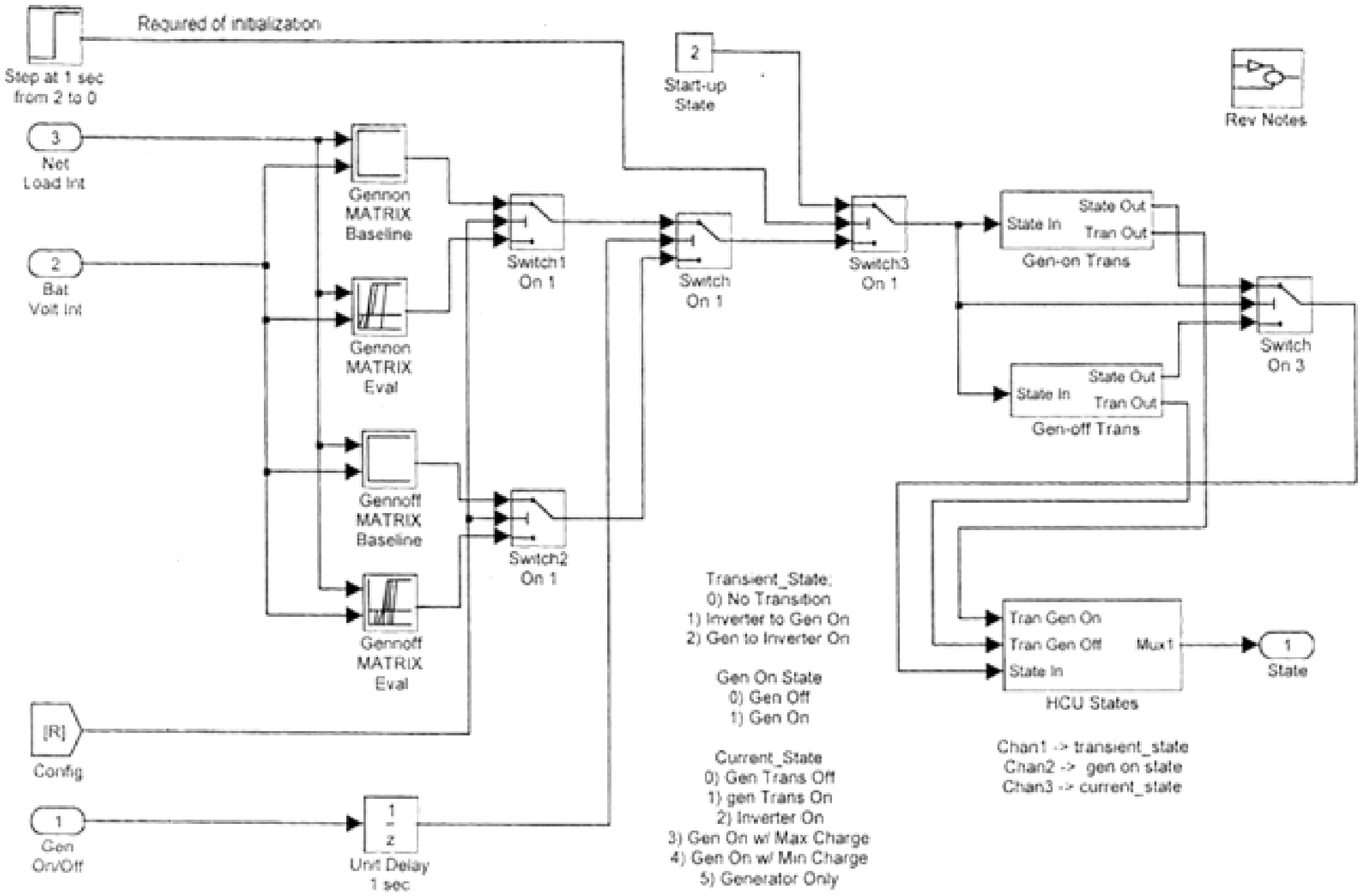




\begin{tabular}{lllllllllllll} 
Net & \multicolumn{11}{c}{ Load } & \multicolumn{11}{c}{ Battery State of Charge (SOC) } \\
& 1 & 2 & 3 & 4 & 5 & 6 & 7 & 8 & 9 & 10 \\
& & & & & & & & & & \\
0 & 3 & 2 & 2 & 2 & 2 & 2 & 2 & 2 & 2 & 2 \\
1 & 3 & 2 & 2 & 2 & 2 & 2 & 2 & 2 & 2 & 2 \\
2 & 3 & 3 & 3 & 2 & 2 & 2 & 2 & 2 & 2 & 2 \\
3 & 3 & 3 & 3 & 3 & 2 & 2 & 2 & 2 & 2 & 2 \\
4 & 3 & 3 & 3 & 5 & 5 & 5 & 5 & 5 & 2 & 2 \\
5 & 3 & 3 & 5 & 5 & 5 & 5 & 5 & 5 & 5 & 2 \\
6 & 3 & 3 & 5 & 5 & 5 & 5 & 5 & 5 & 5 & 5 \\
7 & 3 & 3 & 5 & 5 & 5 & 5 & 5 & 5 & 5 & 5 \\
8 & 3 & 3 & 5 & 5 & 5 & 5 & 5 & 5 & 5 & 5 \\
9 & 3 & 3 & 5 & 5 & 5 & 5 & 5 & 5 & 5 & 5
\end{tabular}

MXEVON1 Desired State MATRIX for Evaluation Gen On (Rev 1)

Net

Load Battery State of Charge (SOC)

$$
\begin{array}{llllllllll}
1 & 2 & 3 & 4 & 5 & 6 & 7 & 8 & 9 & 10
\end{array}
$$

$\begin{array}{lllllllllll}0 & 3 & 3 & 2 & 2 & 2 & 2 & 2 & 2 & 2 & 2\end{array}$

$\begin{array}{lllllllllll}1 & 3 & 3 & 3 & 2 & 2 & 2 & 2 & 2 & 2 & 2\end{array}$

$\begin{array}{lllllllllll}2 & 3 & 3 & 3 & 3 & 3 & 2 & 2 & 2 & 2 & 2\end{array}$

$\begin{array}{lllllllllll}3 & 3 & 3 & 5 & 5 & 5 & 5 & 5 & 5 & 5 & 2\end{array}$

$\begin{array}{lllllllllll}4 & 3 & 5 & 5 & 5 & 5 & 5 & 5 & 5 & 5 & 2\end{array}$

$\begin{array}{lllllllllll}5 & 3 & 5 & 5 & 5 & 5 & 5 & 5 & 5 & 5 & 2\end{array}$

$\begin{array}{lllllllllll}6 & 3 & 5 & 5 & 5 & 5 & 5 & 5 & 5 & 5 & 5\end{array}$

$\begin{array}{lllllllllll}7 & 3 & 5 & 5 & 5 & 5 & 5 & 5 & 5 & 5 & 5\end{array}$

$\begin{array}{lllllllllll}8 & 3 & 5 & 5 & 5 & 5 & 5 & 5 & 5 & 5 & 5\end{array}$

$\begin{array}{lllllllllll}9 & 3 & 5 & 5 & 5 & 5 & 5 & 5 & 5 & 5 & 5\end{array}$

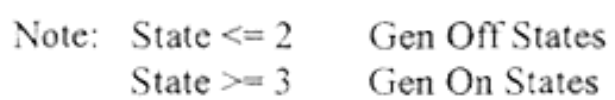

$$
5=\text { lew ouly }
$$




\section{MXBLOFF1 Desired State MATRIX for Baseline Gen Off (Rev 1)}

\begin{tabular}{lllllllllll} 
NET & \multicolumn{11}{c}{ Load } & \multicolumn{11}{c}{ Battery Capacity } & (SOC) \\
& 1 & 2 & 3 & 4 & 5 & 6 & 7 & 8 & 9 & 10 \\
& & & & & & & & & & \\
0 & 3 & 2 & 2 & 2 & 2 & 2 & 2 & 2 & 2 & 2 \\
1 & 3 & 2 & 2 & 2 & 2 & 2 & 2 & 2 & 2 & 2 \\
2 & 3 & 2 & 2 & 2 & 2 & 2 & 2 & 2 & 2 & 2 \\
3 & 3 & 2 & 2 & 2 & 2 & 2 & 2 & 2 & 2 & 2 \\
4 & 3 & 2 & 2 & 2 & 2 & 2 & 2 & 2 & 2 & 2 \\
5 & 3 & 2 & 2 & 2 & 2 & 2 & 2 & 2 & 2 & 2 \\
6 & 3 & 2 & 2 & 2 & 2 & 2 & 2 & 2 & 2 & 2 \\
7 & 3 & 2 & 2 & 2 & 2 & 2 & 2 & 2 & 2 & 2 \\
8 & 3 & 2 & 2 & 2 & 2 & 2 & 2 & 2 & 2 & 2 \\
9 & 3 & 2 & 2 & 2 & 2 & 2 & 2 & 2 & 2 & 2
\end{tabular}

MXBLON1 Desired State MATRIX for Baseline Gen On (Rev 1)

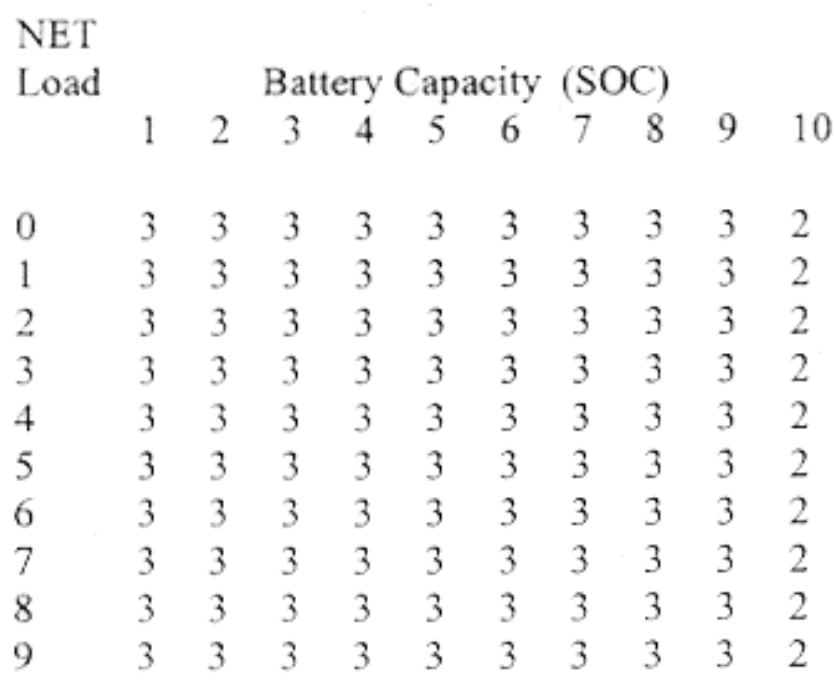

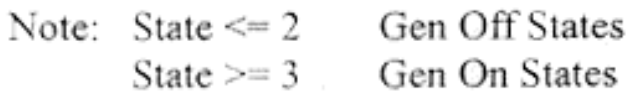




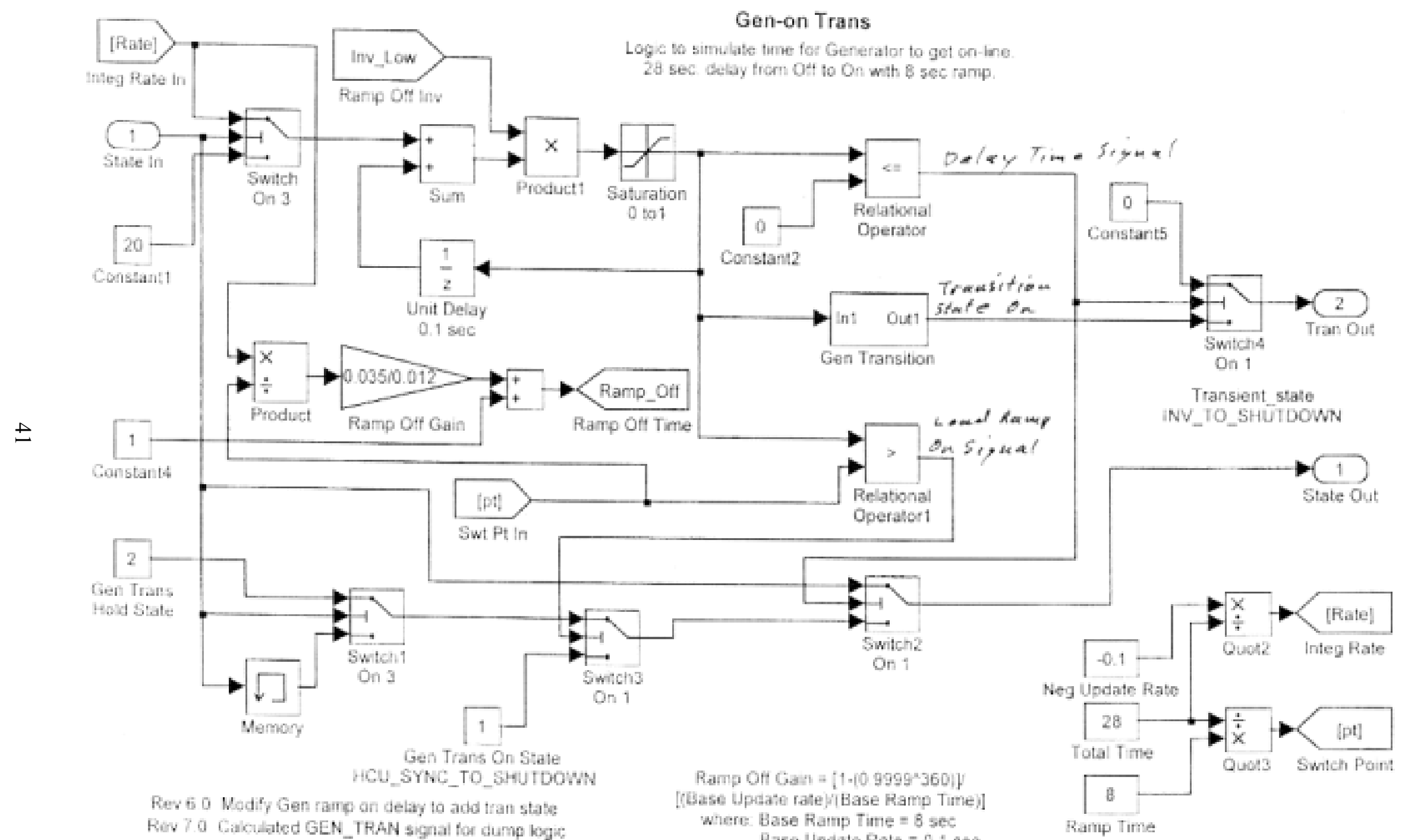

Rev 70 Caiculated GEN TRAN sicgal for dump boge

Rev 8.0 Added Ramp_Off calc to automate trans, jaad

lease update rate fil Base Ramp Timiel. Base Update Rate $=0.1$ sec

Rev 90 Added transient_state caicioutput INV_TO_SHUTDOWN

Ver 5 Updatud ramp time and added Inv_Low transtion

Ver 5.0 Modfied caic of tamp timers constant - [Rate] and constant3 = [pt]

Ver 50 Modined On Rate tme va'iabie nputs (simplify) 


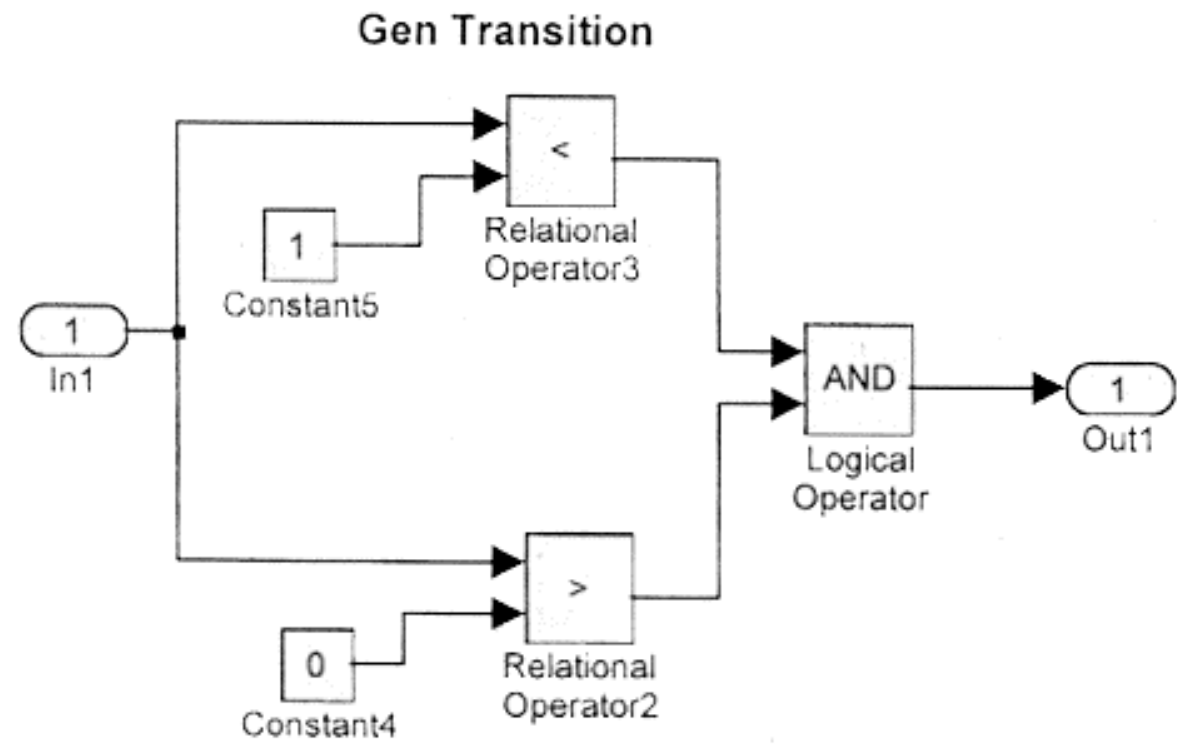




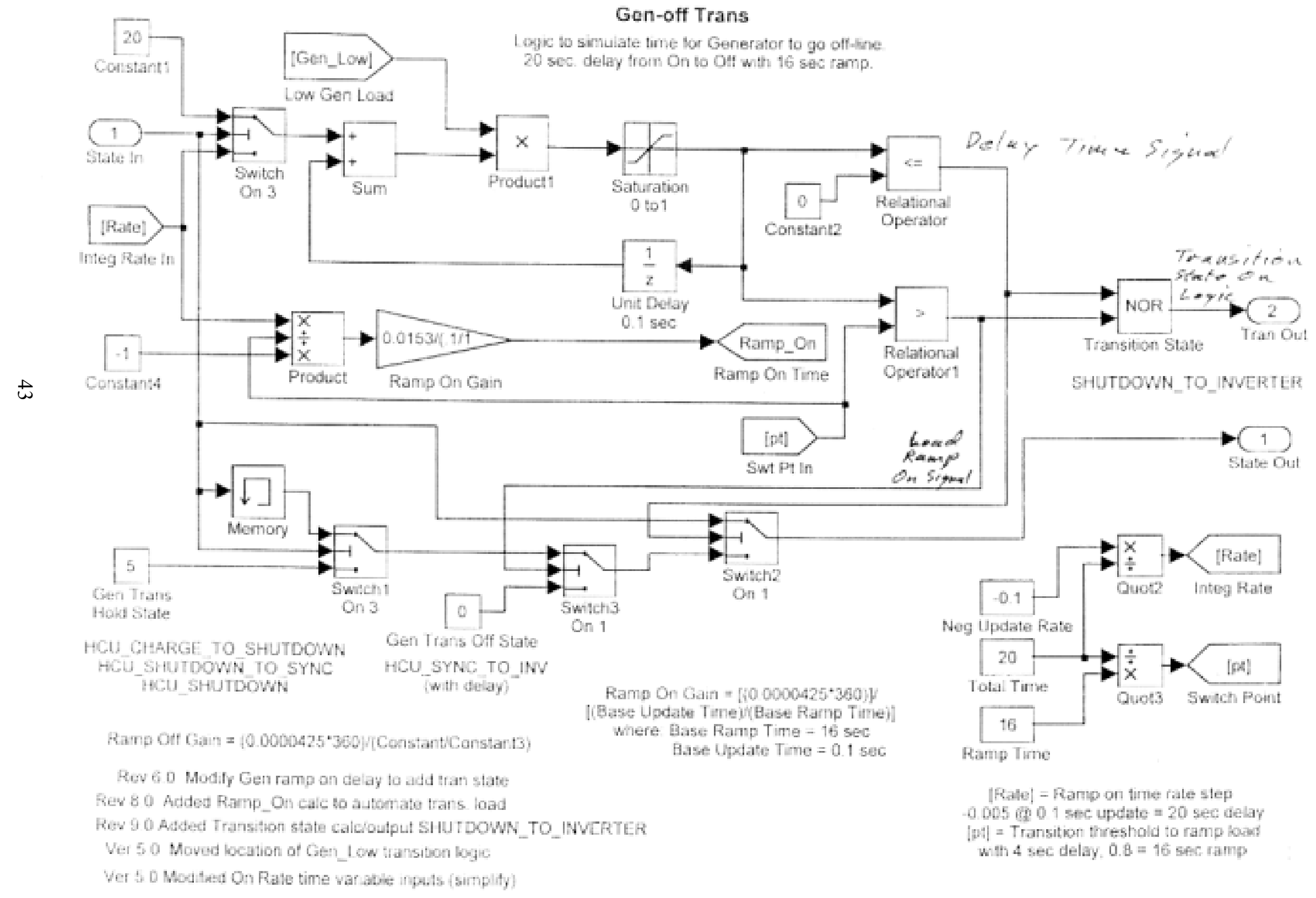


HCU States

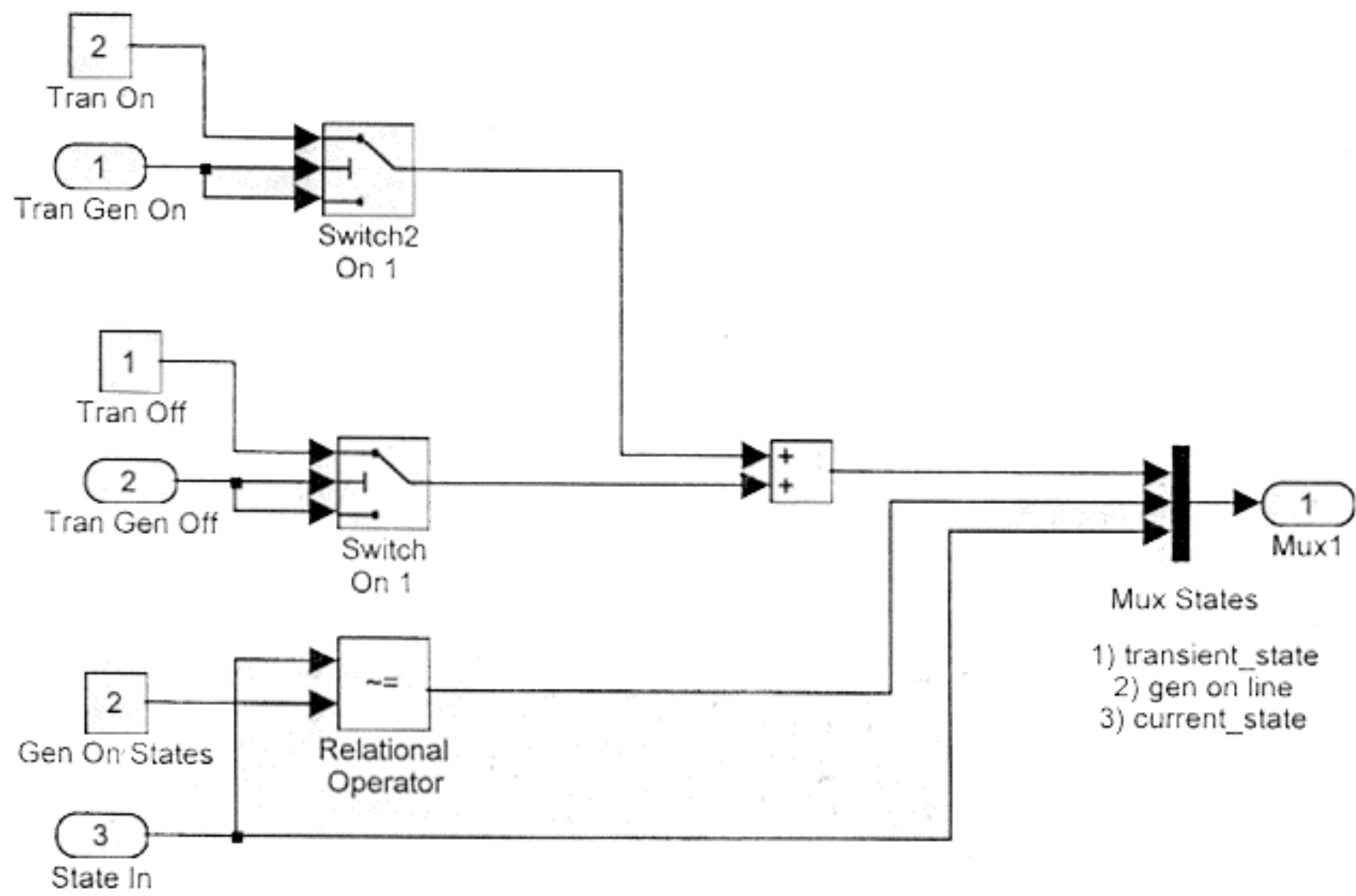


In r Model

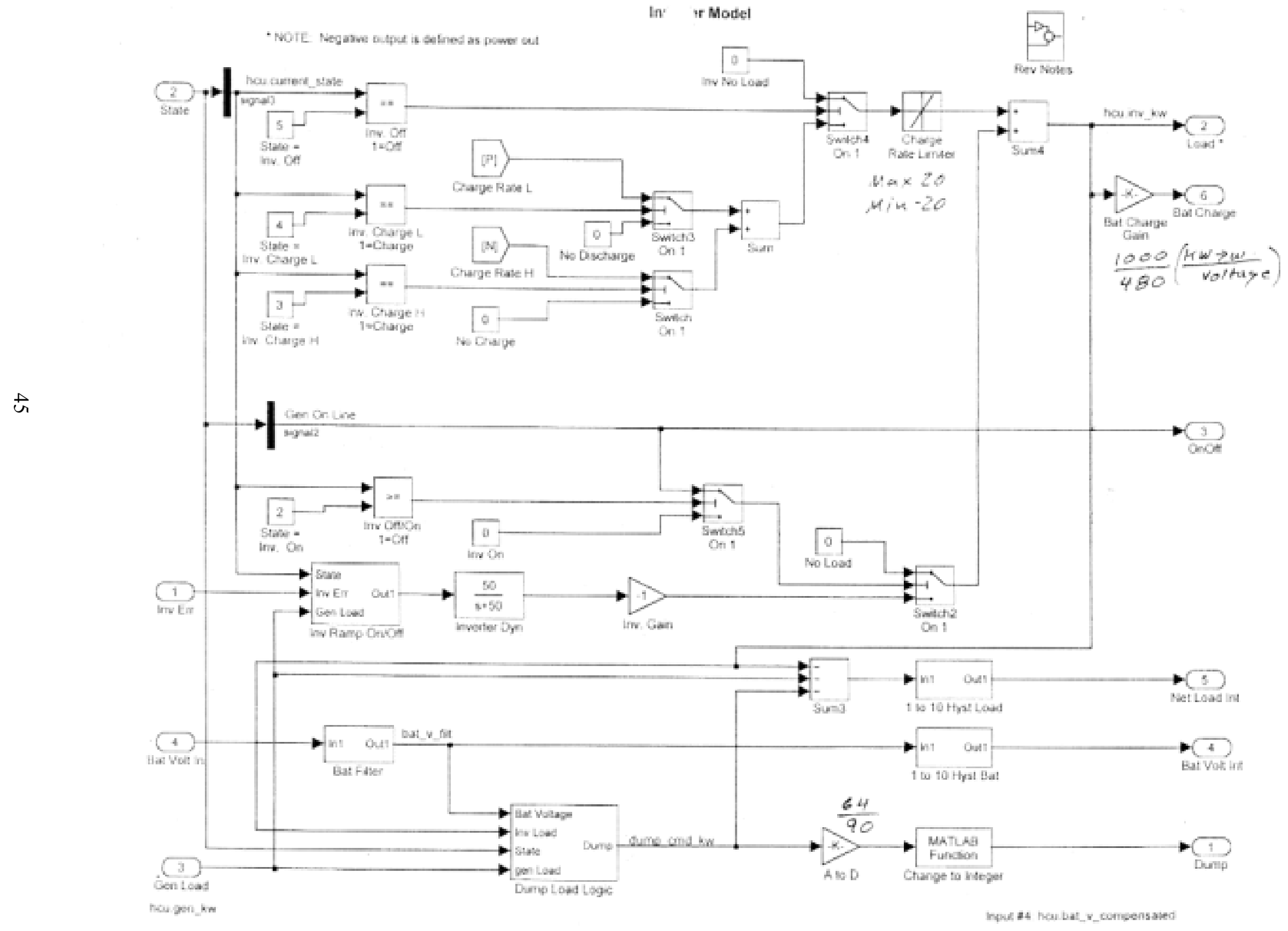


Inv Ramp On/Off

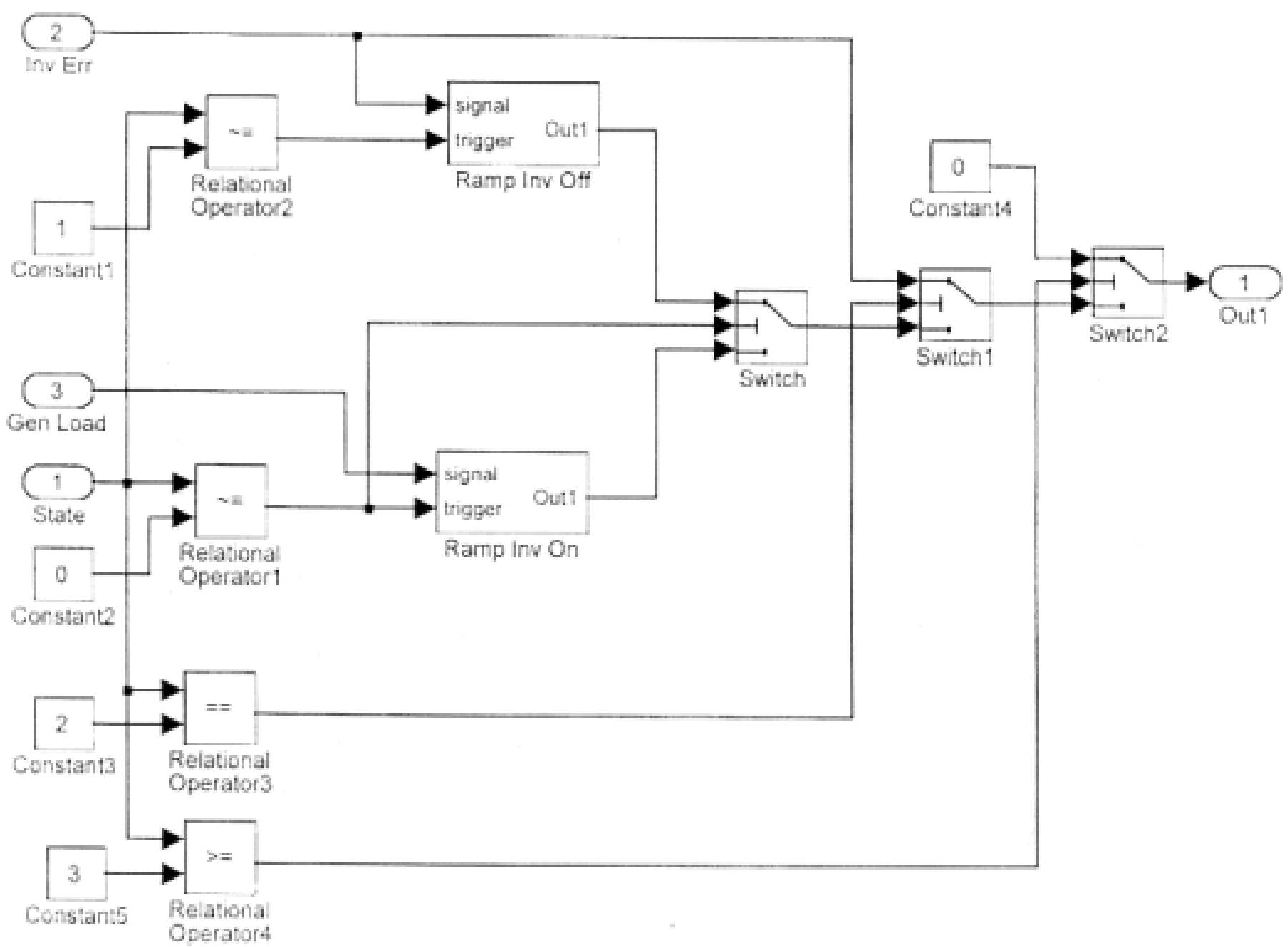


Ramp Inv Off Signal

$\exists$

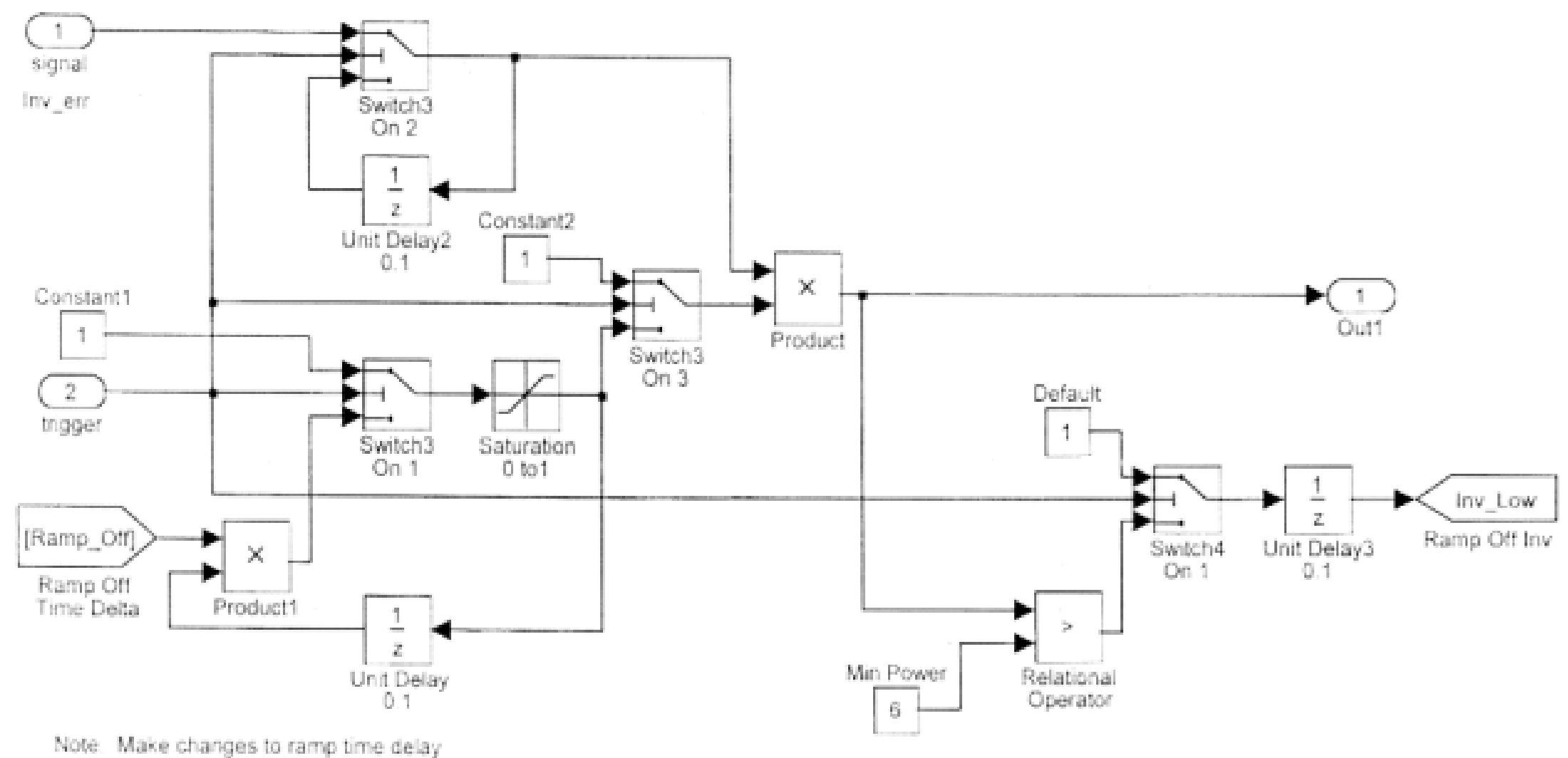
witi "Gen-OHit Trans" tunction

Rev 80 Added Ramp_OH signal to set load transfer rate Ver 50 Added Inv_Low Calc and mod ramp oft logic 


\section{Ramp Inv On Signal}

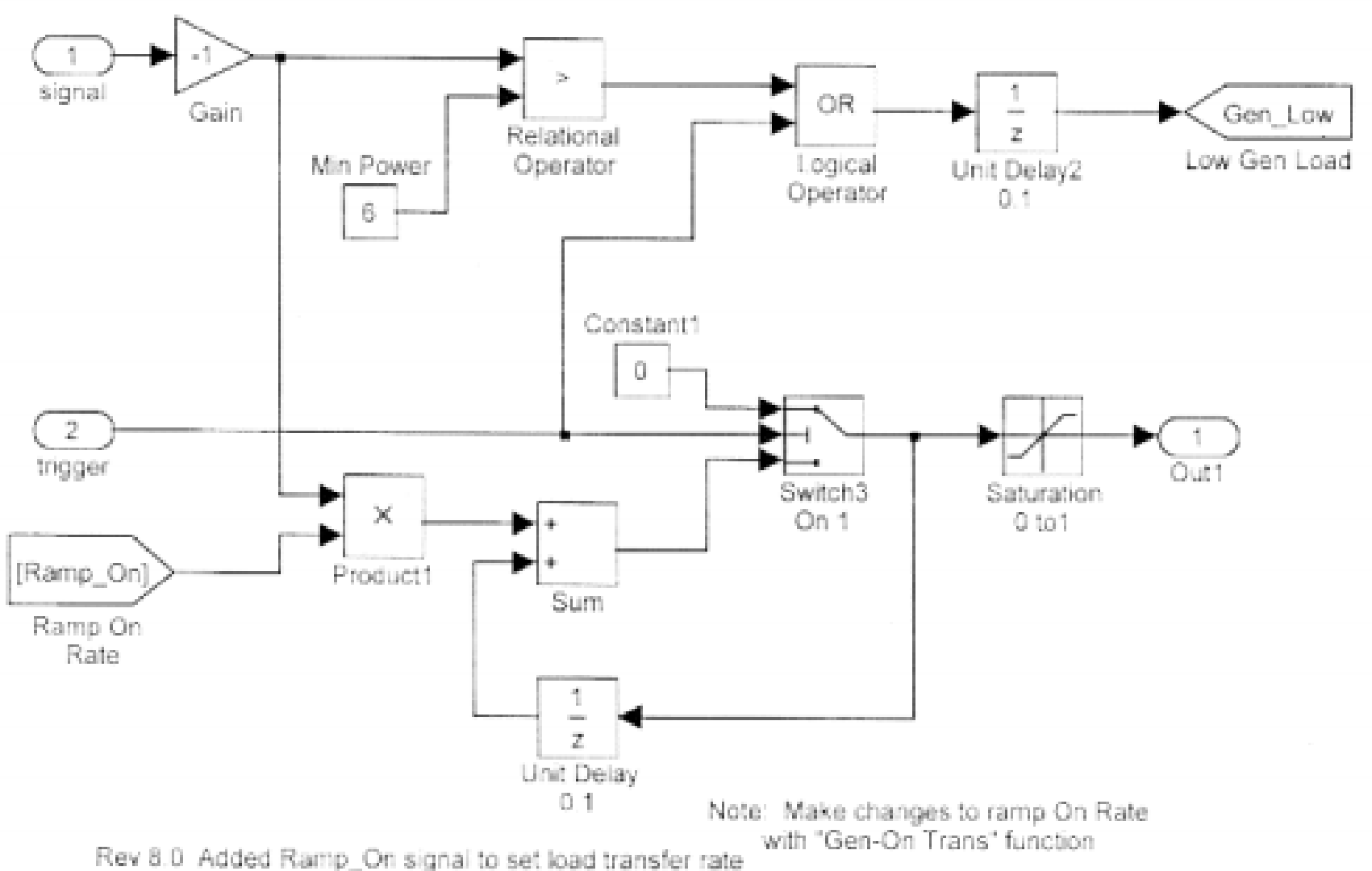

Rev 8 . D Added Ramp_On signal to se: load transter rate

Rev 8.0 Calc Gen_Low signal to determine min gen load during franfer of load

Rev 8.0 Added delay to Gen_low signal to address algebratc kop

Ver 50 Changes sense ot Gen_low signal and added state lockout 
Bat Filter

bat_filter()

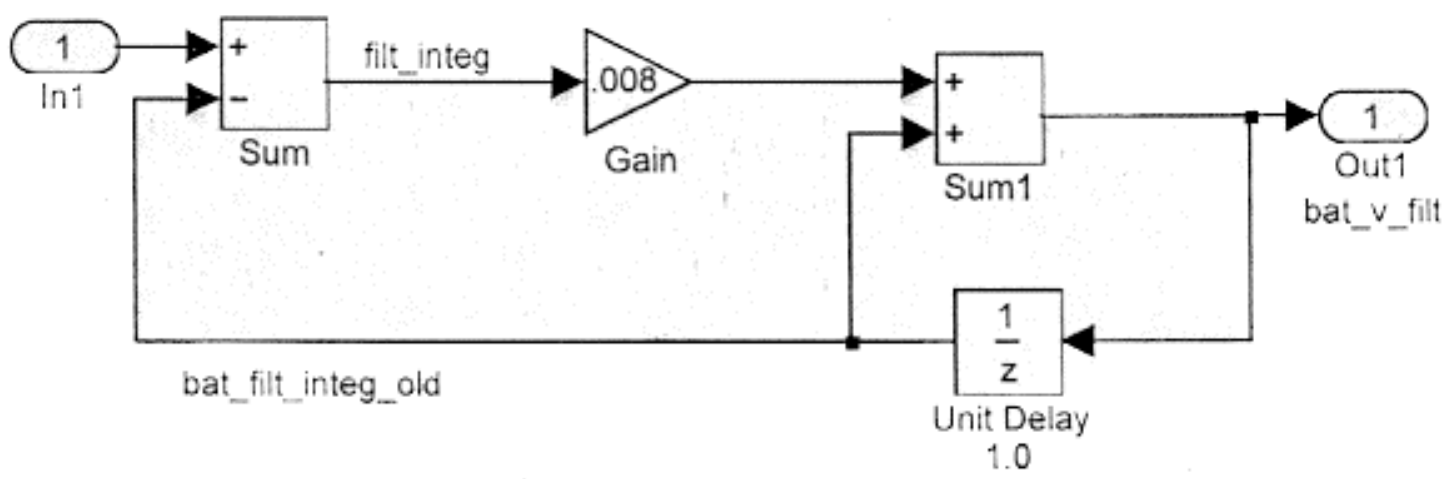

$\sim 125 \sec$ Tine Constant 
1 to 10 Hyst Load

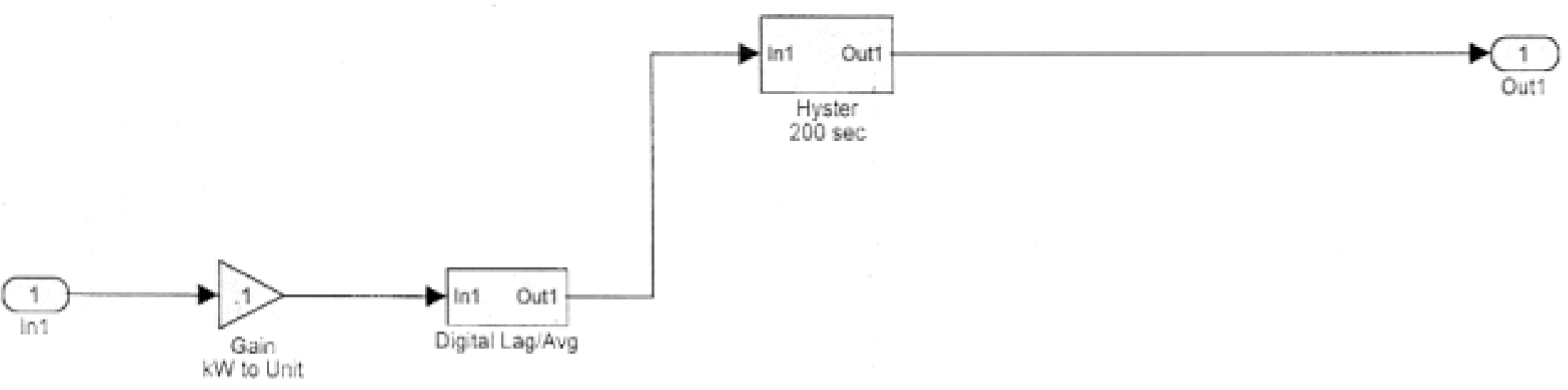

Rev 3: Changed First order lag (4 Step Lag) function to discrete implementation (Dig tal Lag) 


\section{Digital Lag/Avg}

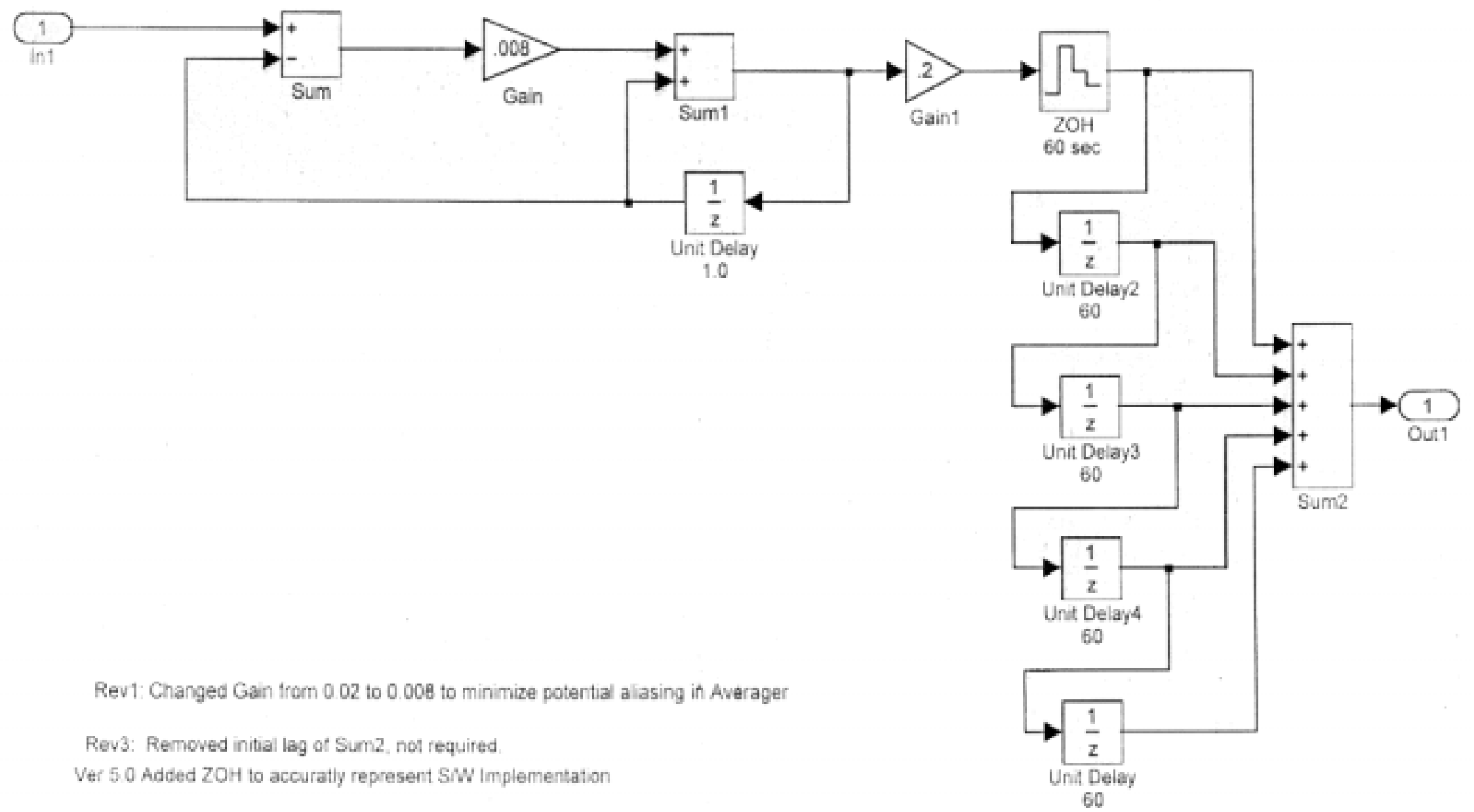




\section{Hyster 200 sec}

(Float to Integer Conversion with hysteresis

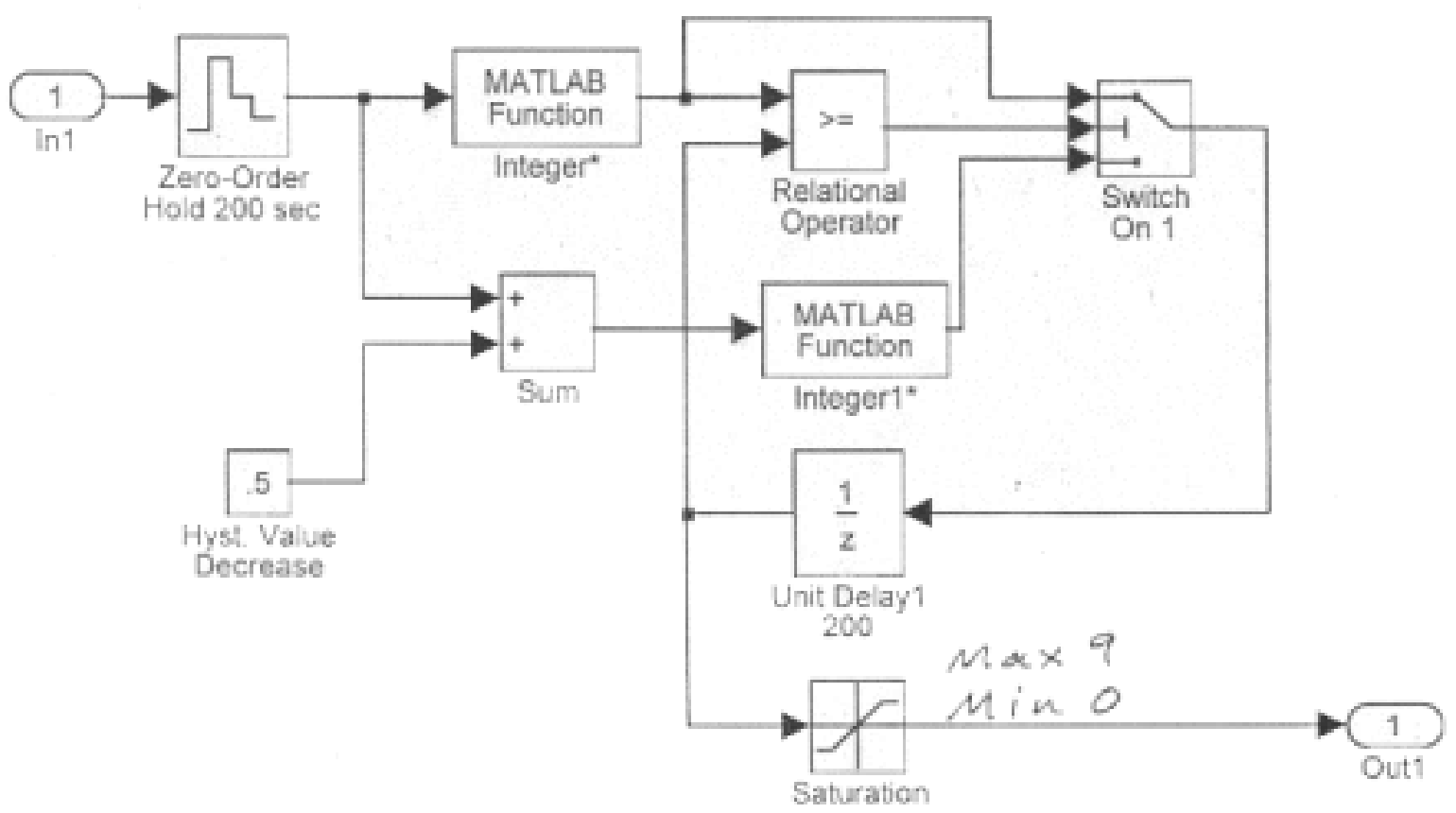

- NOTE: Float to Integer Conversion

Rev 1.0 Change Saturation Limits to 0 to 9

Rev 4.0 Changed Load Hyster input delay to 200 sec ZOH \& output delay to 1 sec Ver 5.0 Changed Net Load Unit Delay to $200 \mathrm{sec}$ 


\begin{tabular}{|c|c|}
\hline $\ln \left(v_{0}(t s)\right.$ & out (soc) \\
\hline 182.4 & 0.0 \\
\hline
\end{tabular}

$205.2 \quad 0.0$

1 to 10 Hyst Bat

$231.4 \quad 4.3$

236.07 .1

$250.8 \quad 10.0$

$273.6 \quad 10.0$

$319.2 \quad 10.0$

us

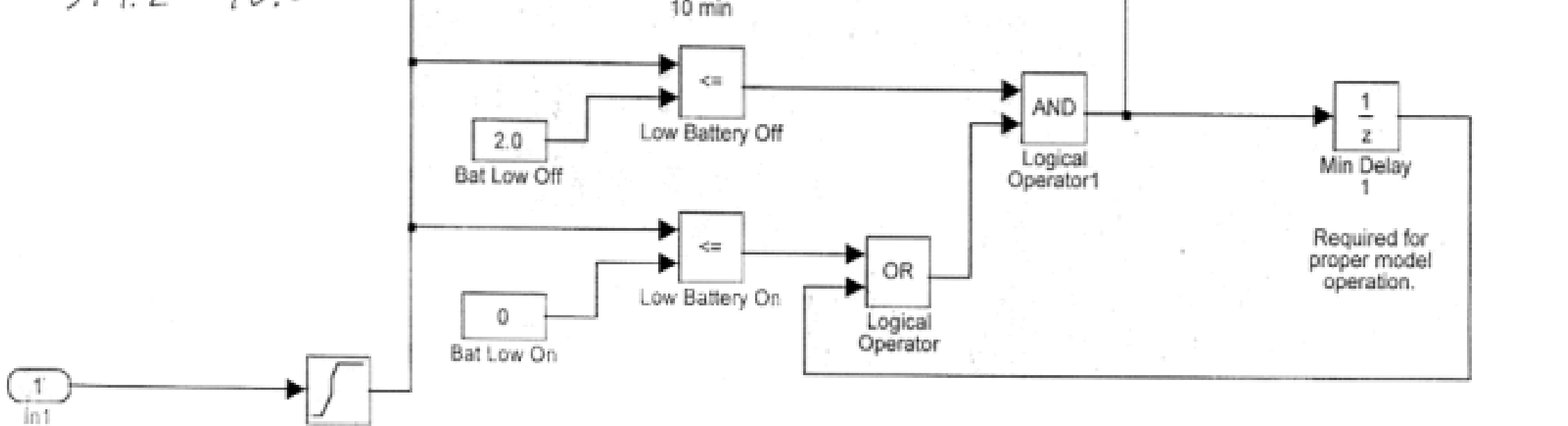

Rev 3: Add real time low battery condion logic

Ver 2.01 to 6 Hyst Bat. Modify for NREL. HW (Battery Voltage to Storage)

Rev 10 Changed $V$ to Unts Table for new $\#$ of cells (100 10 114)

Rev 4.0 Changed Battery Hyster input delay to $600 \sec \mathrm{ZOH} \&$ output delay to $1 \mathrm{sec}$ 


\section{Hyster $10 \mathrm{~min}$}

(Float to Integer Conversion with hysteresis

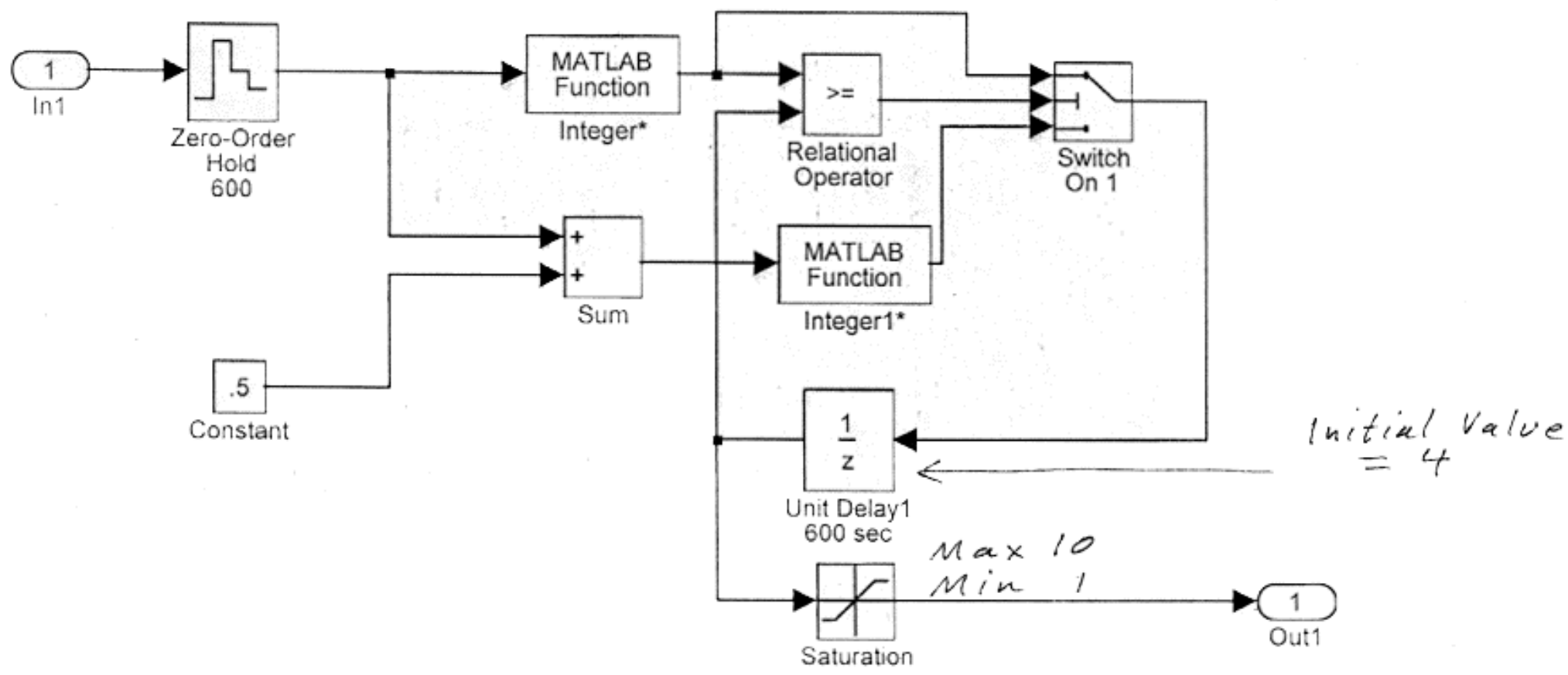

* NOTE: Float to Integer Conversion

Ver 2.0 Hyster: Update Unit Delay and Saturation Limits

Rev 4.0 Changed Battery Hyster input delay to $600 \mathrm{sec}$ ZOH \& output delay to $1 \mathrm{sec}$ Ver 5.0 Changed Battery Hyst Unit Delay to $600 \mathrm{sec}$ 


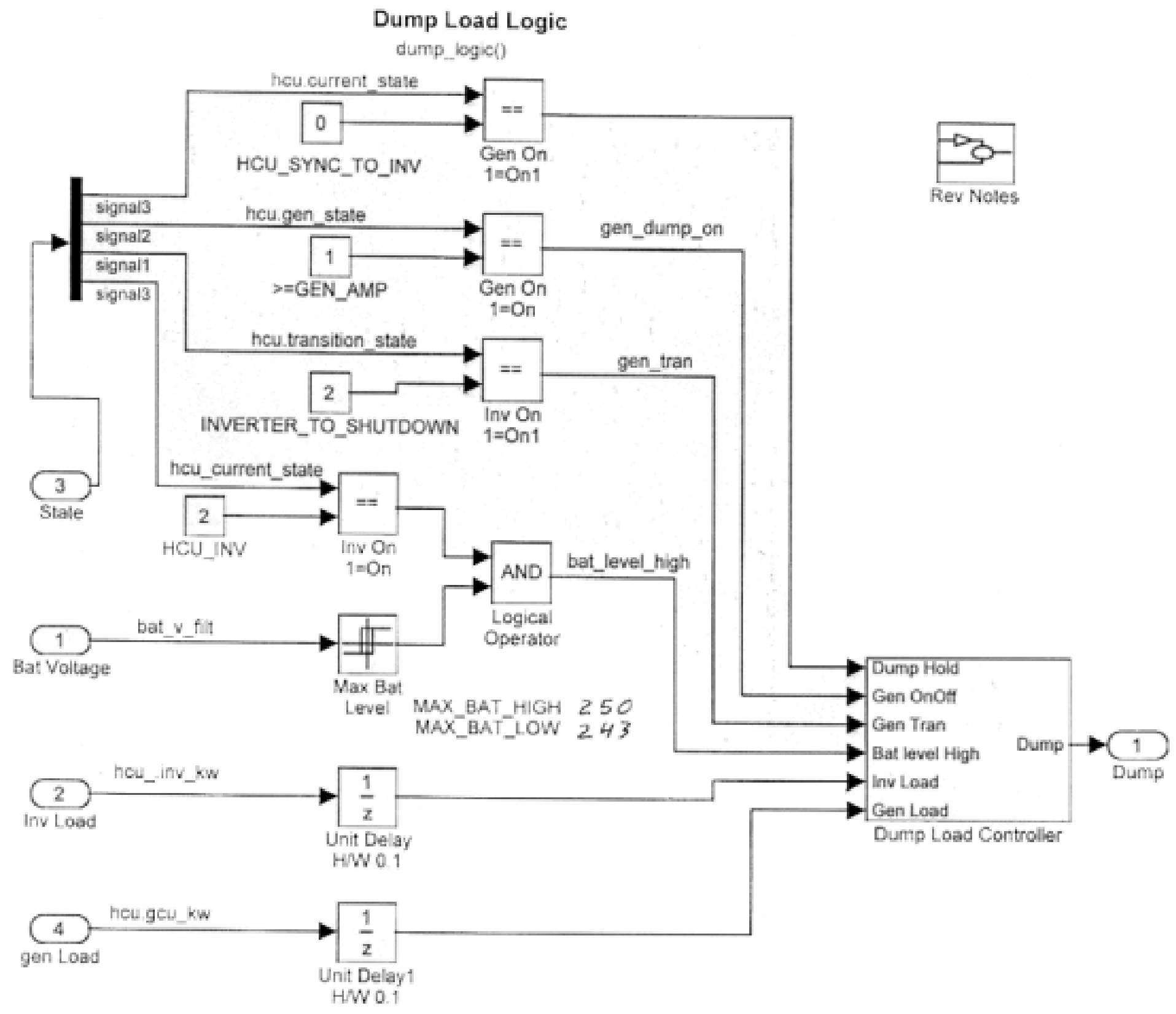




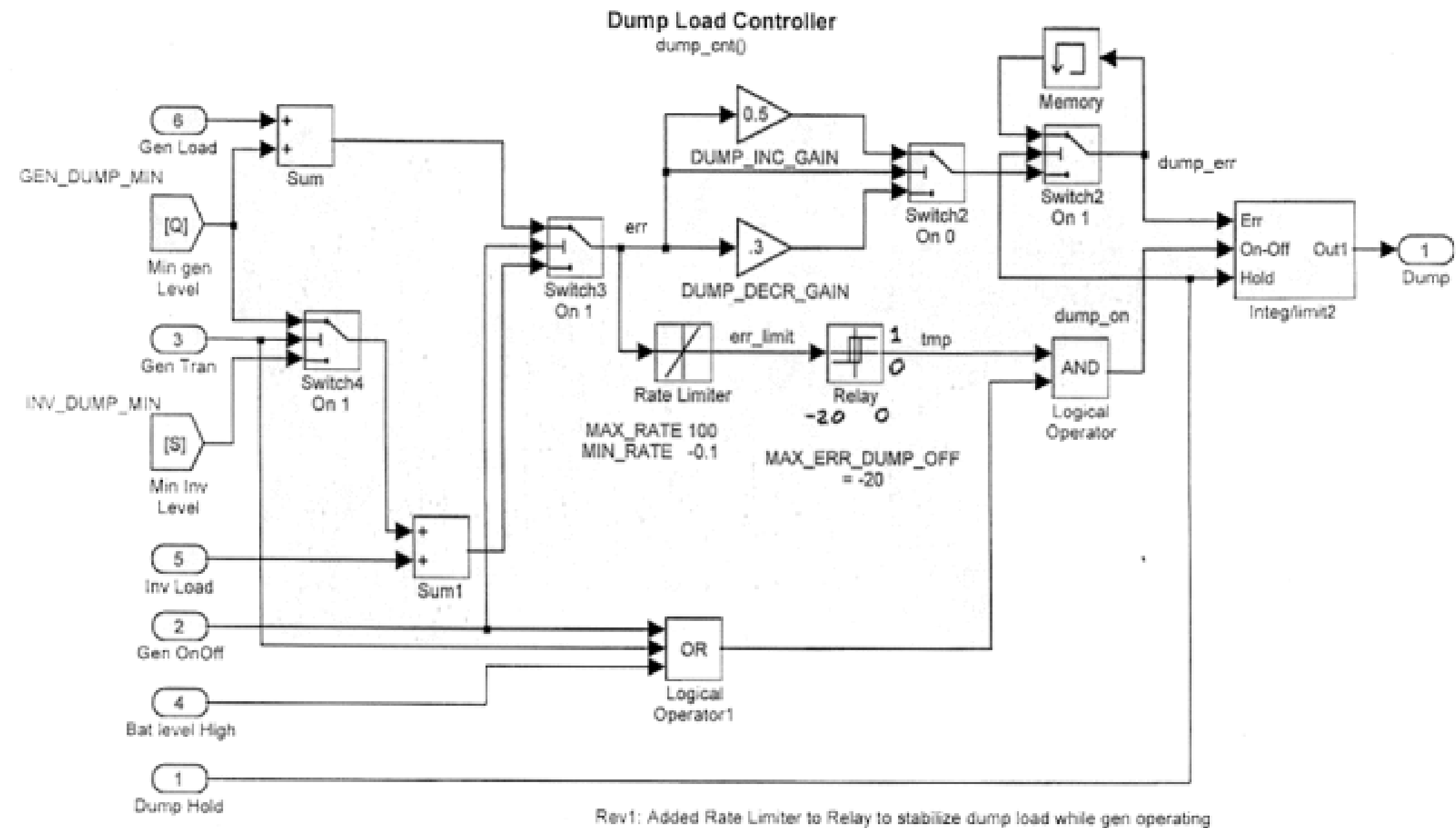

Ver 4.0 Changed 'Inv err signal' to Imwerter load value 8 required Dump Load controlier changes Rev 2.0 Added gen transition on logic to dump load

Rev 7.0 Changed DUMP_DECR_GAN 100.3

Rev 7.0 Added hold function to Integ/imit1 function 
Integ/Limit Funetion
oump_nlego

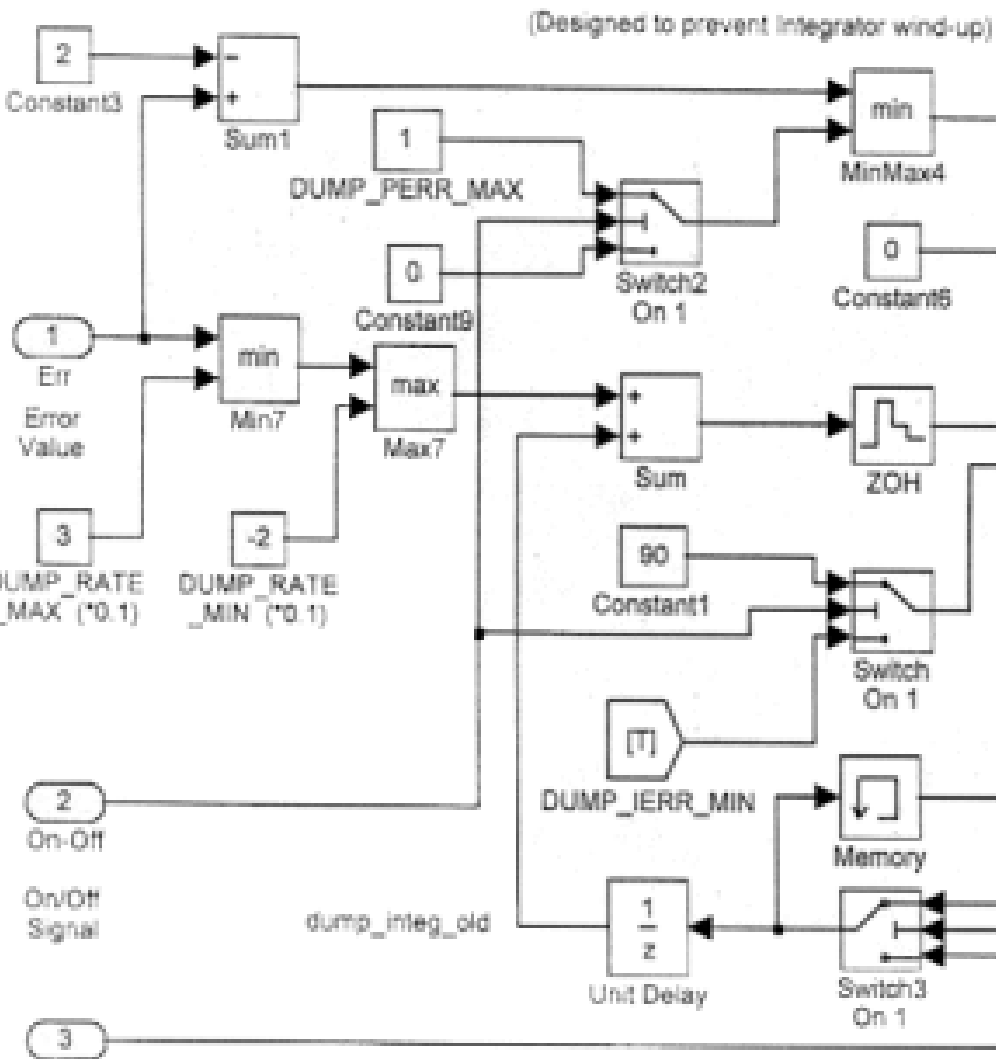

Rev 1 Dump Load integrator, added proportional gain

Rev3. Moafied Dump Loed integlimit function (added propononel gan lerm and mod rate limas)

Rev 3 . Added minimum qump load vaue

Rev 70 Changed DUMP_RATE_MIN to -20

Rev 7.0 Changed DUMP_PERR GAN to 3.0 due to faster gen oynamics

Ver 50 Modified integrator Rase imits and added $\mathrm{ZOH}$ (Detter smulate actual code) 


\section{SIMULINK Diagrams of Dispatch Transient Model}

Model Name: "nreltrn6.mdl" Version 6.0 Rev 0 


\section{NREL Modified Inverter Model Revision Notes}

Version 1.0 Baseline

Rev 1: Changed 0 to 6 Hyst Logic, in Inverter Model, to simulate $\mathrm{C}$ code implementaton

Rev 2: Integlimit mod for $\mathrm{C}$ code implementation

Rev 2: Changed inc rate from 2.0 to $0.02 \mathrm{\&}$. Dec rate from 0.3 to 0.003

Rev 2: Added step function to force start-up in Inverter mode, Required due to unt step delays in hyst function

Rev 2: Changed MATRIX Genon(1,3) from 3 to 2

Rev 3: Changed First order lag (4 Step Lag) function to discrete implementabon (Digital Lag)

Rev 3: Updated wind turbine model for TSR input to Kp Table

Rev 3: Added offset to windspeed inputs to turbines $\mathbf{* 2 , 3}$ and 4

Rev 3: Modified turbine logic to divide power delta by speed to get torque into integrator

Rev 3: Added Ref Speed to properly calculate output power

Rev 3: Add real time low battery condition logic

Version 30 Baseline Transient Model

Ver 30 Modified Model to remove dynamacs to change time step to 1.0 = 1.0 hour. Improve run time Ver 3.0 Modfied Wind Turbine Model to Simplifed Power Curve

Ver 30 Modifed Durrp Logic to use Gen Load and Net Erf, directly

Ver 3.0 modified MATRIX tables to ref. MXBLON, MXBLOFF, MXEVON, and MXEVOFF

Ver 3.0 Upated Hysteresis to a time step of $1.0=1.0 \mathrm{hr}$

Rev 1: Update to MATLAB Release 11

Rev 2. Updated max dump load value to $90 \mathrm{~kW}$

Rev 2: Added min inverter load value

Rev 2: Removed discharge and added charge L. 8 charge $H$

Rev 2: Change Net Load (row) saturation limits to 0 to 9 and update to new MATRIX tabies

Rev 2: Updated the V to Units Look-up Table

Rev 2 . Updated at of batery cells to 114

Rev 2: Added Gen Transition on logic to dump load

Rev 2: Modify the Max Bat Level Hyst. values due to change in \# of battery cells

Rev 2 Added battery filter

Rev 3: Added min dump load value

Ver 6.0 Rev 0.0 Update to Ver 5.0 Dynamic Model

Ver 6.0 Set Gen Tran to OH

Ver 6.0 Changed load delay to $200 \sec \mathrm{ZOH}$

Ver 6.0 Changed delay to 600 sec $2 \mathrm{OH}$

Ver 6.0 Removed delay1, not recuired

Ver 60 Modised Gains for 1 hr update fate

Ver 6.0 Added $Z \mathrm{OH}$ to accuratly represent SW Implementation

Ver 60 loorporated wind turbine simulation 


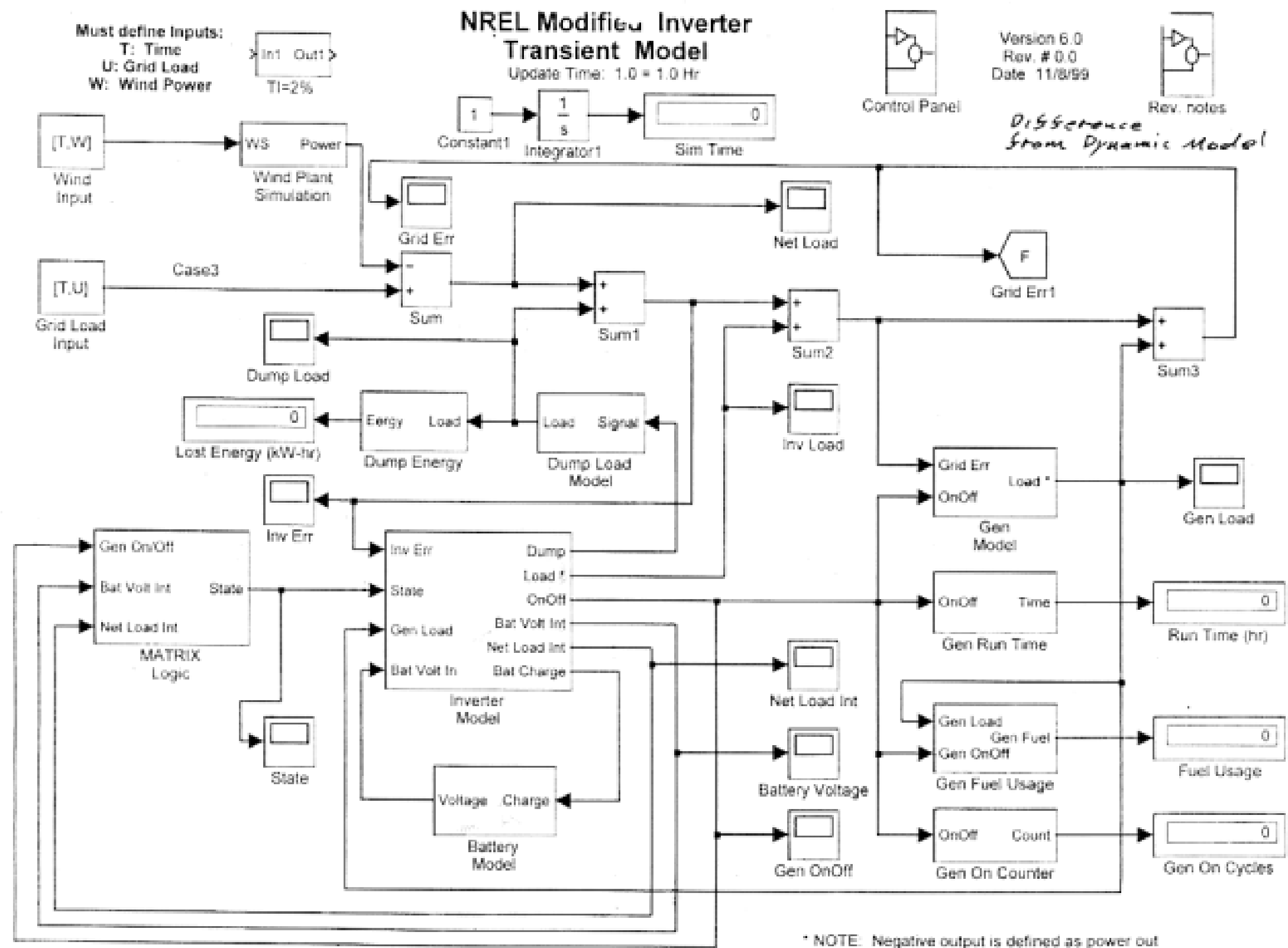


NREL Modified Inverter Model

Input/Output Control Panel
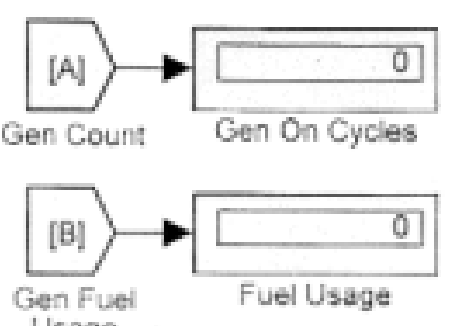

Usage

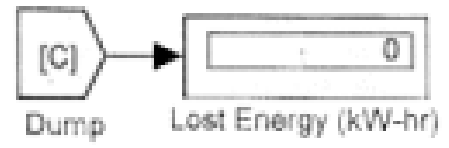

$\curvearrowright$
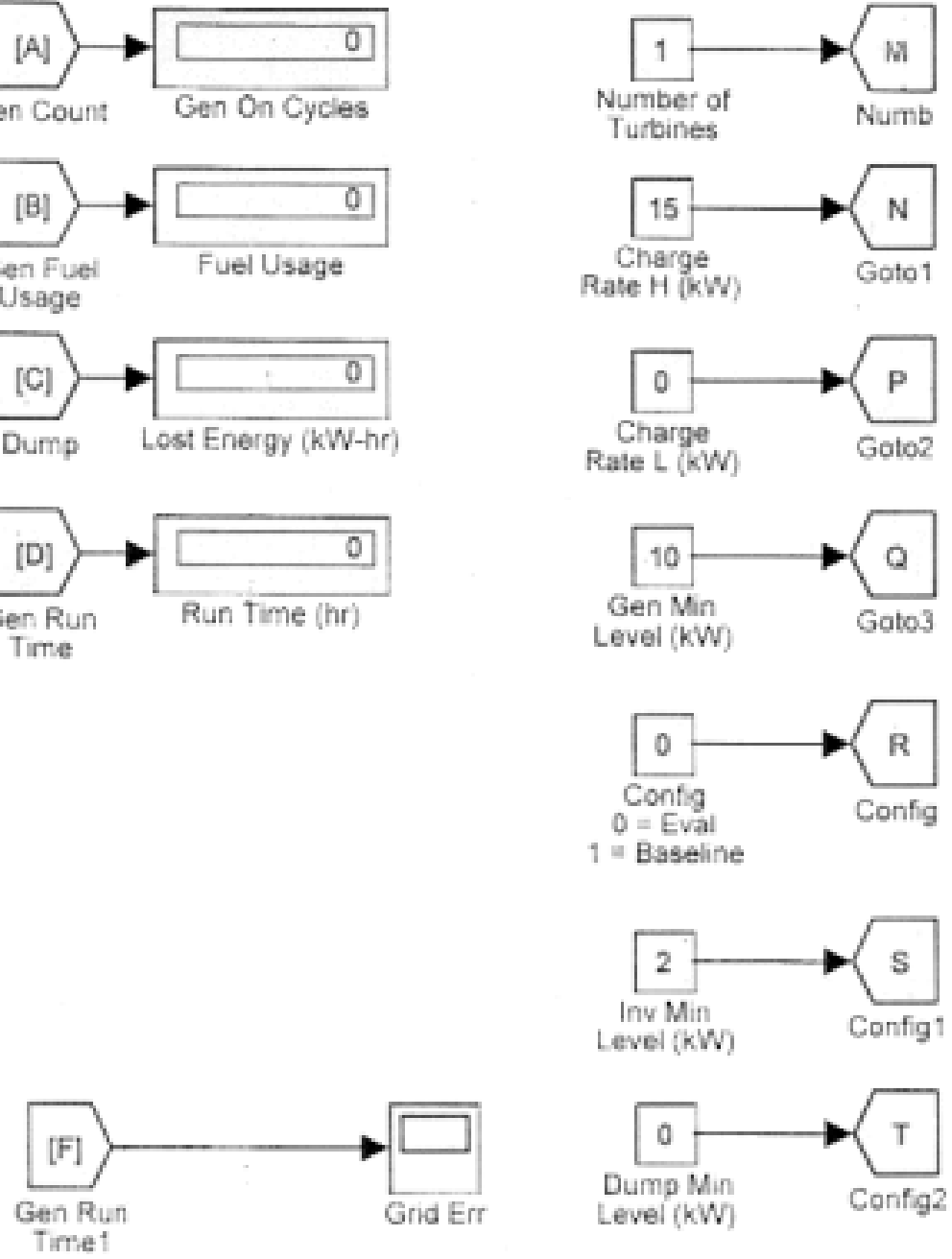

Rev 2: Added min inverler load value

Rev 2. Removed discharge and added charge L \& charge H

Rev 3 Added min dump load value 
Wind Plant Simulation

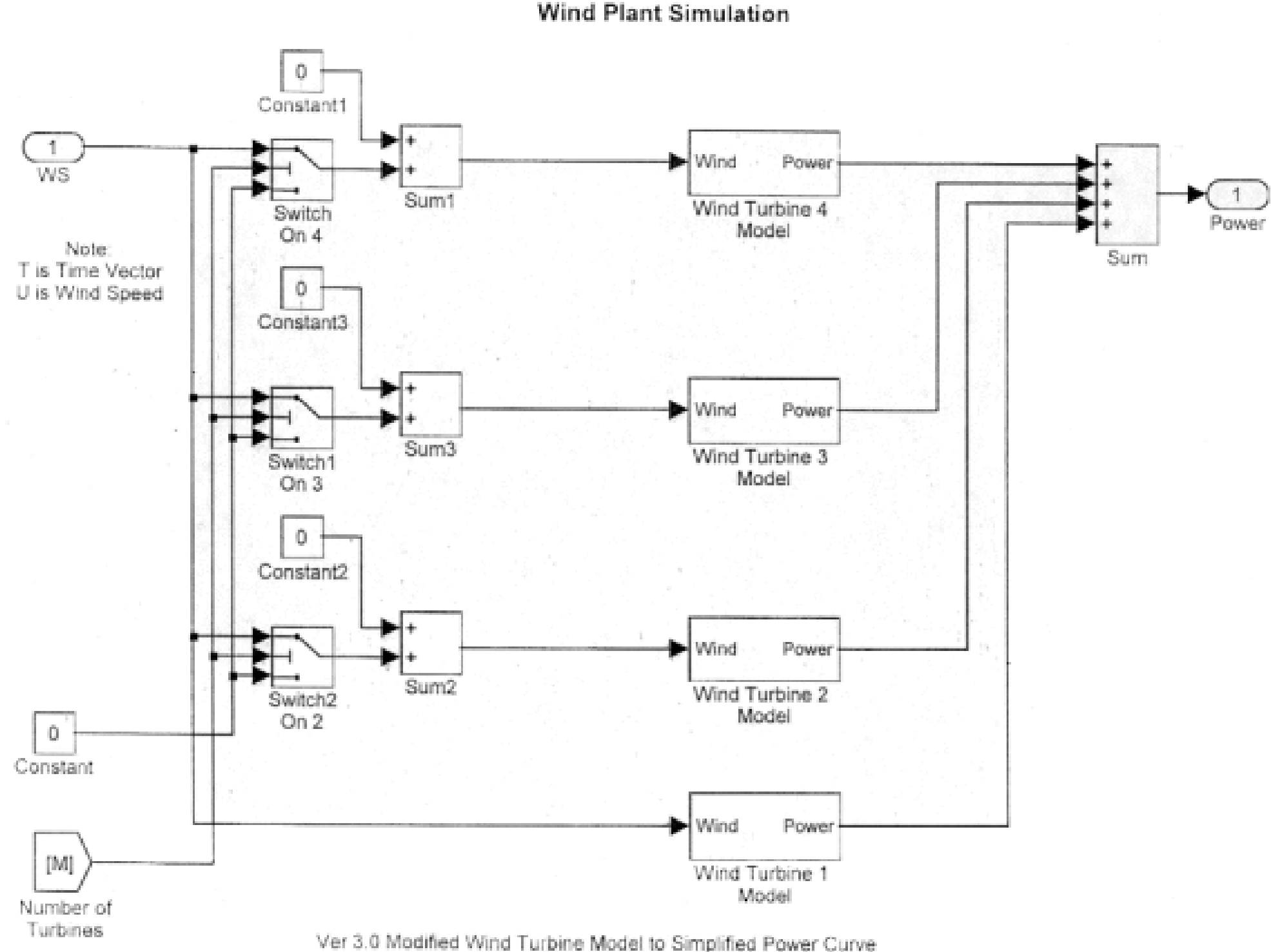


Wind Turbine Model
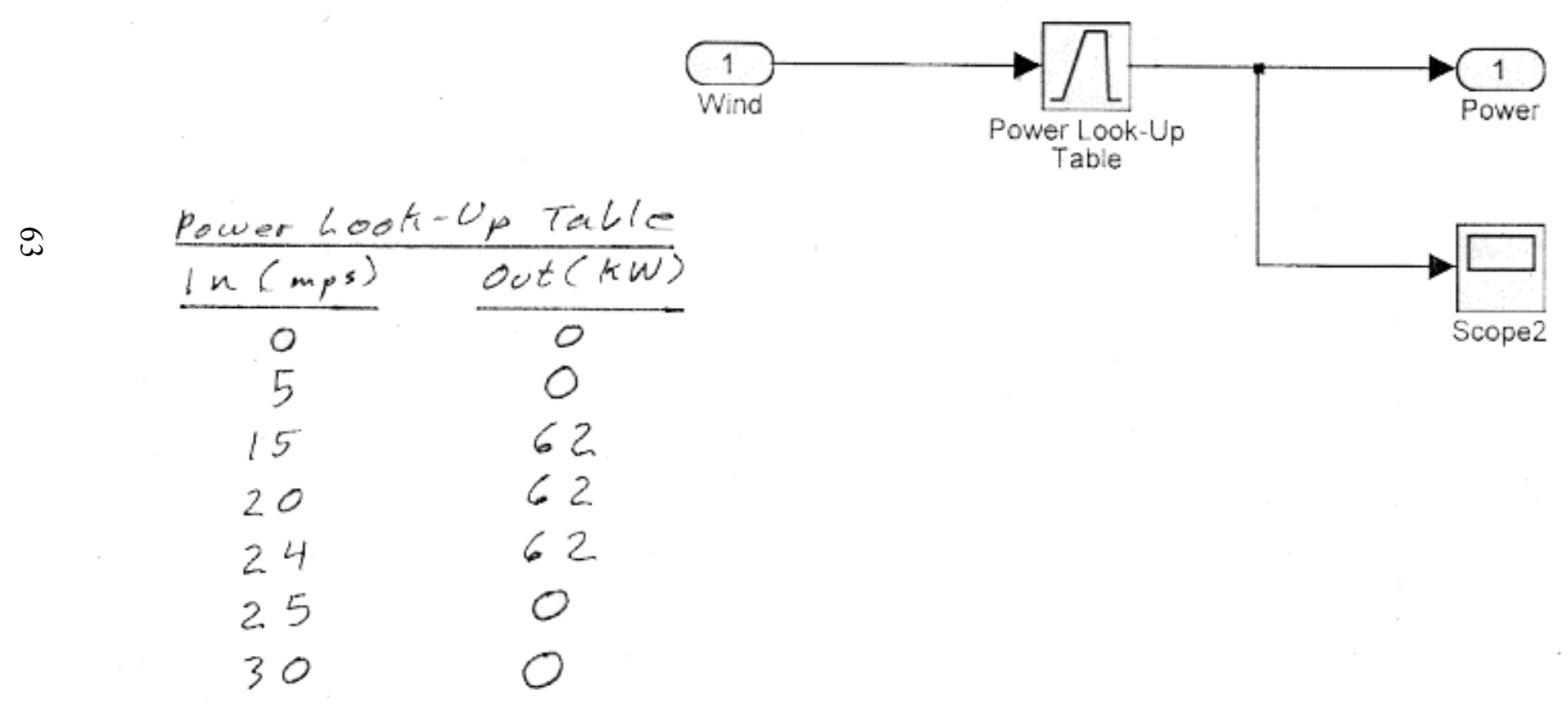


\section{Dump Load Model}

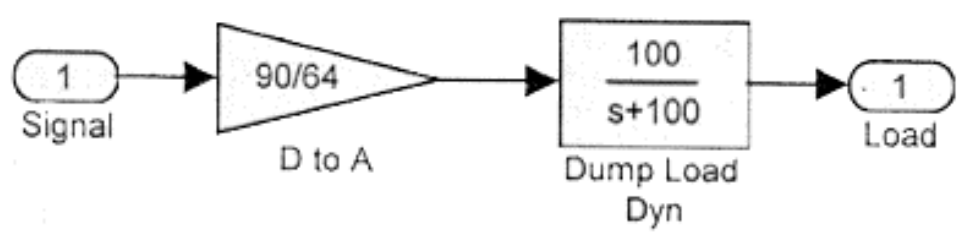

Rev 2: Updated max dump load value to $90 \mathrm{~kW}$ 


\section{Battery Model}

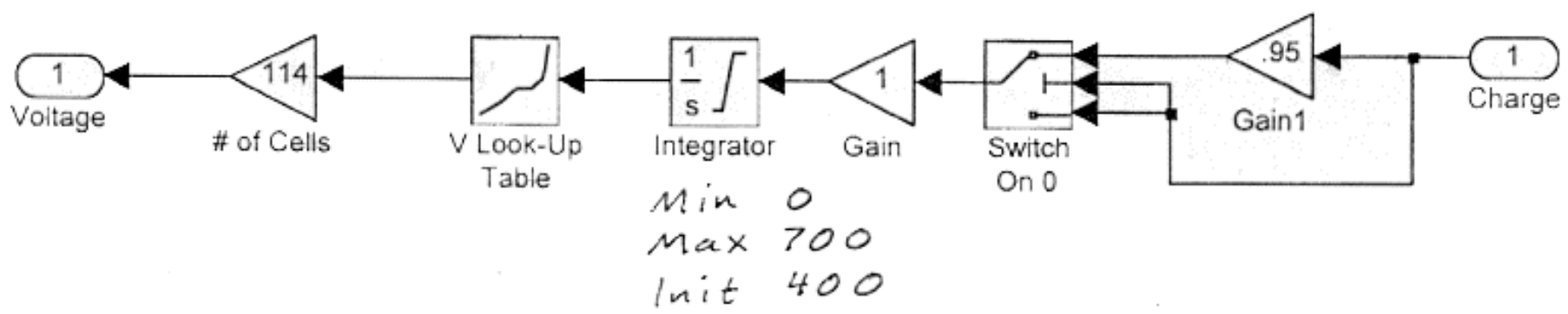

Rev 2: Updated \# of battery cells to 114

\begin{tabular}{ll}
$\frac{v \text { hook-up }}{\ln (\text { Amp-hr })}$ & Table \\
\hline 0 & $\frac{\text { out (Volts) }}{1.6}$ \\
195 & 1.8 \\
390 & 2.03 \\
520 & 2.07 \\
650 & 2.20 \\
675 & 2.40 \\
700 & 2.80
\end{tabular}


Generator Model

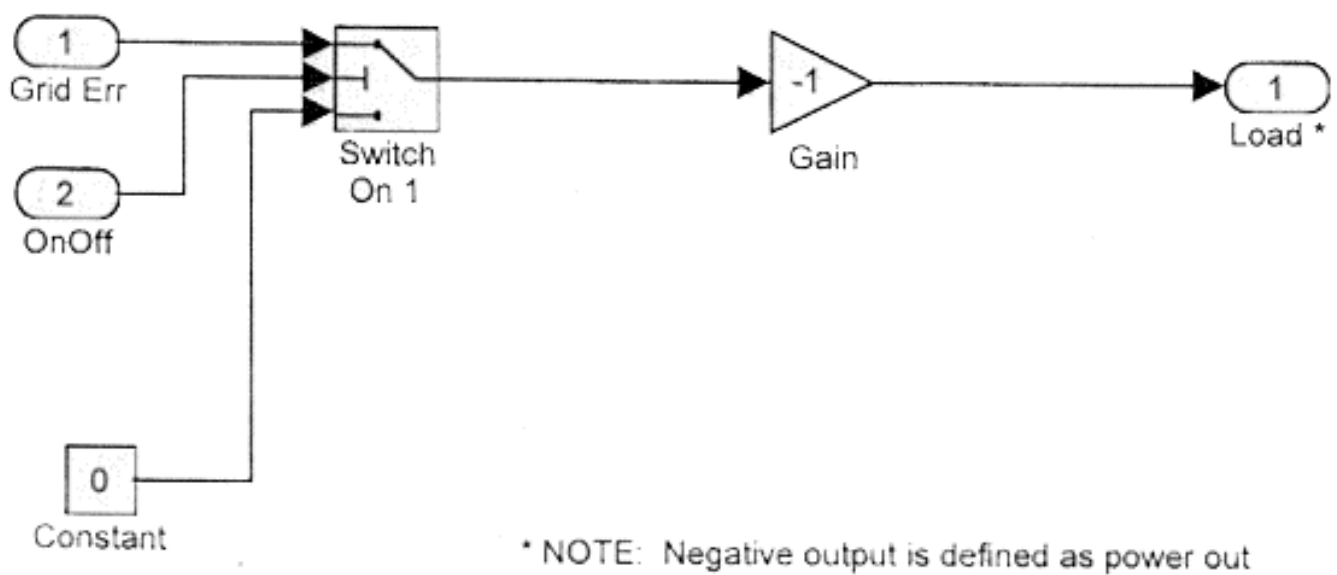

Ver 3.0 Modified Model to remove dynamics to change time step to $1.0=1.0$ hour. Improve run time. 
Matrix Logic

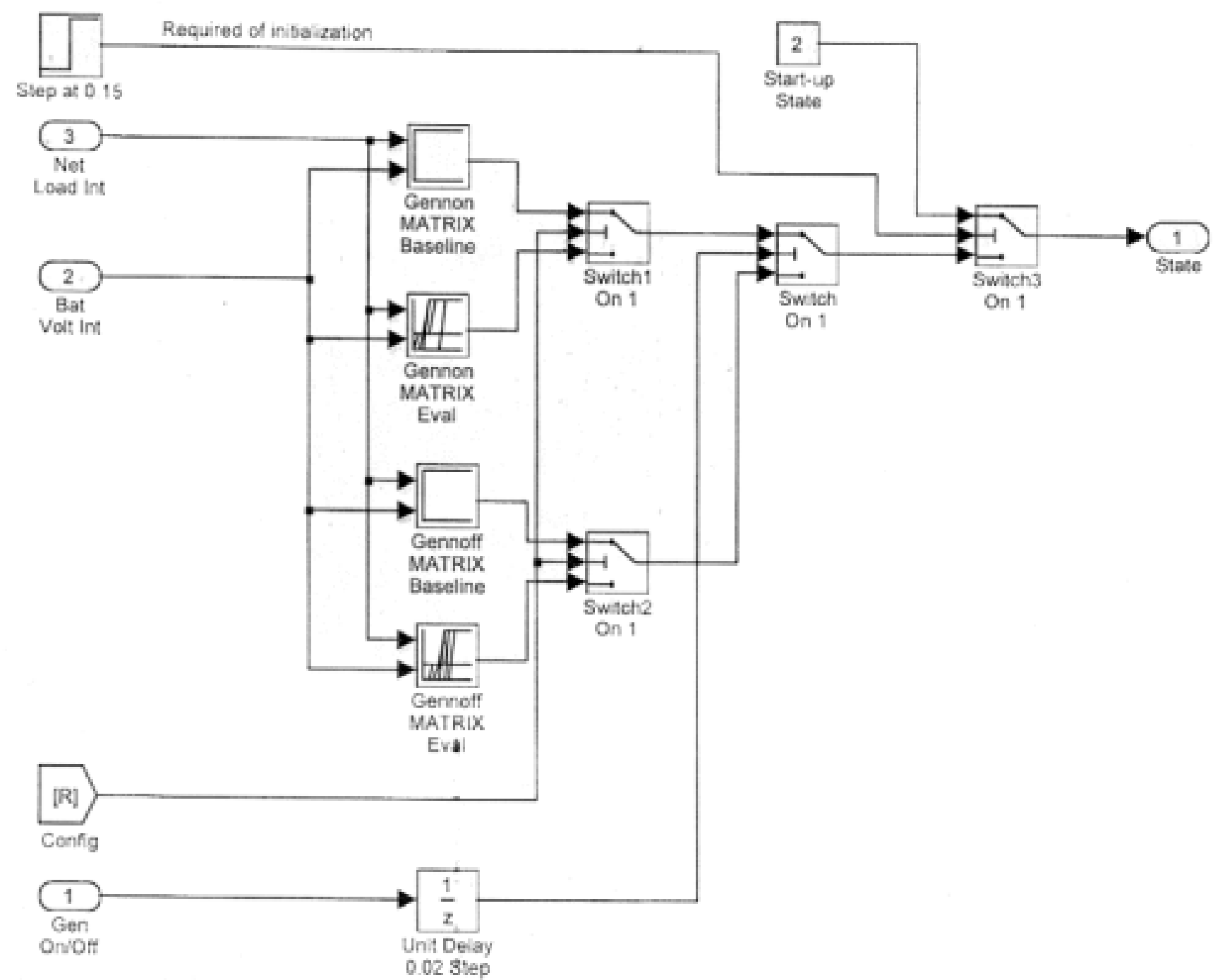

Rev 2: Added slep function to force start-up in Inverter mode, Required due to Unt step delays in hyst function Rev 2; Changed MATRIX Genon(1,3) from 3 io 2

Ver 3.0 modified MATRIX tables to ref. MXBLON, MXBLOFF, MXEVON, and MXEVOFF

Rev 2: Change Net Load (row) saturation limits to 0 to 9 and update to new MATRIX tables 


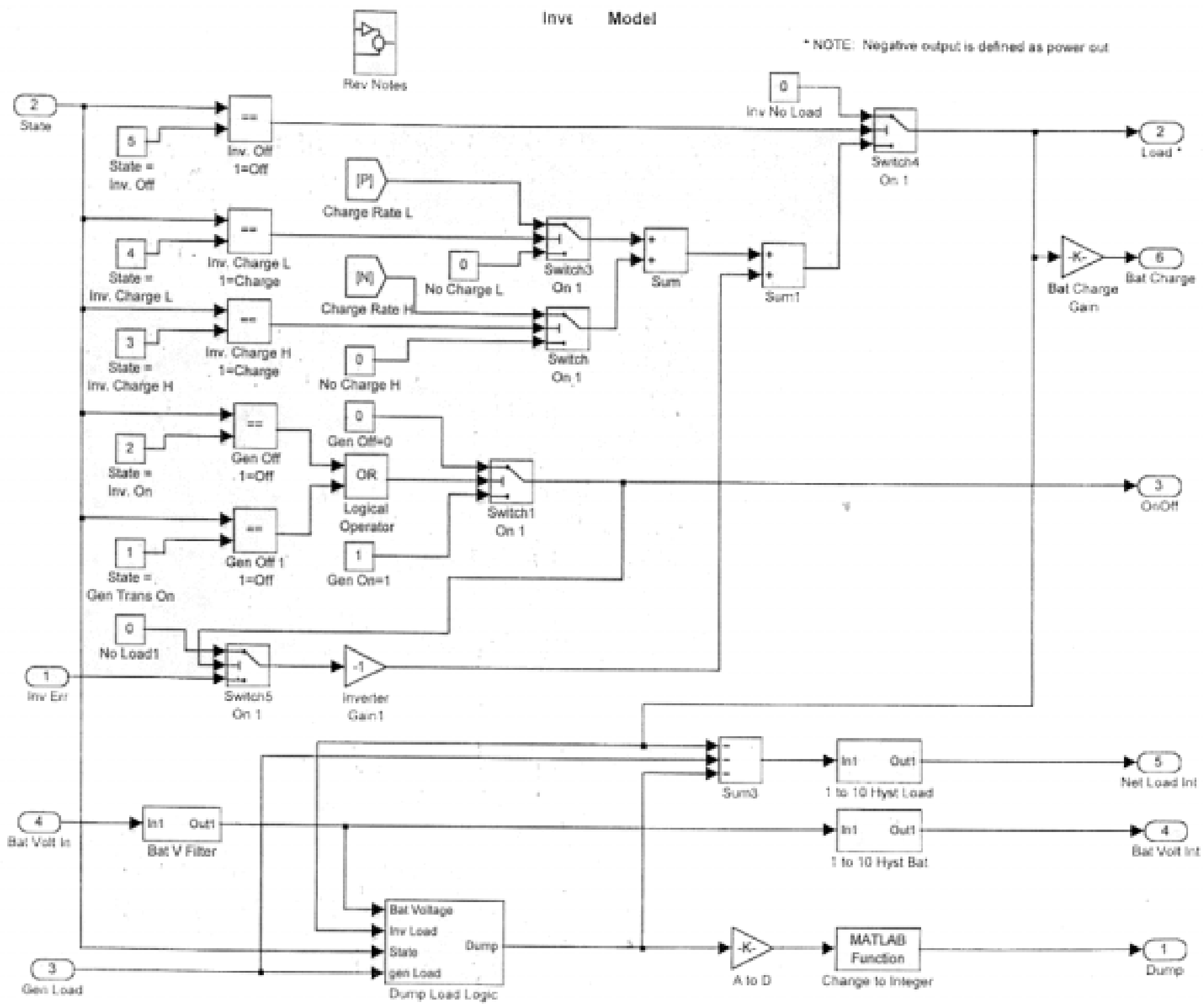




\section{Bat V Filter}

Delay to simulate dynamic filter

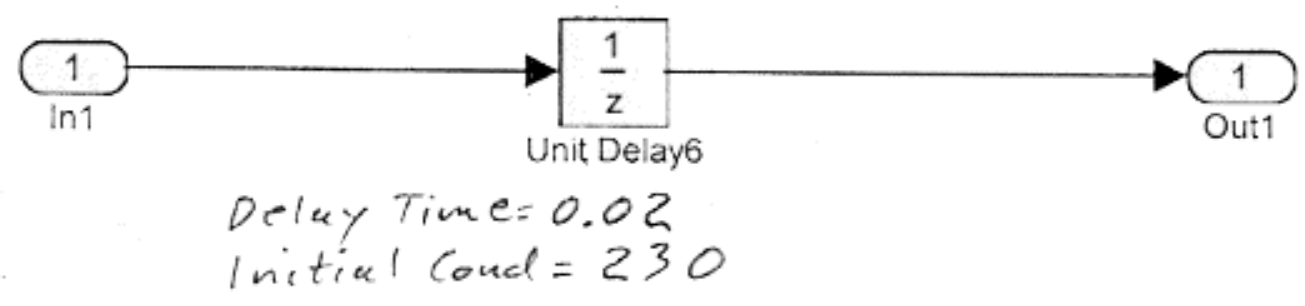

Rev 2: Added battery filter 
1 to 10 Hyst Load

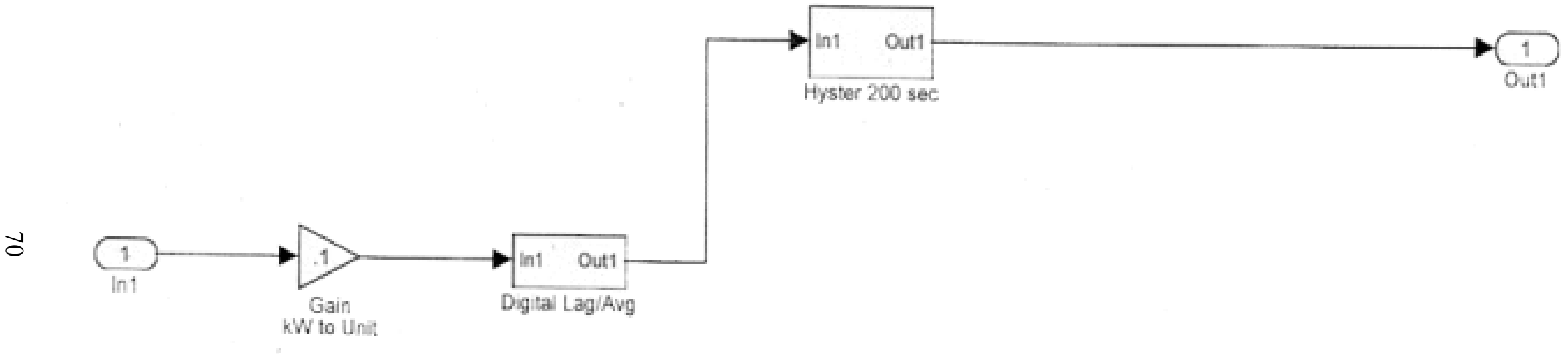

Rev 3. Changed First order lag (4 Step Lag) function to discrete implementation (Digital Lag) 


\section{Digital Lag/Avg}

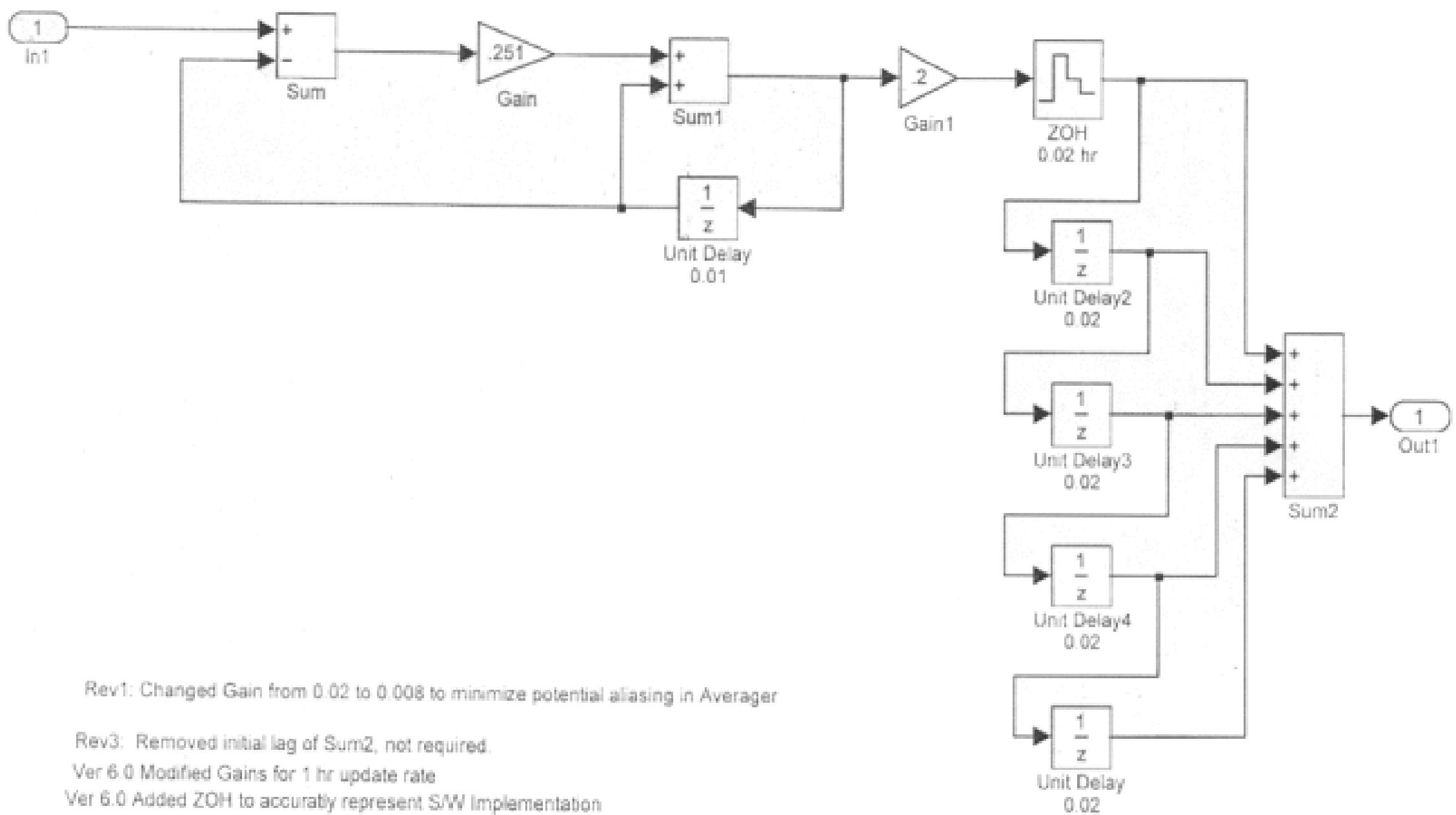




\section{Hyster 200 sec}

(Float to Integer Conversion with hysteresis

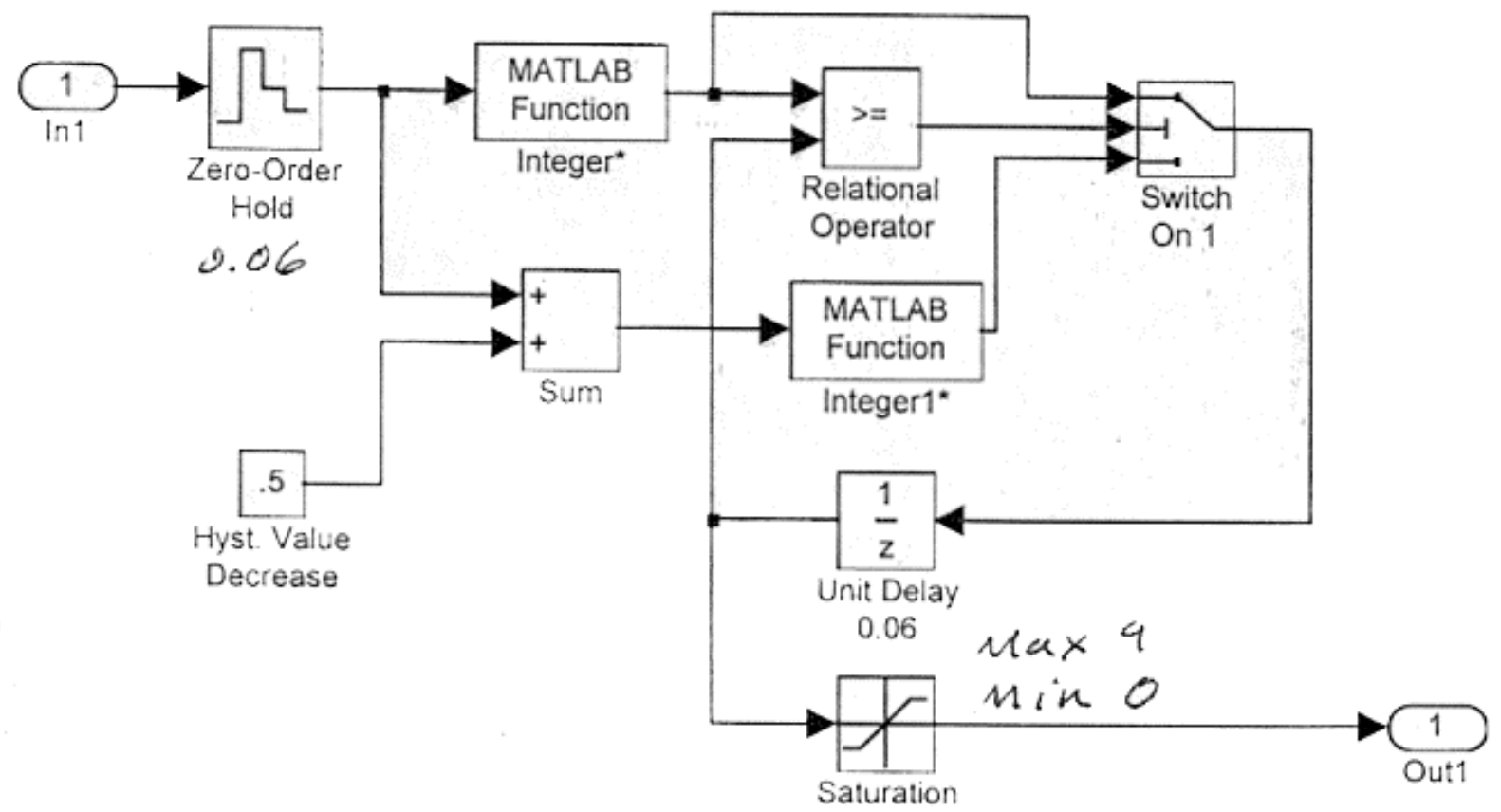

- NOTE: Float to integer Conversion

Ver 3.0 Upated Hysteresis to a time step of $1.0=1.0 \mathrm{hr}$ Rev 2: Change Net Load saturation limits to 0 to 9

Ver 6.0 Changed load delay to $200 \mathrm{sec} Z O H$ 
V to Units Gook-up Tak/e

In (Volts) out(soc/10)

$\begin{array}{ll}182.4 & 0.0 \\ 205.2 & 0.0 \\ 231.4 & 4.3 \\ 236.0 & 7.1 \\ 250.8 & 10.0 \\ 273.6 & 10.0 \\ 319.2 & 10.0\end{array}$

w

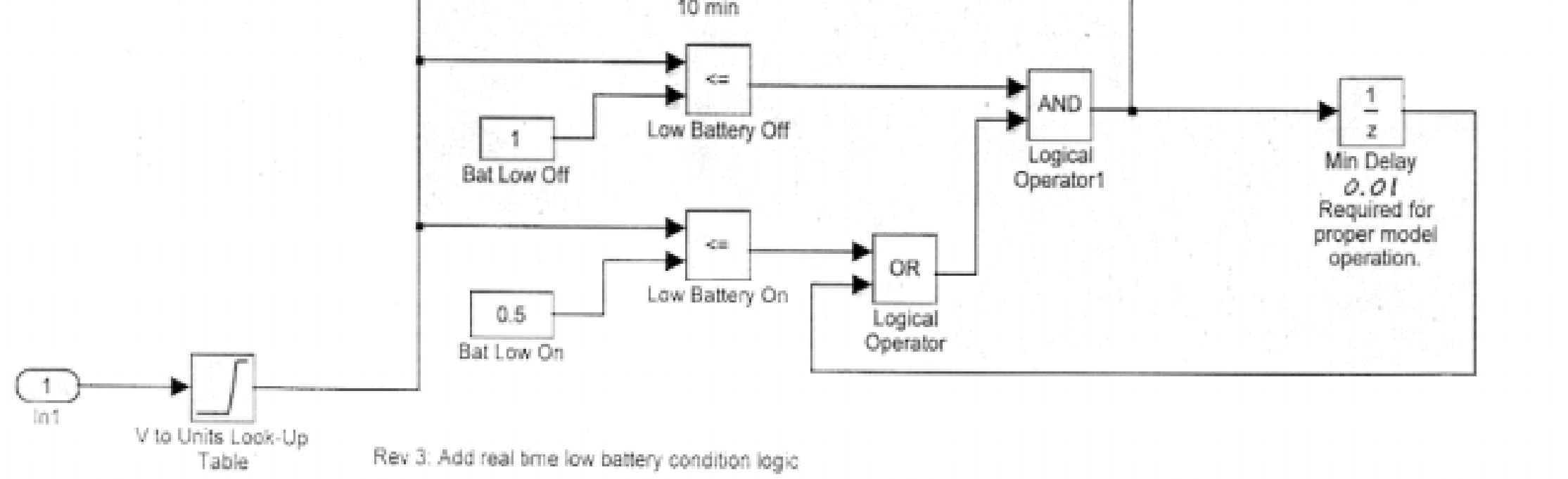

Rev 2. Updated the V to Units Look-up Table 


\section{Hyster 10 Min}

(Float to Integer Conversion with hysteresis

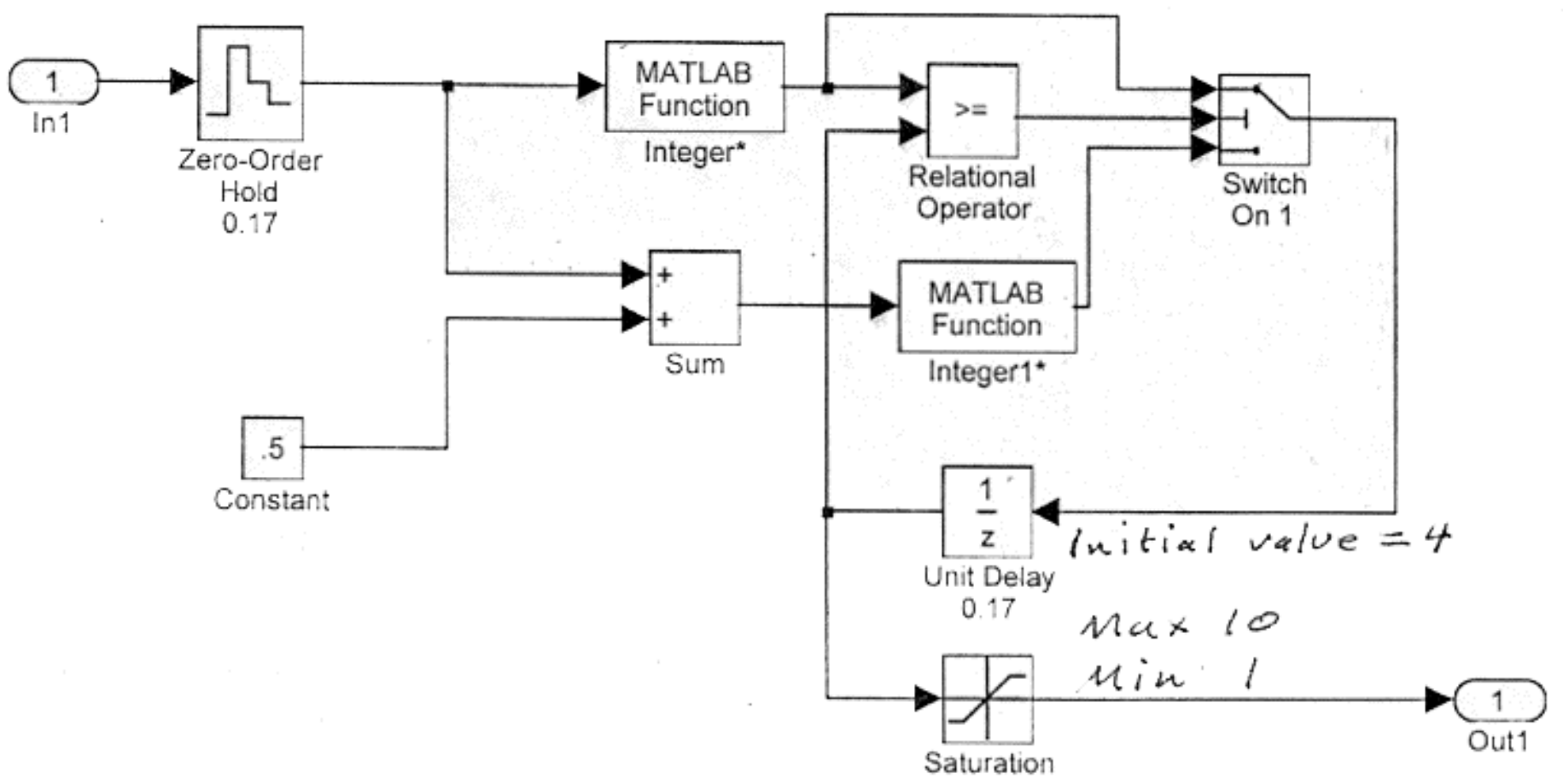

- NOTE: Float to Integer Conversion

Ver 3.0 Upated Hysteresis to a time step of $1.0=1.0 \mathrm{hr}$

Ver 6.0 Changed delay to $600 \mathrm{sec} Z \mathrm{ZH}$ 


\section{Dump Load Logic}

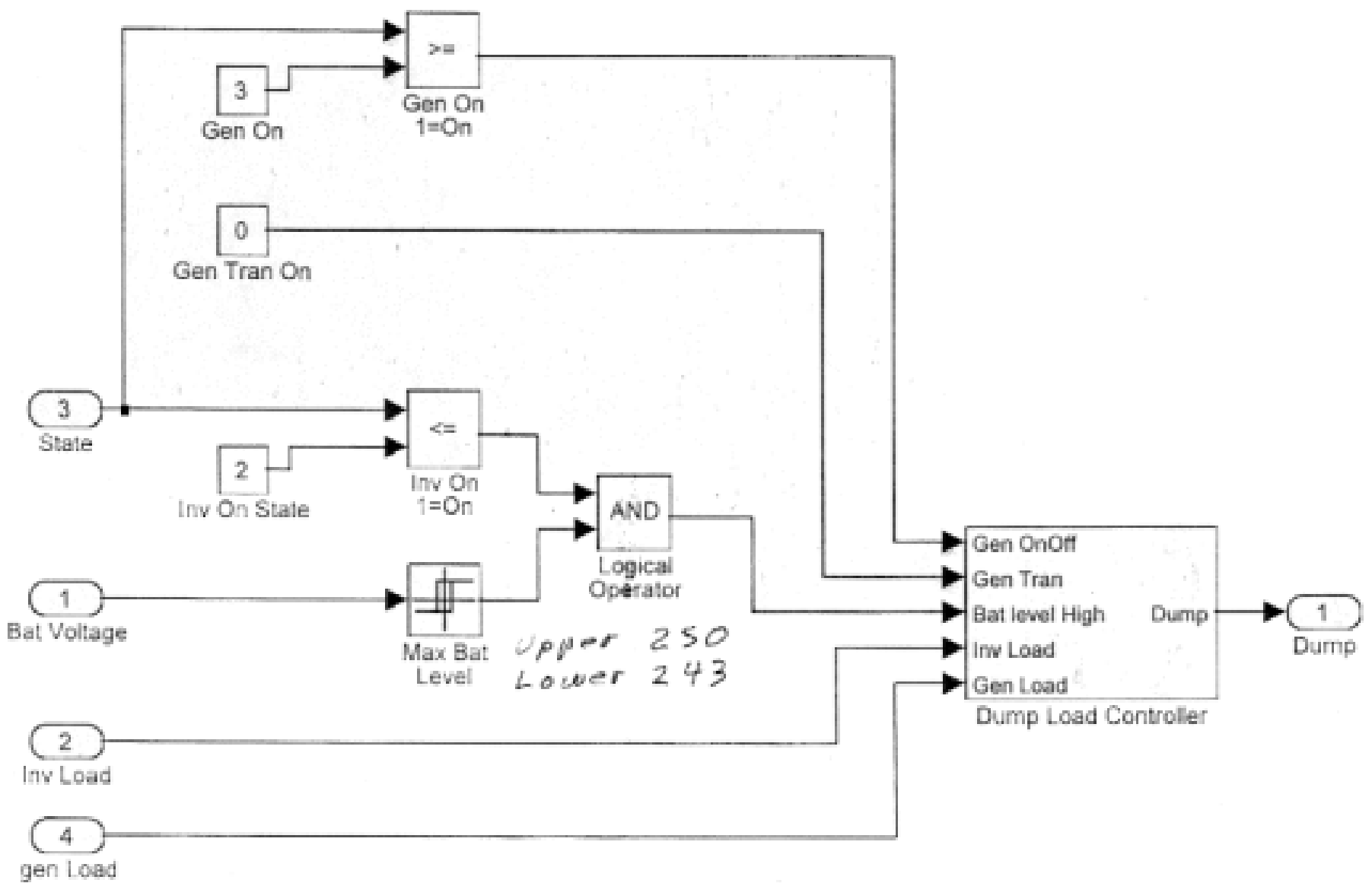

Ver 3.0 Modifed Dump Logic to use Gen Load and Net Err. directly Rev 2: Added Gen Transition on logic to dump load

Rev 2. Modify the Max Bat Level Hyst values due to change in \# of battery cells Ver 6.0 Set Gen Tran to O4 


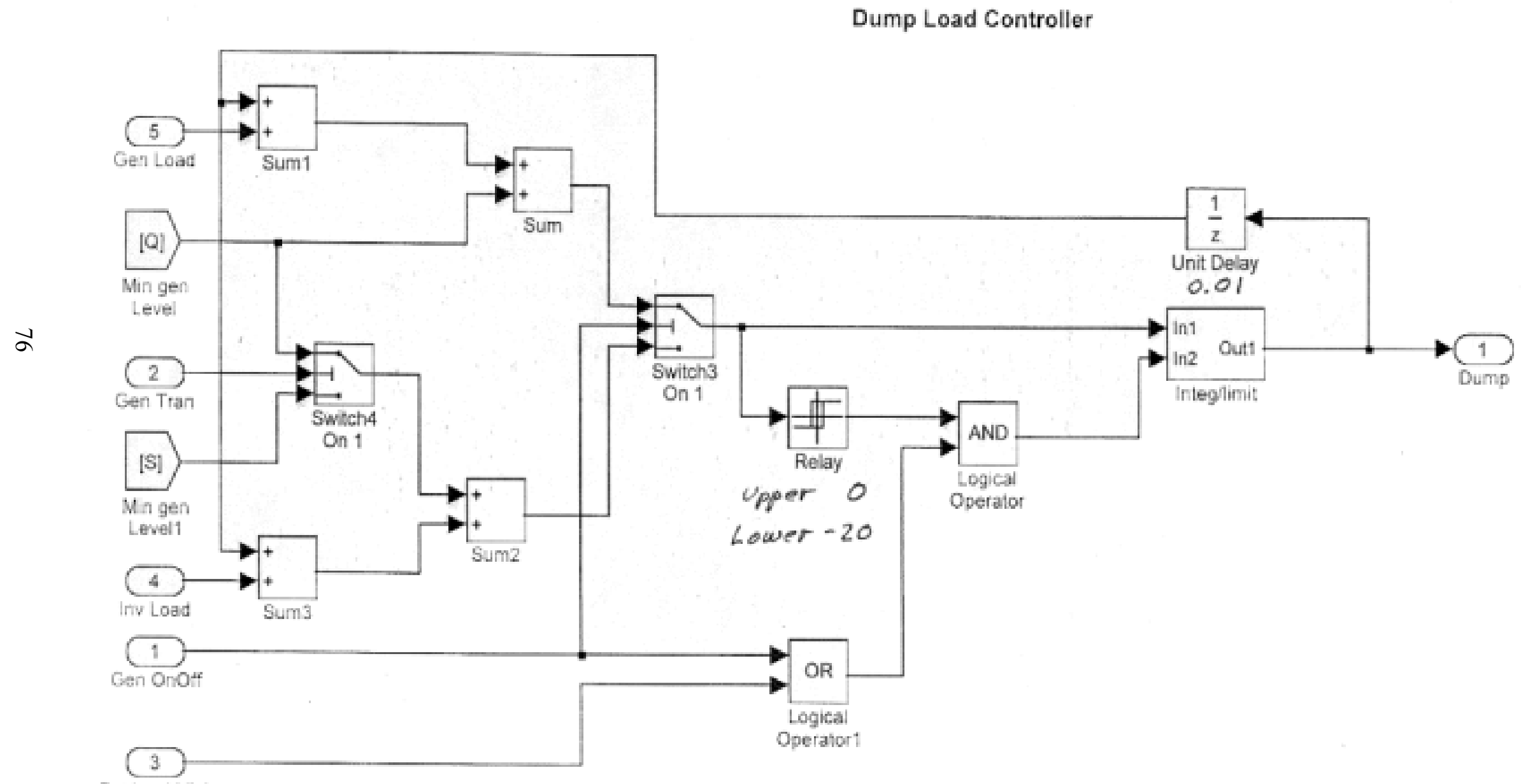

Bat devel High

Rev 2: Added Gen Transition on logic to dump loas 


\section{Integ/Limit Function}

(Designed to prevent Integrator wind-up)

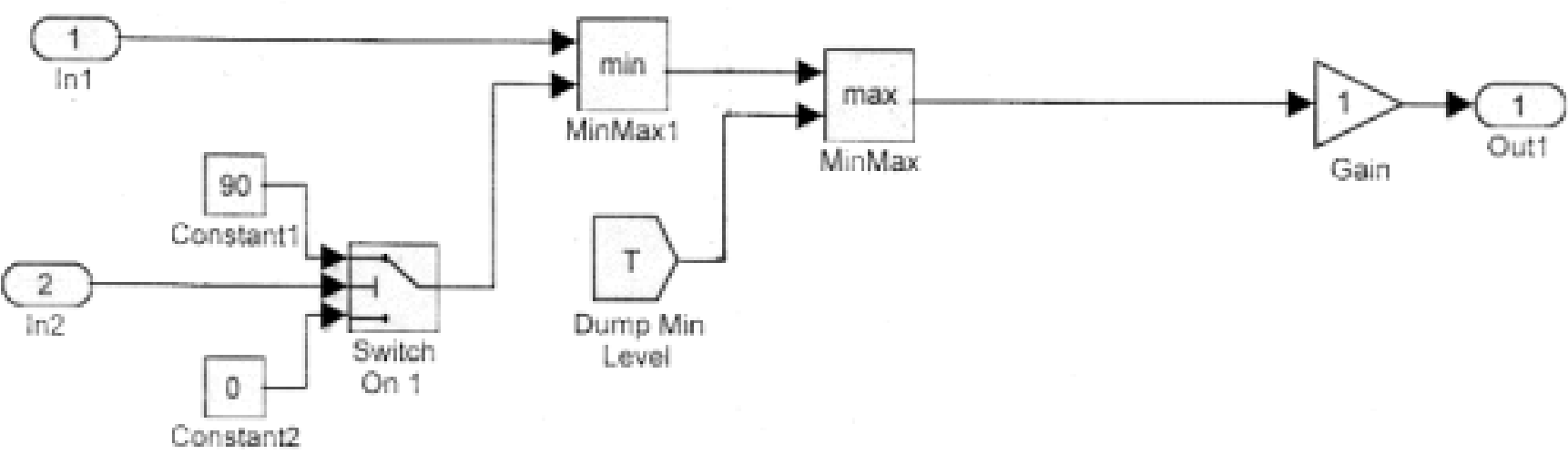

Rev 3: Added min dump load value 


\section{Appendix C: Inverter Test Results}

\section{Functionality Checks}

Before running the tests, functionality checks were conducted to verify proper inverter operation and state transition for steady- and quasi-steady-state operation. These checks verified that the system operated the way the hybrid controller intended it to and allowed any shortcomings to be noted. Although many of these checks had been performed on previous software revisions for the hybrid controller, these checks were necessary to benchmark the latest revision of the software code. Before starting the test, all inverter settings were confirmed on the inverter and recorded. Table 1 shows a listing of the inverter set points. Table 2 lists the functionality checks performed.

Table 1. Inverter Settings (Latest Code revision is Tag File rev 13)

\begin{tabular}{|c|c|c|c|}
\hline Parameter Name* & Value & Units & Description \\
\hline gen_warmup_time & 15 & $\mathrm{sec}$ & Generator warm-up time during start-up \\
\hline MAX̄BAT_HIGH & 265 & VDC & Max battery voltage for turning ON min dump load \\
\hline MAX_BAT_LOW & 257 & VDC & Min battery voltage for turning OFF min dump load \\
\hline $\begin{array}{l}\text { MAX_ERR_DUMP_OF } \\
\text { F }\end{array}$ & -20 & units & $\begin{array}{l}\text { Inv/gen load level at which the dump function is } \\
\text { turned OFF }\end{array}$ \\
\hline DUMP_INC_GAIN & 50 & units & Dump load integrator increase error gain \\
\hline DUMP_DECER_GAIN & 30 & units & Dump load integrator decrease error gain \\
\hline GEN_DUMP_M̄MIN & 15 & $\mathrm{~kW}$ & $\begin{array}{l}\text { Trickle charge level after Max Bat High Voltage was } \\
\text { reached }\end{array}$ \\
\hline INV_DUMP_MIN & 35 & $\mathrm{~kW}$ & Inverter min load level when battery is fully charged \\
\hline DUM̄P_RATE_MAX & 30 & $\mathrm{~kW} / \mathrm{sec}$ & Dump load max rate of change \\
\hline DUMP_RATE_MIN & 30 & $\mathrm{~kW} / \mathrm{sec}$ & Dump load min rate of change \\
\hline DUMP_PERR_MAX & 10 & $\mathrm{~kW}$ & Dump load proportional error offset \\
\hline DUMP_PERR_GAIN & 30 & units & Dump load proportional error gain \\
\hline DUMP_IERR_MIN & & $\mathrm{Kw}$ & Dump load min setting \\
\hline
\end{tabular}

*Parameter name may not imply the function, as in the case of GEN_DUMP_MIN. 
Table 2. Functionality Checks Performed

\begin{tabular}{|c|c|c|}
\hline $\begin{array}{l}\text { Functionality } \\
\text { Check }\end{array}$ & HCU State & Description \\
\hline $\begin{array}{l}\text { Generator } \\
\text { Min Load }\end{array}$ & $\begin{array}{l}\text { Shutdown } \\
\text { and Charge }\end{array}$ & $\begin{array}{l}\text { Verify generator minimum load is } 10 \mathrm{kWs} \text { when village load is taken off system, } \\
\text { add load back in } 2-\mathrm{kW} \text { increments, and verify that min load }=10 \mathrm{kWs}\end{array}$ \\
\hline \multicolumn{3}{|c|}{ Result: Function confirmed } \\
\hline $\begin{array}{l}\text { State } \\
\text { Transition } \\
\text { from Inv. To } \\
\text { Charge }\end{array}$ & Inv-Charge & Verify state transition with and without AC Source Sim running \\
\hline \multicolumn{3}{|c|}{ Result: Transition confirmed both with and without AC Source Sim running } \\
\hline $\begin{array}{l}\text { State } \\
\text { Transition } \\
\text { from Charge } \\
\text { to Inverter }\end{array}$ & Charge-Inv & Verify state transition with and without AC Source Sim running \\
\hline \multicolumn{3}{|c|}{ Result: Transition confirmed both with and without AC Source Sim running } \\
\hline $\begin{array}{l}\text { Battery } \\
\text { Charging } \\
\text { Algorithm }\end{array}$ & $\begin{array}{l}\text { Charge and } \\
\text { Inv }\end{array}$ & $\begin{array}{l}\text { Verify that battery-charging algorithm works with diesel and with AC Source Sim } \\
\text { (i.e., diesel-on and diesel-off modes). Verify that dump load absorbs all excess } \\
\text { power at Max Bat High setting above Gen Dump Min setting. Verify that hysterisis } \\
\text { works and that batteries start charging when voltage drops below Max Bat Low } \\
\text { (both diesel-on and diesel-off modes) }\end{array}$ \\
\hline \multicolumn{3}{|c|}{ Result: Charging algorithm verified } \\
\hline Dump Load & Inv & $\begin{array}{l}\text { Verify that dump load absorbs all excess power when battery voltage is greater } \\
\text { than Max Bat High and AC Source SIM is running }\end{array}$ \\
\hline \multicolumn{3}{|c|}{ Result: Functionality of dump load verified } \\
\hline $\begin{array}{l}\text { Transition to } \\
\text { Shutdown on } \\
\text { Inverter Fault }\end{array}$ & $\begin{array}{l}\text { Inv- } \\
\text { Shutdown }\end{array}$ & $\begin{array}{l}\text { In inverter mode, disconnect batteries (DC bus) and verify that inverter transitions } \\
\text { to shutdown mode and that diesel starts and connects to village load }\end{array}$ \\
\hline \multicolumn{3}{|c|}{ Result: Function verified } \\
\hline $\begin{array}{l}\text { Gen Dump } \\
\text { Min }\end{array}$ & Inv & $\begin{array}{l}\text { Verify that Gen Dump Min setting equals charging power to batteries when } \\
\text { batteries are fully charged (i.e., trickle charge) }\end{array}$ \\
\hline
\end{tabular}




\subsection{Test Results with AC Source Simulator}

The testing described in this section was conducted with the AC source simulator. The AC source simulator is a variable-speed drive that is connected to a nominal $60-\mathrm{kW}$ induction generator that has a soft start connected in series. The test setup can be seen in Figure 5 in the main body of the report.

Note: All figures are "screen dumps" from the data acquisition system and as such, the units could not be put on the axis. The x-axis units are the time period in minutes, and the y-axis units are referenced in the figure title.

\subsubsection{Test: Village Load Step Changes: Adding Load}

Purpose: Determine the largest step load using the village load simulator that the system can handle both with and without the diesel generator and with and without the AC Source Simulator (AC SIM). Figure 6 is a time series plot demonstrating a typical load profile for this testing.

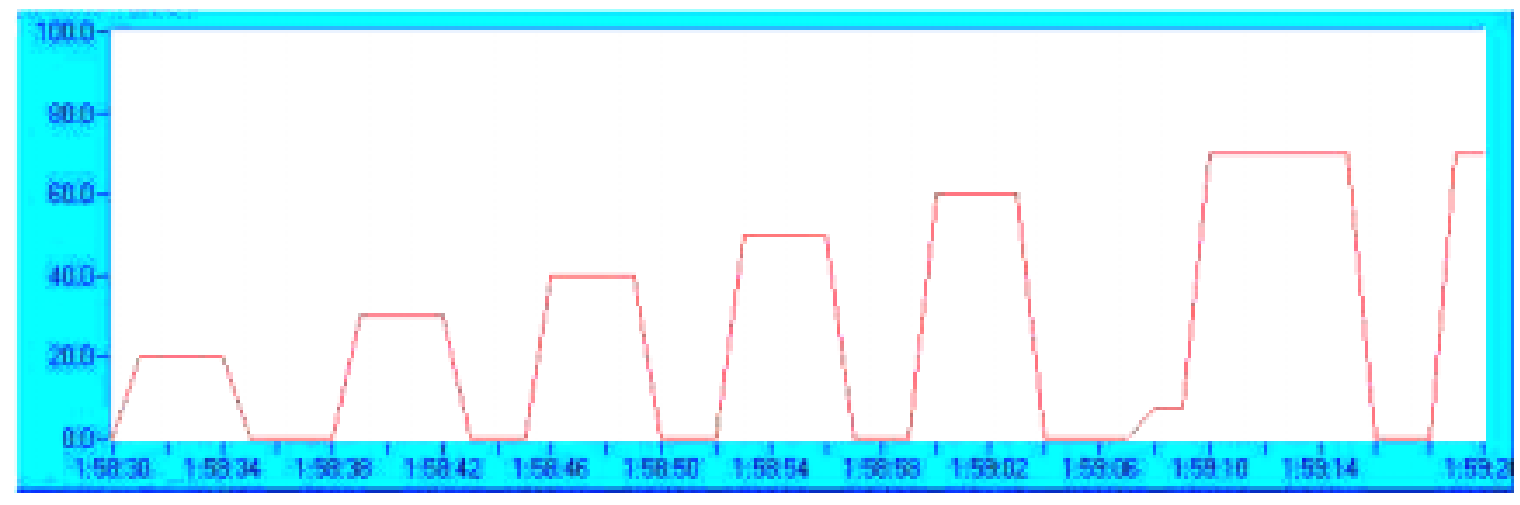

Figure 6. Village load $(\mathrm{kW})$.

1. Methodology: Gen Only State: starting with a $0-\mathrm{kW}$ Village Load (VL), increase the load stepwise on the VL to $20 \mathrm{~kW}$. Repeat at 30, 40, 50, 60, and $70 \mathrm{kWs}$ as appropriate (stop incrementing load at first fault for tests 1-14). Repeat test with a VL power factor of 0.5 .

Result: No faults to $70 \mathrm{kWs}$. Same test results with the VL power factor set at 0.5 .

2. Methodology: Repeat \#1 in Charge State with AC SIM $=0 \mathrm{kWs}$; up to $70 \mathrm{kWs}$ VL. Repeat test with a VL power factor of 0.5 .

Result: No faults to $80 \mathrm{kWs}$. With the power factor set at 0.5 , there were no faults to 70 kWs.

3. Methodology: Repeat \#1 in Charge State with AC SIM $=10 \mathrm{kWs}$; up to $80 \mathrm{kWs}$ VL. Repeat test with a VL power factor of 0.5 .

Result: No faults to $80 \mathrm{kWs}$. Tests began at $20 \mathrm{~kW}$ because it was the minimum stable village load. Same results with the VL power factor set at 0.5 .

4. Methodology: Repeat \#1 in Charge State with AC SIM = $56 \mathrm{kWs;} \mathrm{up} \mathrm{to} 100 \mathrm{kWs}$ VL. Repeat test with a VL power factor of 0.5 . 
Result: No faults to $60 \mathrm{kWs}$. With a VL power factor at 0.5 , the inverter was stable to 60 $\mathrm{kWs}$; it faulted at $80 \mathrm{kWs}$ due to low inverter frequency.

5. Methodology: Repeat \#1 in Inverter State up to $100 \mathrm{kWs}$ w/no AC SIM. Repeat test with a VL power factor of 0.5 .

Result: Fault at $60 \mathrm{kWs}$ because the inverter frequency was too low. With VL power factor at 0.5 , the inverter was stable to $58 \mathrm{kWs}$ and then faulted because the inverter frequency was too low.

6. Methodology: Repeat \#1 in Inverter State up to $100 \mathrm{kWs}$ w/no AC SIM. Repeat test with a VL power factor of 0.5 .

Result: Fault at $100 \mathrm{kWs}$, inverter frequency too low. System was able to function under an $80-\mathrm{kW}$ load. With a VL power factor at 0.5 , the inverter was stable to $60 \mathrm{kWs}$; it faulted at $80 \mathrm{kWs}$ due to low inverter frequency.

7. Methodology: Repeat in Inverter State up to $100 \mathrm{kWs}$ with AC SIM $=65 \mathrm{kWs}$. Repeat test with a VL power factor of 0.5 .

Result: No faults to $100 \mathrm{kWs}$. Same result with the VL power factor set at 0.5 .

\subsubsection{Test: Village Load Step Changes: Decreasing Load}

Purpose: Determine the largest step load that the system can handle in both diesel-on and dieseloff modes (also with and without the AC SIM). Figure 7 shows a time series plot demonstrating a typical decreasing load pattern used during the tests.

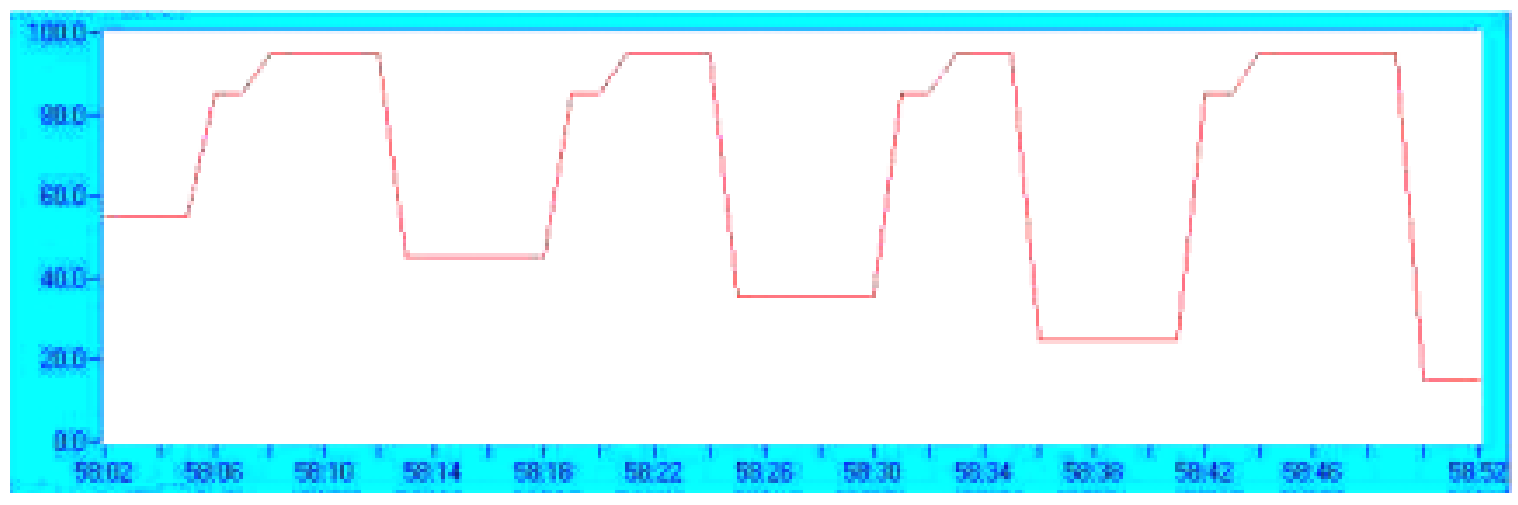

Figure 7. Village load $(\mathrm{kW})$.

1. Methodology: Gen Only State: starting with a 75-kW VL, put a step load decrease on the $\mathrm{VL}$ of $20 \mathrm{~kW}$. Repeat at 30, 40,50,60, and $70 \mathrm{kWs}$ as appropriate (stop decreasing load at first fault). Repeat test with a VL power factor of 0.5 .

Result: No faults up to the 70-kW starting point. Same results with the VL power factor set at $0.5 .70 \mathrm{kWs}$ was the highest VL that the diesel generator could handle.

2. Methodology: Repeat \#1 in Charge State with AC SIM $=0 \mathrm{kWs}$; up to $70 \mathrm{kWs}$ VL. Repeat test with a VL power factor of 0.5 .

Result: No faults to $70 \mathrm{kWs}$. Same results with the VL power factor set at 0.5 . 
3. Methodology: Repeat \#1 in Charge State with AC SIM $=10 \mathrm{kWs}$; up to $90 \mathrm{kWs}$ VL. Repeat test with a VL power factor of 0.5 .

Result: No faults to $90 \mathrm{kWs}$. With VL power factor at 0.5 , the inverter had no faults to $80 \mathrm{kWs}$. At $80 \mathrm{kWs}$, the inverter was unstable (high harmonic distortion in the current waveform).

4. Methodology: Repeat \#1 in Charge State with AC SIM $=65 \mathrm{kWs}$ up to $100 \mathrm{kWs}$ VL. Repeat test with a VL power factor of 0.5 .

Result: No faults to $100 \mathrm{kWs}$. Same results with the VL power factor set at 0.5 .

5. Methodology: Repeat \#1 in Inverter State up to $100 \mathrm{kWs}$ w/no AC SIM and up to 100 $\mathrm{kWs}$, starting the VL at $95 \mathrm{kWs}$. Repeat test with a VL power factor of 0.5 .

Result: This test was completed with the modification of the VL starting power. The inverter faulted if the test began with a VL higher than $50 \mathrm{kWs}$. With a VL starting power of $50 \mathrm{kWs}$, there were no faults.

6. Methodology: Repeat in Inverter State up to $100 \mathrm{kWs}$ with AC SIM $=10 \mathrm{kWs}$, starting the VL at $95 \mathrm{kWs}$. Repeat test with a VL power factor of 0.5 .

Result: This test was completed up to a $50-\mathrm{kW}$ starting point. That was the maximum VL starting point that the system could handle. The AC SIM was unstable but oscillated around $10 \mathrm{kWs}$. With the power factor at 0.5 , the AC SIM was not stable enough to complete the test.

7. Methodology: Repeat in Inverter State up to $100 \mathrm{kWs}$ with AC SIM $=65 \mathrm{kWs}$ starting the VL at $95 \mathrm{kWs}$. Repeat test with a VL power factor of 0.5 .

Result: No faults to $100 \mathrm{kWs}$.

\subsubsection{Test: Wind Turbine Trip Offline: Diesel Generator On}

Purpose: Determine the system stability, including dump load response, when an induction wind turbine contactor opens at near rated wind turbine power with the diesel generator online.

1. Methodology: Charge State. With AC SIM $=65 \mathrm{kWs}$, batteries at low state of charge, diesel generator $=$ about $40 \mathrm{~kW}, \mathrm{VL}=75 \mathrm{kWs}$ (this should be the max load the diesel generators can handle) @ PF=1.0, open the wind turbine contactor and record response. Vary system settings as required to characterize system response. Verify dump load response.

Result: After the contactor was opened, the diesel generator output increased to $78 \mathrm{~kW}$ to meet the village load. Dump load never came on during the tests. No faults during the test.

2. Methodology: Charge State. With AC SIM $=65 \mathrm{kWs}$ and batteries at high state of charge, diesel generator $=10 \mathrm{~kW}$ (before transition to Inverter State) and DL making up the rest of power balance at $\mathrm{VL}=0 \mathrm{~kW}$ and $\mathrm{PF}=1.0$, open the wind turbine contactor and record response. Vary system settings as required to characterize system response, repeating with $\mathrm{VL}=5 \mathrm{~kW}$.

Result: Tested with both a $0-\mathrm{kW}$ village load and a $5-\mathrm{kW}$ village load. The inverter was able to handle the wind turbine dropping off the grid for both tests. When the turbine dropped off the grid, the dump load turned off. There were no faults during this test. 


\subsubsection{Test: Wind Turbine Trip Offline: Diesel Generator Off}

Purpose: Determine the system stability, including dump load response, when an induction wind turbine contactor opens at near rated wind turbine power with the diesel generator offline.

1. Methodology: Inverter State. With $\mathrm{AC} \mathrm{SIM}=65 \mathrm{kWs}$ and $\mathrm{VL}=90 \mathrm{kWs}$ at $\mathrm{PF}=1.0$ and batteries at low state of charge, open the wind turbine contactor and record response.

Vary system settings as required to characterize system response. Try test with lower PF on VL. Repeat test with VL at $5 \mathrm{kWs}$.

Result: Inverter faulted at village loads of 5, 50, and $60 \mathrm{kWs}$ (power factor of 1). With the diesel generator off, the batteries need to pick up the load; however, they were unable to support the change in load while at a low state of charge.

2. Methodology: Inverter State. With $\mathrm{AC} \mathrm{SIM}=65 \mathrm{kWs}$ and $\mathrm{VL}=80 \mathrm{kWs}$ at $\mathrm{PF}=1.0$ and batteries at high state of charge, open the wind turbine contactor and record response. Vary system settings as required to characterize system response. Repeat test with lower PF on VL. Repeat test with VL at $5 \mathrm{kWs}$.

Result: Inverter faulted at village loads of 60 and $80 \mathrm{kWs}$ with power factors of both 1 and 0.5 . With a VL of $5 \mathrm{kWs}$, the inverter didn't fault.

\subsubsection{Test: Battery Charging}

Purpose: Verify battery charging algorithm at Max Bat High and Low set points and at Inv Dump Min and Gen Dump Min levels.

Background: The set points associated with the battery charging algorithm are Max Batt High, Max Batt Low, Inv Dump Min, and Gen Dump Min. In the inverter state, the charging algorithm allows the batteries to be charged at any charging rate until the battery bank reaches Max Batt High. Once the battery voltage reaches the Max Batt High set point (in this case, 265 volts), the dump load comes on, taking a percentage of the available charging power. The percentage of power dumped is determined by Max Batt Low, Inv Dump Min, and Gen Dump Min.

In the charge state, the batteries are charged until a voltage set point is reached; then the charging rate tapers off. The set point name is Battery Charging Voltage. The diesel-charging algorithm also incorporates a set point called the Battery Maximum Charging Current, which sets a limit on the battery charging current. This set point protects the batteries from charging at too great a charging rate.

1. Methodology: Verify that battery charging algorithm works with the AC SIM and the diesel generator. Verify that dump load absorbs all excess power at Max Bat High above Gen Dump Min Setting. Verify that hysterisis works and that batteries start charging when voltage drops below Max Bat Low (in both diesel-on and diesel-off modes) and no greater than the Inv. Dump Min Level.

Result: The battery charging algorithm worked per the control algorithm specification. The following charging and discharging processes were confirmed. 1) When the battery voltage reached the battery max depth of discharge voltage setting, the inverter shut down. 2) The battery charging algorithm was also confirmed. 3) The diesel charging algorithm was also verified. 
Figures 8- 13 show time series plots for the testing. The setting during the following test diagrams are Max Batt High 265 volts, Max Batt Low 255 volts, Gen Dump Min 10 kW, and Inv Dump Min at $90 \mathrm{kw}$.

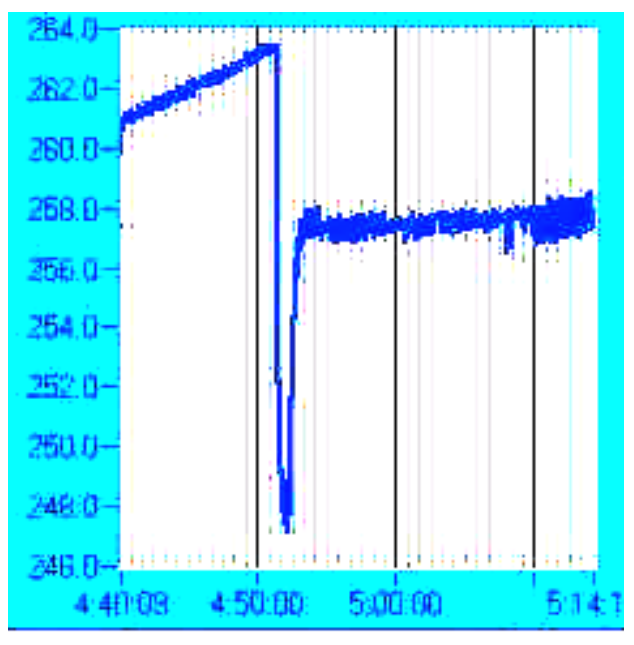

Figure 8. Battery voltage (V).

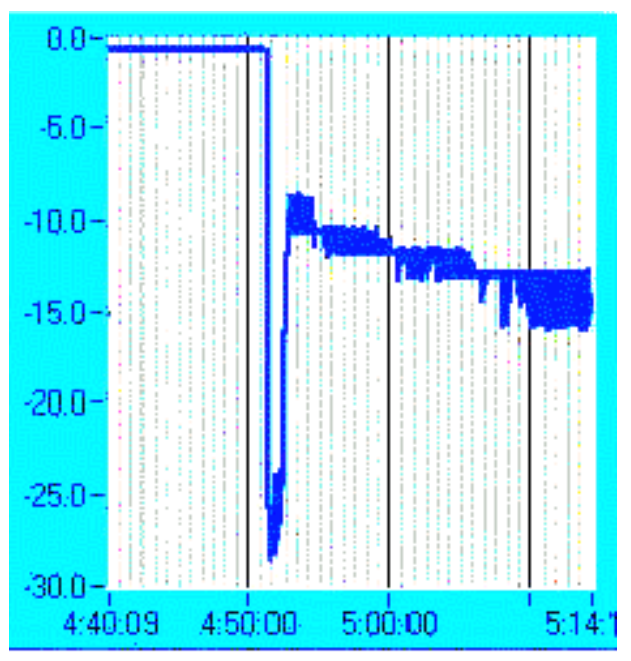

Figure 10. AC SIM power $(\mathrm{kW})$.

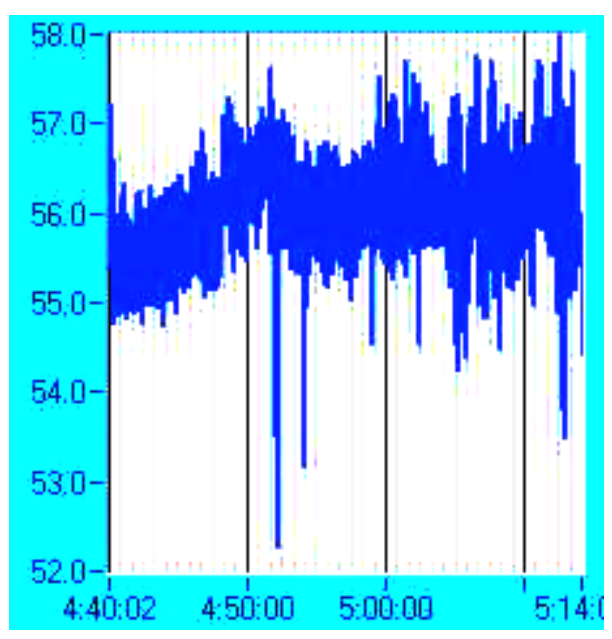

Figure 9. Village load (kW).

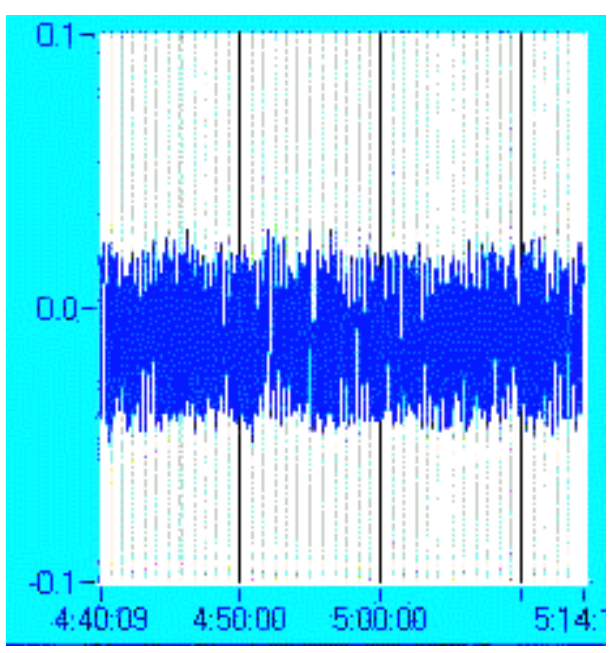

Figure 11. Genset power $(\mathrm{kW})$. 


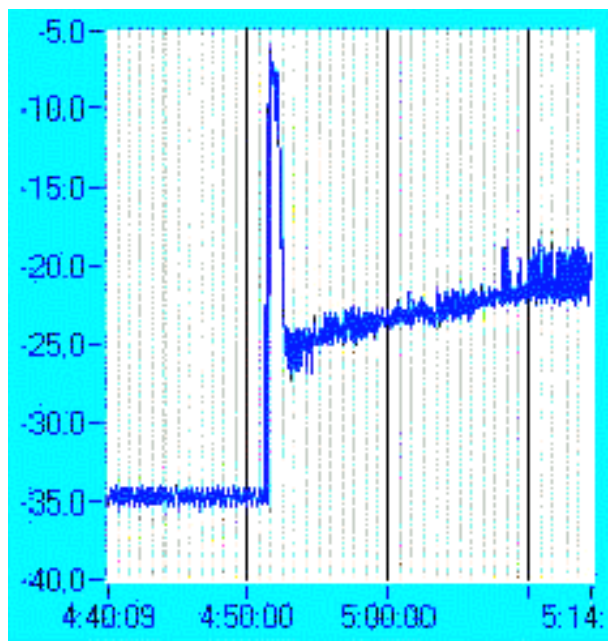

Figure 12. Inverter power $(\mathrm{kW})$.

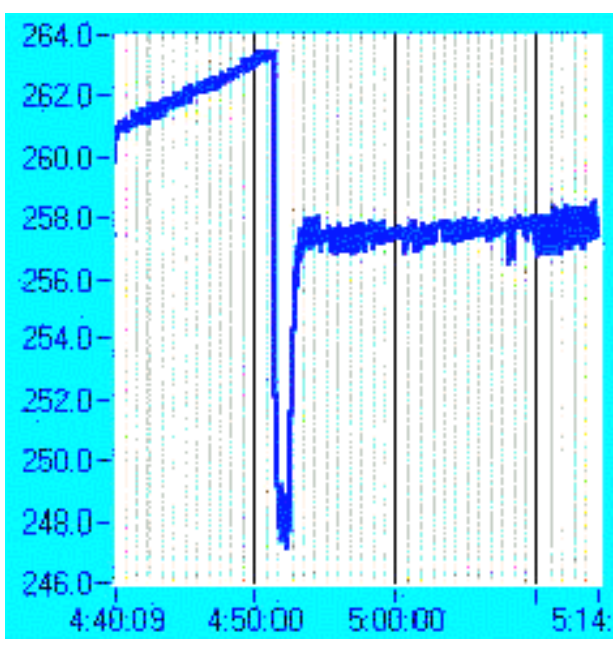

Figure 13. Dump load power (kW).

\subsubsection{Test: State Transition from Inverter to Charge and from Charge to Inverter}

Purpose: Verify state transition with and without AC Source Simulator running.

1. Methodology: Take time series plot of state transition Inverter to Charge and from Charge to Inverter with and without AC SIM.

Result: Figures 14-19 show time series plots of state transitions without the AC SIM running. The first transition shows the beginning of the test when the AC SIM is shut down and the inverter is put in inverter state. The next transition is from inverter state to charge state, followed by charge state to inverter state. At the end of the test, the AC SIM was turned on for the following tests with the AC SIM on:

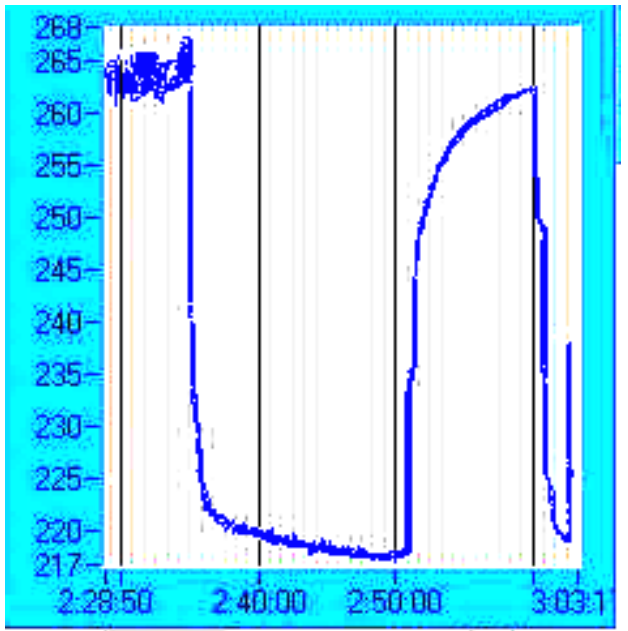

Figure 14. Battery voltage (V).

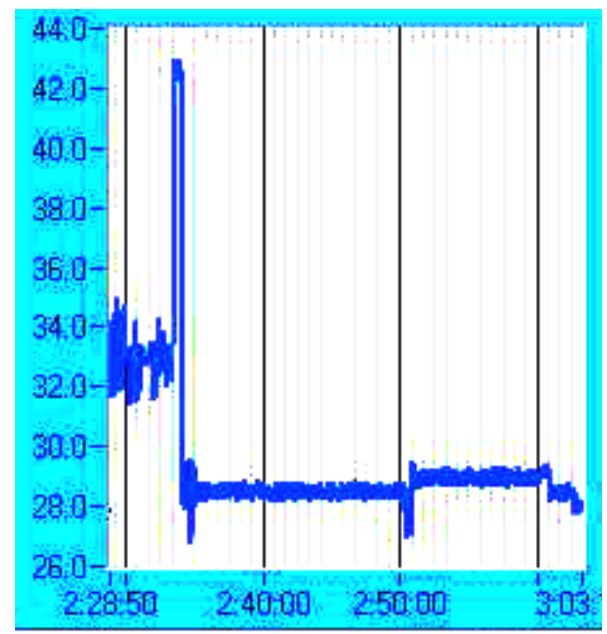

Figure 15. Village load (kW). 


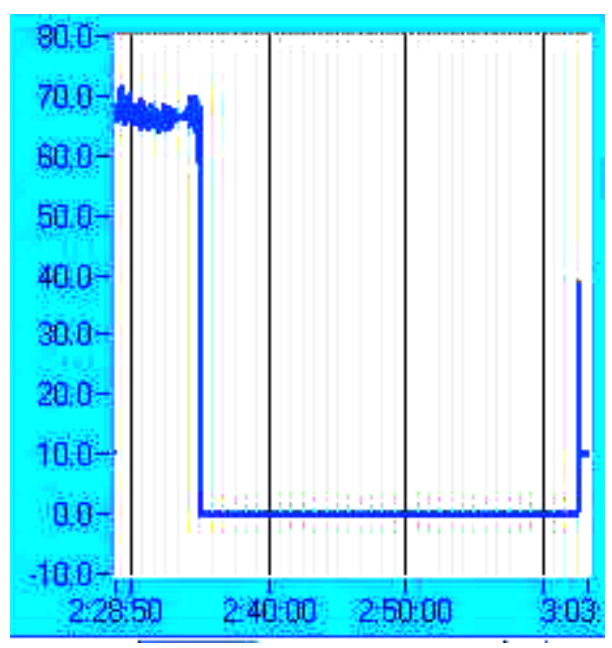

Figure 16. AC SIM power (kW).

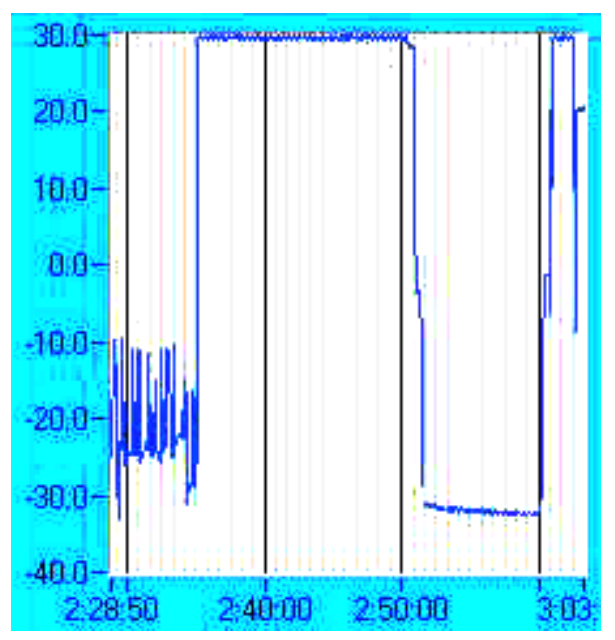

Figure 18. Inverter power $(\mathrm{kW})$.

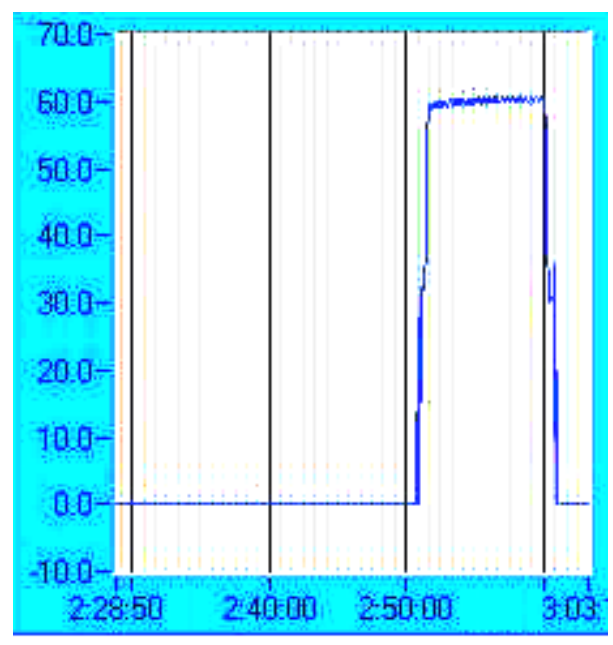

Figure 17. Genset power $(\mathrm{kW})$.

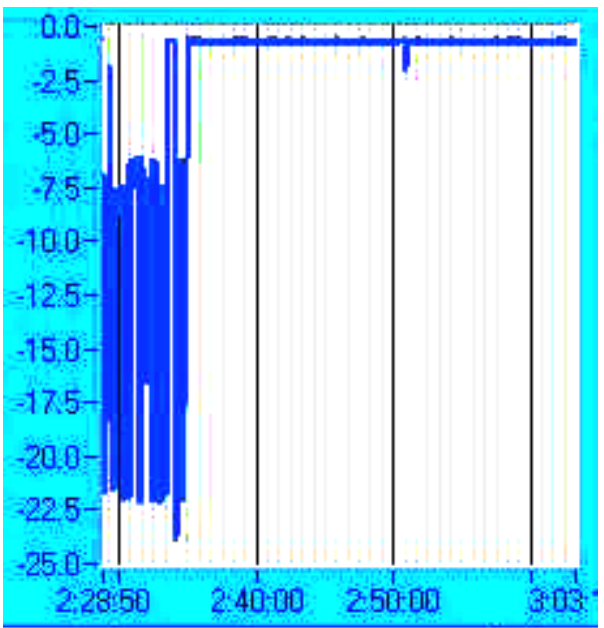

Figure 19. Dump load power (kW).

Figures 20-25 show time series plots of the tests with the AC SIM running. The tests began at the 40.00-min time mark when the inverter was put into inverter state. The following transition shows the inverter going into charge state. The next transition shows the inverter coming out of charge state and into inverter state. The continued increase in voltage is due to the AC SIM continuing to charge the batteries in inverter state. 


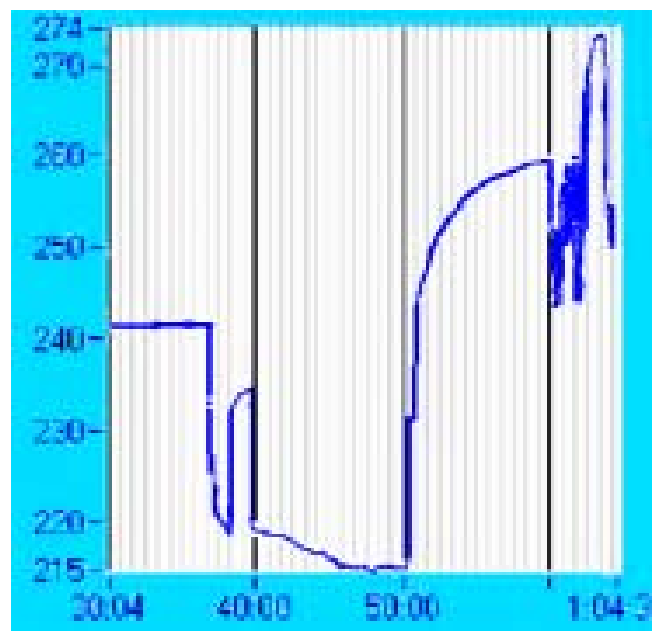

Figure 20. DC bus voltage (V).

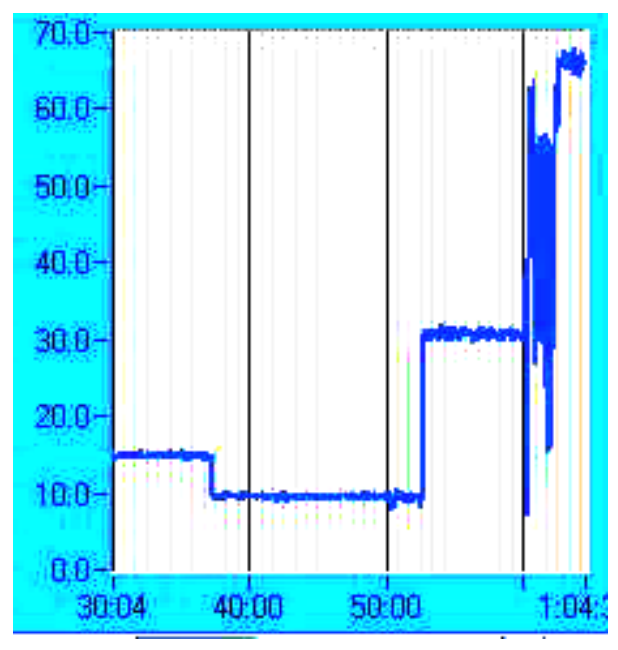

Figure 22. AC SIM power $(\mathrm{kW})$.

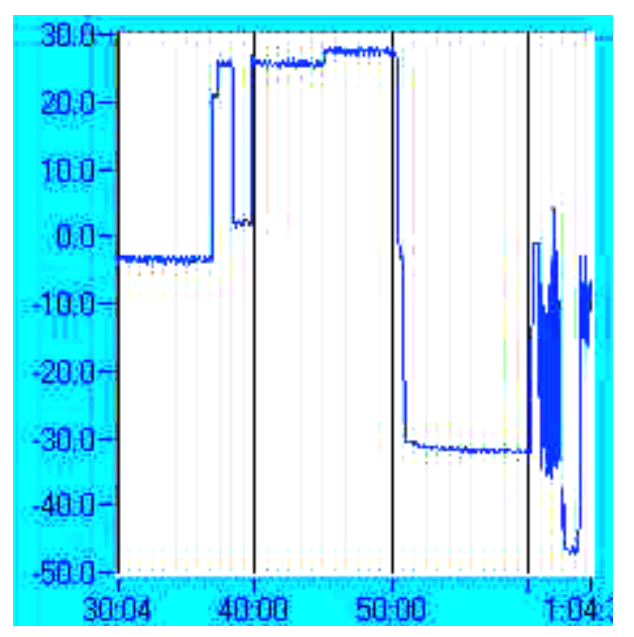

Figure 24. Inverter power $(\mathrm{kW})$.

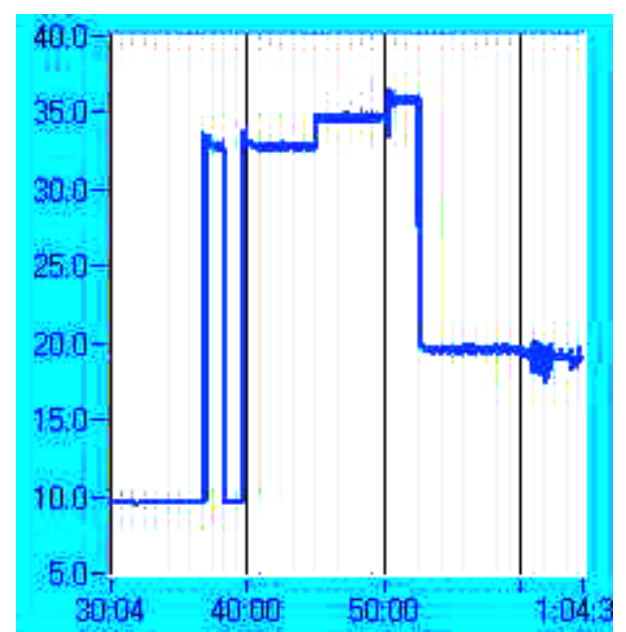

Figure 21. Village load (kW).

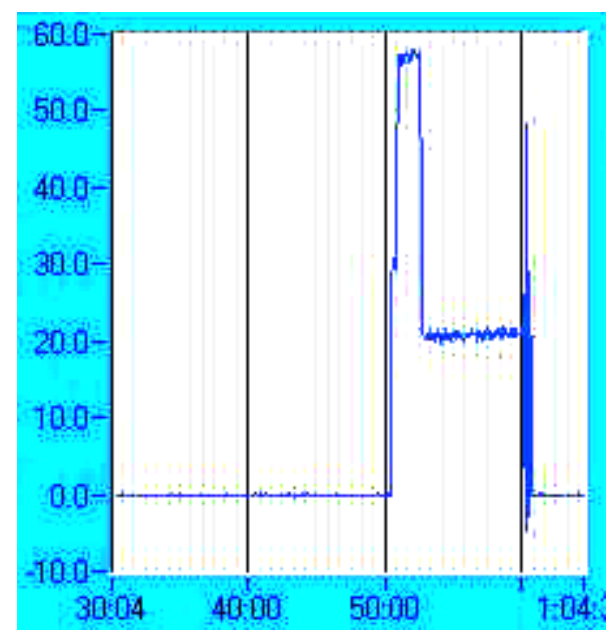

Figure 23. Genset power (kW).

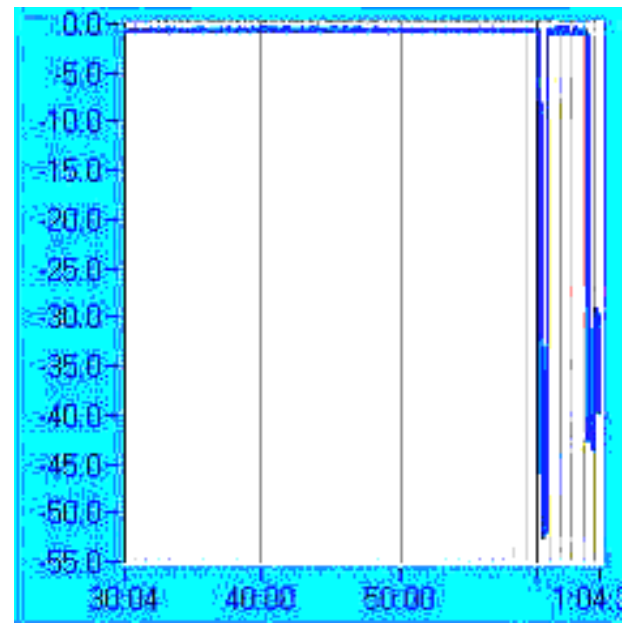

Figure 25. Dump load power (kW). 


\subsubsection{Test: Transition to Shutdown on Inverter Fault}

Purpose: Verify Gen Only State on inverter fault.

1. Methodology: In inverter state, disconnect batteries (DC bus) and verify that inverter transitions to Gen Only State and that diesel generator starts and connects to village load. Result: This transition was verified. When the batteries were disconnected, the inverter went to Gen Only State and the generator came on.

\subsection{Testing with the AOC 15/50 Wind Turbine}

\subsubsection{Test: Wind Turbine Startup at High Power with Diesel}

Purpose: Characterize system response to a high wind startup. Note: The AC SIM could not be used for this test or the following three tests. The AC SIM ramp up to high power production is too slow and therefore cannot characterize a high power. The AOC wind turbine was used, and as a result, these tests were dependent on ambient conditions (hence the variation in startup power).

1. Methodology: Charge State. Start AOC on diesel grid, batteries at low state of charge, diesel generator $=$ about $10 \mathrm{~kW}, \mathrm{VL}=5 \mathrm{~kW} @ \mathrm{PF}=1.0$. Vary system settings as required to characterize system response.

Result: AOC contactor closed with an initial power output of $38 \mathrm{kWs}$. The dump load came on with the AOC and took most of the AOC output power. The diesel generator ran unsteadily at low power. No faults during testing.

2. Methodology: Charge State. Start AOC on diesel grid, batteries at low state of charge, diesel generator= about $75 \mathrm{~kW}, \mathrm{VL}=60 \mathrm{~kW} @ \mathrm{PF}=1.0$. Vary system settings as required to characterize system response.

Result: AOC contactor closed with an initial power output of $40 \mathrm{kWs}$. No faults.

3. Methodology: Charge State. Start AOC on diesel grid, batteries at high state of charge and dump load absorbing power, diesel generator=about $10 \mathrm{~kW}, \mathrm{VL}=5 \mathrm{~kW} @ \mathrm{PF}=1.0$. Vary system settings as required to characterize system response. Verify dump load response.

Result: The AOC contactor closed at $53 \mathrm{kWs}$. The dump load was active before and after the contactor closed. The system response was that the diesel generator unloaded and ran unsteady with output fluctuating between 5 and $13 \mathrm{kWs}$.

4. Methodology: Charge State. Start AOC on diesel grid, batteries at high state of charge and dump load absorbing power, diesel generator = about $75 \mathrm{~kW}, \mathrm{VL}=60 \mathrm{~kW} @ \mathrm{PF}=1.0$. Vary system settings as required to characterize system response.

Result: The AOC contactor closed at $44 \mathrm{kWs}$. There was no dump load prior to contactor closing or after the contactor closed. The system response to the contactor closing was the diesel generator unloaded to $40 \mathrm{kWs}$. 


\subsubsection{AOC 15/50 Soft Start Mode Start Up}

Purpose: Verify that the AOC soft start is operational with the Xantrex inverter and that the inverter can bring the $\mathrm{AOC}$ on to the grid without faulting the inverter or overspeeding the turbine.

1. Methodology: Measure the voltage and current with an oscilloscope immediately after the AOC contactor has closed in order to verify that the soft start is operational. Confirm that the inverter does not fault and the AOC does not overspeed.

Result: Following in Figure 26 is the voltage and current on the startup. The scale is located in the bottom left corner of the plot. The AOC did not overspeed, and the inverter did not fault.

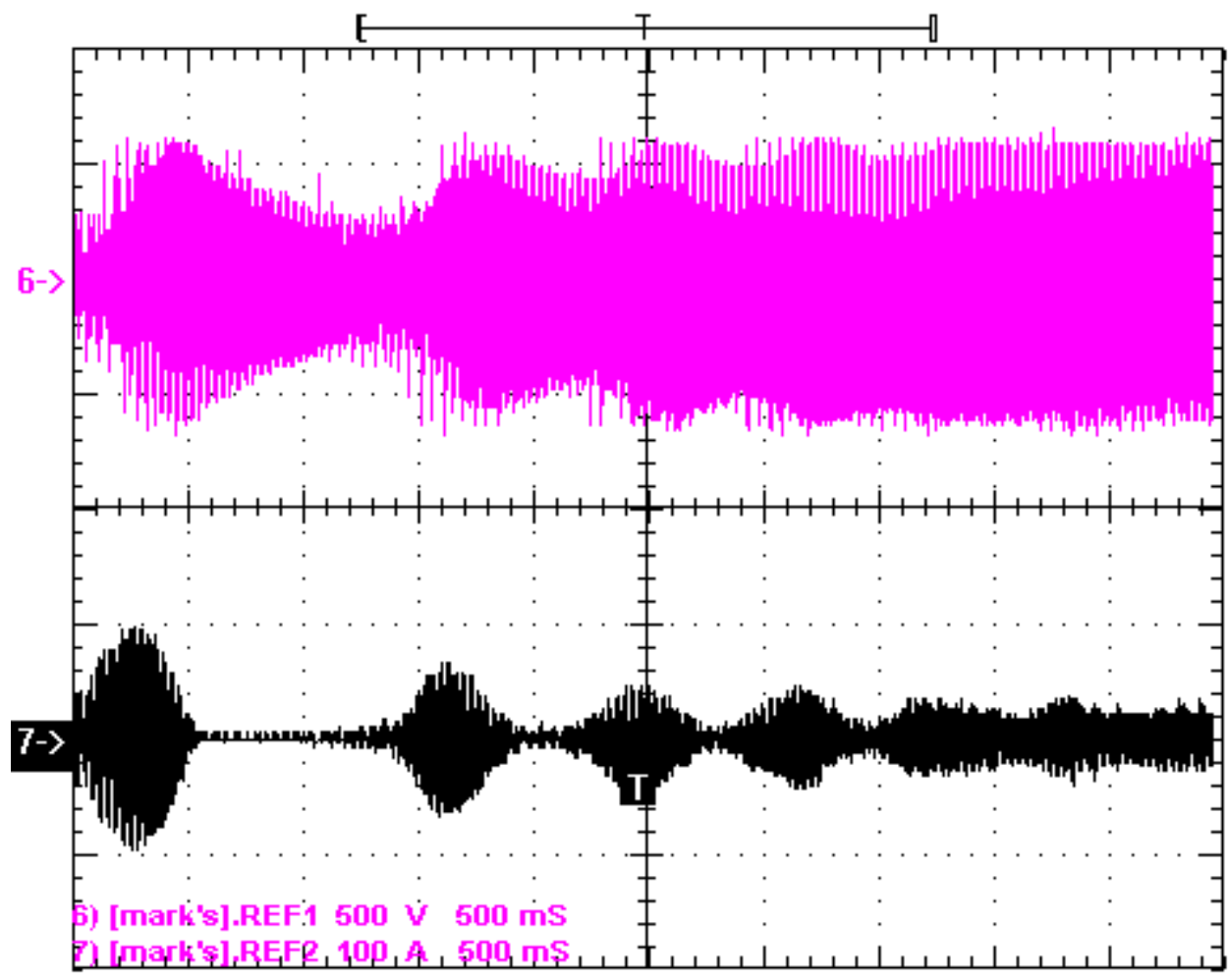

Figure 26. Oscilloscope reading of AOC startup.

Although the above test was performed successfully, it was not repeatable, and many times the AOC did not start successfully with the inverter but instead faulted on an overspeed condition. In order to rectify this situation, adjustments to the AOC soft start need to be made.

Once the AOC 15/50 turbine was online, the system would run without fault. Total run time with the AOC online was in excess of 80 hours, with good transitions between diesel-on and diesel-off modes. 


\section{Appendix D: A Preliminary Description of Parallel Operation of the Inverter with a Diesel Genset}

The concept of limiting "max" generator output power on a hybrid inverter system has been implemented in prior projects by Xantrex with some success. The basic approach used an external device to the inverter to calculate the amount of current the inverter should discharge to limit the generator power. A separate controller was used because more information was available external to the inverter to help determine how much current the inverter should "source."

When the inverter operates in the charge state and the sign of the current command is set opposite to the normal charge command, the inverter will discharge current to the grid. Although the mechanics of configuring the inverter to discharge current in the charge state are relatively simple, several issues must be addressed to ensure that the system functions properly. These issues are listed below.

1) Control stability of the limit loop is a major design factor. The dynamics of the inverter, generator, and overall grid must be considered when attempting to regulate a "fixed" generator power level; therefore, the system should be modeled to determine the response characteristics required and evaluate whether this can be achieved by the inverter. Trying to limit max generator power will also have a major impact on the design. If the design requirements are to minimize generator operation at high power, then a relatively simple control loop could be implemented. If the design requirements are to ensure the generator never exceeds a fixed limit, then a much more complex control logic would be required. Also, other issues must be considered with more stringent design requirements (see \#3).

2) Logic would have to be included to ensure the inverter did not source power to the generator at low grid loads. Slow dynamics (for stability) may not respond fast enough during rapid drops in the grid load, resulting in the inverter sourcing current back into the generator.

3) The question of what to do when the battery is not charged sufficiently to support the required current demand must be addressed.

4) Maximum increasing and decreasing current ramp rates would have to be established to provide adequate stability while not limiting the response during rapid drops in grid power (see \#2).

As described in the introductory notes, care should be taken to define the type and quantity of input signals required to control the amount of current the inverter should source. This may drive the design if the peak shave logic can be incorporated into the inverter or if a separate controller is required. 


\section{REPORT DOCUMENTATION PAGE}

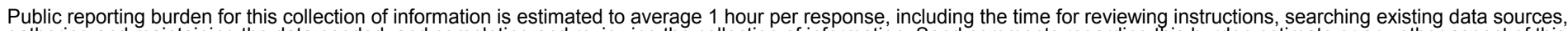

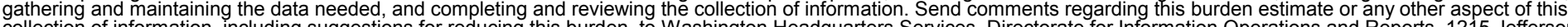
Davis Highway, Suite 1204, Arlington, VA 22202-4302, and to the Office of Management and Budget, Paperwork Reduction Project (0704-0188), Washington, DC 20503.
1. AGENCY USE ONLY (Leave blank)
2. REPORT DATE
3. REPORT TYPE AND DATES COVERED
May 2003
Technical Report

4. TITLE AND SUBTITLE Integration of Xantrex HY-100 Hybrid Inverter with an AC Induction Wind Turbine

5. FUNDING NUMBERS

6. $\operatorname{AUTHOR}(\mathrm{S})$

IG13.5000

D. Corbus, C. Newcomb, S. Friedly

7. PERFORMING ORGANIZATION NAME(S) AND ADDRESS(ES)

National Renewable Energy Laboratory

1617 Cole Blvd.

Golden, CO 80401-3393

9. SPONSORING/MONITORING AGENCY NAME(S) AND ADDRESS(ES) REPORT NUMBER

NREL/TP-500-33445

10. SPONSORING/MONITORING AGENCY REPORT NUMBER

11. SUPPLEMENTARY NOTES

12a. DISTRIBUTION/AVAILABILITY STATEMENT

National Technical Information Service

12b. DISTRIBUTION CODE

U.S. Department of Commerce

5285 Port Royal Road

Springfield, VA 22161

13. ABSTRACT (Maximum 200 words)

Several issues must be addressed before solid-state inverters can be used in wind-diesel systems with larger wind turbines. This project addresses those issues by using a commercial hybrid inverter designed for PV-diesel systems and modifying the inverter for use with an AC induction wind turbine. Another approach would have entailed building an inverter specifically for use with an $A C$ induction wind turbine, but that was beyond the scope of this project.

The inverter chosen for this project was a Xantrex HY-100, an inverter designed for PV systems. The unit consists of an inverter/rectifier bridge, a generator interface contactor, a battery charge controller, a hybrid controller, and the associated control electronics. Details of the inverter may be found in Appendix A.

A twofold approach was taken to integrating the existing inverter for use with an AC induction wind turbine: 1) development of a detailed model to model both steady-state and transient behavior of the system, and 2) modification and testing of the inverter with an induction wind turbine based on the modeling results. This report describes these two tasks.

14. SUBJECT TERMS
wind energy; wind turbines; wind-diesel systems; hybrid systems; solid-state inverters;

$\mathrm{AC}$ induction wind turbine; Xantrex HY-100 OF REPORT Unclassified
18. SECURITY CLASSIFICATION OF THIS PAGE Unclassified
15. NUMBER OF PAGES

16. PRICE CODE

20. LIMITATION OF ABSTRACT

UL 